LA-7784-MS

Informal Report

(ISPO-63)

c3

\section{REPRODUCTION \\ COPY}

CIC-14 REPORT COLLECTION

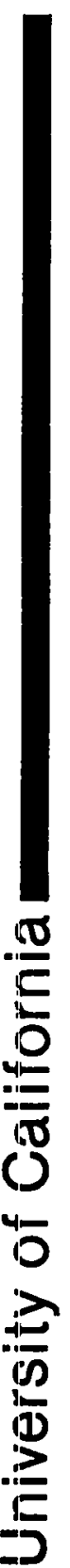

\section{The Measurement of Leached Hulls}


This report was not edited by the Technical Information staff.

Work supported by the US Department of Energy, Office of Safeguards and Security, and by the Program for Technical Assistance to IAEA Safeguards.

Tlus report was prepated as an account uf wotk spunsartid by an Aorncy or ils

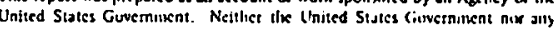

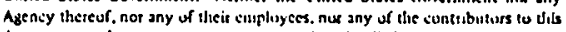
docuanent, makes any watronly, experssed or finglied. or assumes sny keat disbility of responsibitity fix any thard party's use. of the results of sind use. of any Infonition. appatstus. product \& proiss sliselused in this report. $c x$ iepresents that its ure by such thutd party would nut Infrinze prt. valely uwned tights. Further. neithut the subjest malter now the cimtent of this teport rellects any poslicy. expressed os inplied. by the Unized Sistis
Governnent. 


\title{
The Measurement of Leached Hulls
}

\author{
T. Douglas Reilly
}

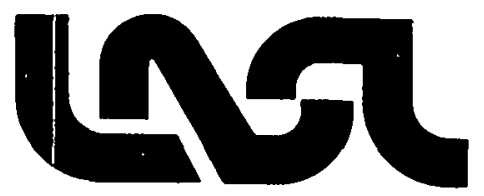



I. INTRODUCTION . . . . . . . . . . . . . . . . . . . I

II. GENERAL HULL CHARACTERISTICS . . . . . . . . . . . . . . . . 4

A. Physical Characteristics . . . . . . . . . . . . . . 4

B. Fission Product Gamma-Ray Levels . . . . . . . . . . . . . 7

C. Cladding Gamma-Ray Levels . . . . . . . . . . . . . . I3

D. Neutron Levels . . . . . . . . . . . . . . . . 19

E. Example: Basket of Leached Hulls . . . . . . . . . . . . 22

III. MEASUREMENT OF FISSION PRODUCT GAMMA RAYS . . . . . . . . . . . . 26

A. Introduction . . . . . . . . . . . . . . . . 26

B. Characteristics of Fission Product Signatures . . . . . . . 26

C. Possible Signatures of Very Long Cooling Times . . . . . . . . 30

D. Detector Choice, Shielding, Geometry . . . . . . . . . . 36

E. Attenuation ..........................41

F. Calibration Procedures .................... 44

G. The Reliability of Fission Product Signatures . . . . . . . . 46

H. User List . . . . . . . . . . . . . . . . . . 52

IV: MEASUREMENT OF SPONTANEOUS FISSION NEUTRONS . . . . . . . . . . 55

A. Introduction ...................... 55

B. Detectors, $3_{\mathrm{He}}$ and Shielding Requirements ......... 57

C. Typical Detector Parameters and Count Rates . . . . . . . . 63

D. A Simple Total Neutron Detector . . . . . . . . . . 65

E. Calibration ..................... 65

F. Water Content and Matrix Attenuation .......... 67

V. DELAYED FISSION NEUTRON ACTIVATION MEASUREMENTS . . . . . . . . . 69

A. Introduction . . . . . . . . . . . . . . 69

B. Accelerator-Based Systems . . . . . . . . . . . . 70

C. Optimized Accelerator Systems . . . . . . . . . . . . 73

D. Radioactive Source System . . . . . . . . . . . . . . 77

VI. ENGLISH HULL MEASUREMENT EXPERIENCE . . . . . . . . . . . . . . 79

A. Introduction ....................... 79

B. Windscale Measurement System . . . . . . . . . . . 79

C. Windscale Calibration Procedure................ 81

D. Windscale Operating Experience ............... 82

E. Dounreay Measurement System . . . . . . . . . . . . 84

F. Dounreay Calibration and Operating Experience......... 85 
VII. FRENCH HULL MEASUREMENT EXPERIENCE . . . . . . . . . . . . . 86

A. Introduction . . . . . . . . . . . . . . . . 86

B. Garma-Ray Hull Monitor at AT-1 . . . . . . . . . . . . 86

C. Gamma-Ray hull Monitor at HAO .. . . . . . . . . . . . 88

D. Active Measurement System at AT-1................ 89

VIII. JAPANESE HULL MEASUREMENT EXPERIENCE $9 I$

A. Introduction . . . . . . . . . . . . . . . . . . . 91

B. Hull Monitor Design . . . . . . . . . . . . . . . . 91

C. Operating Experience ...................... 92

IX. U.S., GERMAN, AND ITALIAN HULL MEASUREMENT EXPERIENCE . • • • • • • 95

A. Introduction . . . . . . . . . . . . . . . . 95

B. Hull Measurement System at AGNS . . . . . . . . . . . . . 95

C. Passive Neutron Hull Monitor at Battelle - PNWL . . . . . . . . . 96

D. Delayed Neutron Activiation Analysis of Leached Hulls at ORNL • . 97

E. Fission Product Gamma-Ray Hull Monitor at WAR . . . . . . . . 98

REFERENCES . . . . . . . . . . . . . . . . . . . . . . 102 
THE MEASUREMENT OF LEACHED HULLS

by

T. Douglas Reilly

\begin{abstract}
Leached hulls are the short lengths of fuel rod cladding and fuel element hardware which constitute a major waste product of a reprocessing plant employing a chop-andleach head-end process. The small, undissolved fuel residue (0.1-1.08 of original fuel content) which is discarded with this waste must be measured for safeguards, material accountability, and process control reasons. This report gives a critical analysis of hull measurement techniques involving the analysis of fission product gamma rays, spontaneous fission neutrons from curium, and delayed neutron activation. Major emphasis is given to the measurement of $2186-\mathrm{keV}$ gamma rays from ${ }^{144} \mathrm{Ce}-144 \mathrm{Pr}$. A detailed description of typical leached hull characteristics is presented at the beginning of the report. An extensive review of experience gained from existing hull measurement systems in the United Kingdom, France, Japan, Germany, Italy, and the United States is presented.
\end{abstract}

\title{
I. INTRODUCTION
}

The purpose of this report is to describe the techniques used to measure the leached cladding hulls that result from spent fuel reprocessing. Each technique is critically analyzed and operational experience from existing reprocessing facilities is reviewed.

Leached hulls are the short lengths of fuel rod cladding and fuel element hardware which constitute a major waste product of a reprocessing plant employing a chop-and-leach head end process. There is always a small undissolved fuel residue which is discarded along with these cladding pieces. The magnitude of this residue is usually between 0.18 and 1.08 of the original fuel content. English experience at windscale with various types of fuel indicates an 
average hull residue of about 0.58 of the original fuel content. ${ }^{1}$ For a pilot plant with a capacity of 300 metric tons of uranium (MTU) per year, this corresponds to a loss of approximately 1.5 MTU per year containing about $15 \mathrm{~kg}$ of ${ }^{235} \mathrm{U}$ and $9 \mathrm{~kg}$ of plutonium. For a large commercial scale facility with 1500 MTU per year capacity, the loses are correspondingly greater (perhaps $75 \mathrm{~kg}$ of ${ }^{235} \mathrm{U}$ and $45 \mathrm{~kg}$ of $\left.\mathrm{Pu}\right)$.

While the above quantities are not particularly large, if unmeasured they could have an adverse effect on the overall nuclear material balance for the plant. An additional concern is that the hulls could provide a means of moving the relatively nonradioactive product plutonium out of a reprocessing plant. The hull radioactivity is many times that of product plutonium so that plutonium oxide could be hidden in the hull waste containers without significantly increasing the total activity. * From a nuclear material safeguards standpoint it is usually considered necessary to measure the fuel content of discarded hulls. This measurement is also necessary from a process control standpoint to guarantee that the dissolution process has not left too much fuel undissolved. Because of the relatively small fuel quantities involved, high accuracy is not required of this measurement. This is fortunate since it is a rather difficult measurement to make. For both safeguards and process control a measurement accuracy of 10-208 is more than sufficient.

This report has two major sections presenting first a technical description of the measurement problem and applicable measurement techniques and then a detailed discussion of existing hull measurement systems. The first section begins with a chapter describing in detail the physical and radiation characteristics of the fuel hulls. This is followed by three chapters dealing with the measurement of fission product gamma rays, the measurement of passive neutrons, and the active interrogation of the fuel residue. In this section only IWR type fuel hulls will be considered. In the second section separate chapters will review the English, French, and Japanese experience with existing hull measurement systems. The final chapter discusses U.S. and other experience. Some types of fuel reprocessing other than LWR will be included in this second section. Table I gives a list of the fuel reprocessing facilities which

\footnotetext{
* The gamma-ray background level from a typical hull basket is equivalent to $10^{7} \mathrm{~g}$ of clean plutonium. The neutron background is equivalent to $500 \mathrm{~g}$ so with respect to this concern it is more sensitive to a possible diversion. 
are included in this review. ${ }^{2,3}$ The most commonly used technique is the indirect assay of the fuel residue by measuring fission product gamma rays especially those from ${ }^{144} \mathrm{Ce}-{ }^{144} \mathrm{Pr}$. The report treats in detail the nature of this signature, the problems in its use, and experience with existing systems.

\section{TABLE I}

REPROCESS ING FACILITIES INCLUDED IN THIS REVIEW (Ref. 2)

\begin{tabular}{|c|c|c|c|}
\hline Plant & Location & Fuel & Capacity (MTU/yr) ${ }^{a}$ \\
\hline Windscale & United Kingdom & $\begin{array}{l}\text { MGR, AGR, } \\
\text { LWR, HWR }\end{array}$ & 800 \\
\hline Dounreay & United Kingdom & $\begin{array}{l}\text { MTR } \\
\text { FBR }\end{array}$ & $\begin{array}{l}0.5 \\
10\end{array}$ \\
\hline $\mathrm{UP2}+\mathrm{HAO}$ & La Hague, France & LWR, HWR & 800 \\
\hline AT1 & La Hague, France & FBR & 0.4 \\
\hline WAR-1 & $\begin{array}{l}\text { Rarlsruhe, Federal } \\
\text { Republic of Germany }\end{array}$ & LWR, HWR & 50 \\
\hline $\begin{array}{l}\text { PNC Tokai } \\
\text { Reprocessing } \\
\text { Plant }\end{array}$ & Tokai-mura, Japan & LWR & 250. (Ref. 3) \\
\hline Eurex-1 & Saluggia, Italy & $\begin{array}{l}\text { MTR } \\
\text { LWR, MGR }\end{array}$ & $\begin{array}{l}0.3 \\
25\end{array}$ \\
\hline Itrec & Rotondella, Italy & $T h+U$ & 4 \\
\hline
\end{tabular}

a $\mathrm{MTU}=$ metric ton of uranium. 


\section{GENERAL HULC CHARACTERISTICS}

The physical and radiation characteristics of spent LWR fuel hulls are considered in this chapter. It should be emphasized from the outset that the numbers presented here are only typical values. Actual fuel rod and element designs vary from one reactor to another even among reactors of the same type. Furthermore fission product to fuel ratios and cladding activation levels depend on rod location and reactor operating history not just fuel burnup. Nevertheless these typical values are useful in analyzing different measurement techniques and are the basis of the analysis in later chapters.

\section{A. Physical Characteristics}

Before describing the cladding hulls it may be useful to review the characteristics of a typical pressurized water reactor (PWR) and boiling water reactor (BWR) fuel element. In both cases the uranium fuel (enriched typically 2-38 ${ }^{235} \mathrm{U}$ ) takes the form of a $\mathrm{NO}_{2}$ ceramic pellet of diameter approximately 9-13 $\mathrm{mm}$ and length less than $20 \mathrm{~mm}$. These pellets are stacked in a stainless steel or zircaloy tubing to an active length of approximately $3.7 \mathrm{~m}$. The pellet stack is held together with various springs and spacers and the fuel rods sealed often with a helium filling. Zircaloy is a zirconium alloy containing about 1.458 tin and smaller amounts of iron, chromium, and nickel (zircaloy-2 contains $0.148 \mathrm{Fe}, 0.108 \mathrm{Cr}$, and $0.058 \mathrm{Ni}$; Zircaloy-4 contains $0.218 \mathrm{Fe}$ and $0.108 \mathrm{Cr}$ ). While stainless steel was used in earlier fuels most LWR fuels today use zircaloy as the cladding due to its very low neutron absorption cross section. The use of $\mathrm{zircaloy}$ or stainless steel cladding impacts the measurement of leached hulls because the activation of zircaloy is very much less than that of stainless steel which always contains small quantities of ${ }^{59} \mathrm{Co},{ }^{58} \mathrm{Ni}$, and ${ }^{54} \mathrm{Fe}$ giving rise to intense gamma-ray emitting activation products.

These fuel rods are then assembled into fuel elements, square matrices of rods held together with stainless steel hardware. Some typical physical characteristics of PWR and BWR fuel elements are presented in Table II.4,5

After discharge from the power reactor these elements are stored for a period of time (probably 90 days minimum) in the reactor fuel storage and cooling pond. They are then transported to the reprocessing facility where they cool further before being reprocessed. Minimum cooling before reprocessing is probably one-half year with an average time of one year envisioned should large-scale commercial reprocessing begin. At present with relatively 
TYPICAL FUEL ELEMENT CHARACTERISTICS(Ref. 4,5)

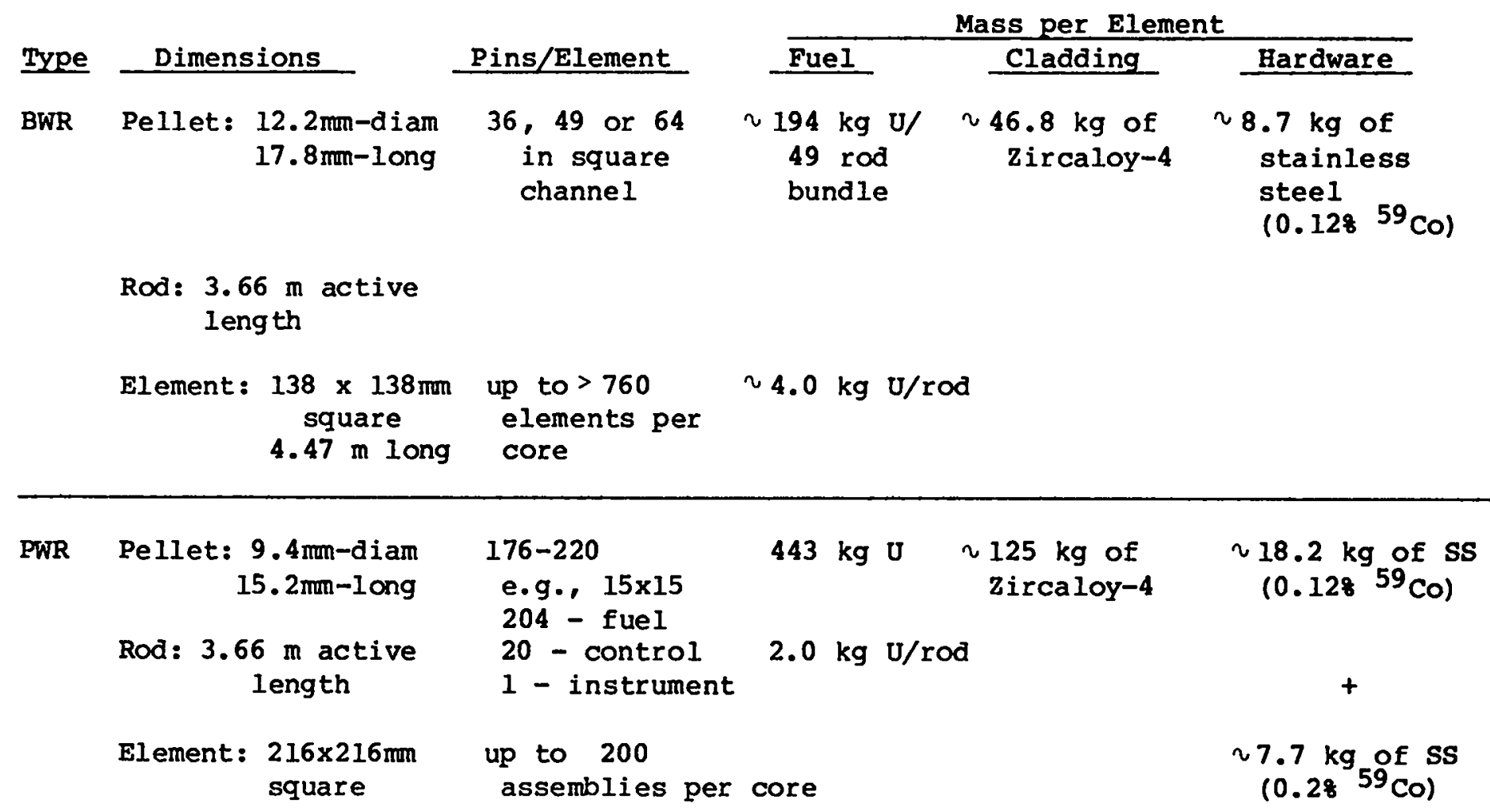

few reprocessing facilities operational in the world and most of these being smaller pilot plants many fuels are seen with very much longer cooling times, sometimes exceeding $10 \mathrm{yr}$.

While some reprocessing has occurred using chemical decladding of fuel, most facilities employ the so-called chop-and-leach process. Here the entire fuel assembly including all end fittings and hardware is fed remotely through a large mechanical shear. This shear removes the element end fittings and then chops the rods into more or less uniform pieces varying in length from approximately $20 \mathrm{~mm}$ to $125 \mathrm{~mm}$ depending on fuel type and the particular reprocessing facility. In a given facility the length of the sheared pieces may be variable to allow for different fuel types and process (dissolution) optimization. 
The entire mixture (end fittings, assembly hardware, springs and small fuel rod pieces) from this shearing operation falls into a heavy steel dissolver basket which is immersed in the dissolver tank. The dissolver contains a strong acid solution (typically 3-8 $\mathrm{N} \mathrm{HNO}_{3}$ plus a neutron poison for criticality control) whose function is to dissolve the $\mathrm{NO}_{2}$ fuel and contained fission products which have been exposed by the shearing operation. The dissolution may continue for 4-6 hours and may be followed by a rinse and releaching in a fresh dissolver solution, the actual cycle parameters, of course, vary from plant to plant.

At the end of the dissolution process most of the fuel and the contained fission products and actinides produced during irradiation in the reactor have gone into solution and stay with the dissolver solution for chemical partitioning by solvent extraction in later stages of the process. In the rinsed basket remain all the metal pieces: cladding hulls, springs, spacers, end fittings, assembly hardware, etc. which are not dissolved by the nitric acid bath. It is this metal mixture which forms the waste product termed leached hulls. Along with the metal pieces there is a small fuel residue as described in the introduction.

Various mechanical processes may contribute to the formation of the fuel residue which accompanies the leached hull waste. 6 The shear may pinch shut (partially or totally) the ends of some hull pieces resulting in insufficient acid-fuel contact during the dissolution cycle. In some instances there may be incomplete dissolution even though the ends of the cladding pieces are sufficiently open. Of lesser importance may be a small deposit of dissolver solution on the walls of the cladding hulls and the entrainment of small insoluble metallic nodules by the hulls.

The dissolver basket containing the leached hull waste is now rinsed and measured by the facility's leached hull monitor to evaluate the magnitude of the remaining fuel residue. Depending on the quantity of fuel remaining a management decision is made whether to releach the hulls or send them to waste disposal. Leached hulls represent the largest single solid waste volume (including solidified or vitrified high level fission product wastes) from the typical fuel reprocessing plant. 7

The hull measurement usually takes place directly in the dissolver basket or in a transfer basket of essentially the same dimensions. The dimensions of this basket and the average hull density are important particularly when 
considering the attenuation involved for systems which measure fission product gamma rays. Table III shows the dimensions at some of the plants considered in this review. ${ }^{8,9}$ The available data is not complete but it is sufficient to illustrate the typical densities and dimensions involved. Table IV shows the apparent average density of the hulls in the dissolver basket. The numbers for the Tokai plant are not stated directly in the Japanese report but are inferred from their statement that hulls from 1 BWR element or $\frac{1}{2}$ PWR element fit in the basket.

\section{B. Fission Product Gamma-Ray Levels}

The radiation levels from leached hulls are very high due to activiation of the cladding and the activity of the residual fuel. The remaining tables in this section are given to illustrate typical activity levels and gamma-ray and neutron radiation levels from leached hulls. These tables are used for much of the later analysis of specific techniques.

Tables V-VIII pertain to the fission product levels and associated gammaray activities for three different conditions of irradiation and burnup. The predicted values for the two higher burnups (33000 and $40000 \mathrm{MWD} / \mathrm{MTU}$ ) come from the code ORIGEN developed at Oak Ridge National Laboratory. The code used to predict the $20000 \mathrm{MWD} / \mathrm{MTU}$ values was not stated. Table $\mathrm{V}$ presents the fission product activities of the most gamma-active nuclides in Ci/MTU after a cooling period of 1 yr from reactor discharge. ${ }^{10}$ Note that the total activity is approximately proportional to burnup. This may be a fortuitous result for these three cases. The variation from proportionality is greater when the individual nuclides are considered. Actual levels for a given nuclide in a given fuel sample are dependent on flux and operating history, rod position within the reactor and axial position within the rod, and many other variables. This table shows that the fission product activity is in the approximate range $1-3 \times 10^{6} \mathrm{Ci} / \mathrm{MTU}$ after long irradiation exposure and a short cooling time of $1 \mathrm{yr}$. Table VI then lists most of the major gamma radiations from these nuclides. 11.12 The nuclides chosen account for over 808 of the total fission product decay activity and an even larger fraction of the gamma-ray emission. Tables VII and VIII present expected fission product gamma-ray intensities at $1 \mathrm{yr}$ and $4 \mathrm{yr}$ from reactor discharge. These tables are derived directly from the preceding two tables. They show that the total gamma-ray intensity is of the order of $10^{16} \mathrm{r} / \mathrm{MTU}-\mathrm{s}$. Approximately onequarter to one-third of the fission product decays are accompanied by energetic gamma rays. 
TABLE III

DISSOLVER BASKET PARAMETERS

\begin{tabular}{|c|c|c|c|}
\hline plant & Dimensions & Hull Mass & Fuel Charge \\
\hline $\begin{array}{l}\text { Windscale } \\
\text { (Ref. I) }\end{array}$ & $\begin{array}{l}\text { 380-mm-diam } \\
\text { 1.5-m-high } \\
\text { 19-mm-wall- } \\
\text { thickness }\end{array}$ & $\begin{array}{l}100-\mathrm{kg}-\mathrm{SS} \\
140-\mathrm{kg}-\mathrm{zirca} \text { oy- } 2 \\
20-50 \mathrm{~mm} \text { long hull pieces }\end{array}$ & $330 \mathrm{~kg}$ \\
\hline $\begin{array}{l}\text { Dounreay } \\
\quad(\text { Ref. 8) }\end{array}$ & $\begin{array}{l}\text { 100-mm-diam } \\
450-m m-h i g h\end{array}$ & $2 \mathrm{~kg} \mathrm{SS}$ & $\mathrm{NA}$ \\
\hline $\begin{array}{l}A T-1 \\
\quad(\operatorname{Ref} .6)\end{array}$ & $\begin{array}{l}\text { 100-mm-diam } \\
950-\pi m-h i g h\end{array}$ & NA & NA \\
\hline $\begin{array}{l}\text { Tokai } \\
\quad(\operatorname{Ref} .3)\end{array}$ & $\begin{array}{l}220-m m-d i a m \\
1.4-m-h i g h\end{array}$ & $\left.\begin{array}{l}55.7 \mathrm{~kg} \\
66.6 \mathrm{~kg}\end{array}\right\} \begin{array}{l}\text { Zircaloy } \\
+\mathrm{ss}\end{array}$ & $\begin{array}{l}\text { l-BWR element } \\
\frac{1}{2}-\text { PWR element }\end{array}$ \\
\hline $\begin{array}{c}\text { CNEN-EUREX } \\
\text { (Ref. 9) }\end{array}$ & $\begin{array}{l}\text { 125-mm-diam } \\
2.0-m-h i g h\end{array}$ & NA & $\begin{array}{l}3 \text { CANDU } \\
\text { elements }\end{array}$ \\
\hline
\end{tabular}

TABLE IV

APPARENT AVERAGE HULI DENSITY

Plant

Windscale

Dounreay

Tokai
Volume and Hull Mass

$$
\begin{array}{rlrl}
V & =0.17 \mathrm{~m}^{3} & \\
M & =100 \mathrm{~kg} \mathrm{SS} & 0.59 \mathrm{~g} / \mathrm{cm}^{3} \\
& =140 \mathrm{~kg} \mathrm{Zircaloy-2} & 0.82 \mathrm{~g} / \mathrm{cm}^{3}
\end{array}
$$$$
v=0.0035 \mathrm{~m}^{3}
$$$$
M=2 \mathrm{~kg} \mathrm{sS}
$$$$
0.57 \mathrm{~g} / \mathrm{cm}^{3}
$$$$
\begin{aligned}
V & =0.053 \mathrm{~m}^{3} \\
M & =55.7 \mathrm{~kg} \mathrm{BWR} \\
& =66.6 \mathrm{~kg} \text { PWR }
\end{aligned}
$$

Average Density

$$
\begin{aligned}
& 1.05 \mathrm{~g} / \mathrm{cm}^{3} \\
& 1.25 \mathrm{~g} / \mathrm{cm}^{3}
\end{aligned}
$$


FISSION PRODUCT ACTIVITIES AT I YR FROM REACTOR DISCHARGE

\section{Ci/MTU}

\begin{tabular}{|c|c|c|c|}
\hline Nuclide & $20000^{a}$ & $33000^{\mathrm{b}}$ & $40000^{\mathrm{C}} \mathrm{MWD} / \mathrm{MTU}^{\circ}$ \\
\hline${ }^{95} \mathrm{zr}$ & $1.82 \times 10^{4}$ & $3.14 \times 10^{4}$ & $3.67 \times 10^{4}$ \\
\hline${ }^{95} \mathrm{Nb}$ & $3.85 \times 10^{4}$ & $6.65 \times 10^{4}$ & $7.81 \times 10^{4}$ \\
\hline${ }^{106}{ }_{\mathrm{Ru}-\mathrm{Rh}}$ & $1.90 \times 10^{5}$ & $2.84 \times 10^{5}$ & $3.87 \times 10^{5}$ \\
\hline${ }^{134} \mathrm{Cs}$ & & $1.10 \times 10^{5}$ & $2.62 \times 10^{5}$ \\
\hline${ }^{137} \mathrm{Cs}$ & $5.97 \times 10^{4}$ & $1.01 \times 10^{5}$ & $1.29 \times 10^{5}$ \\
\hline${ }^{144} \mathrm{Ce}-\mathrm{Pr}$ & $3.82 \times 10^{5}$ & $4.97 \times 10^{5}$ & $5.83 \times 10^{5}$ \\
\hline${ }^{154} \mathrm{Eu}$ & & $9.81 \times 10^{3}$ & $9.68 \times 10^{3}$ \\
\hline
\end{tabular}

Total of above $1.26 \times 10^{6}$

$1.88 \times 10^{6}$

$2.46 \times 10^{6}$

Total fission

$2.30 \times 10^{6}$

$2.91 \times 10^{6}$

product activity

Initial Enrichment Specific Power

$17.5 \mathrm{MW} / \mathrm{T}$

a. Ref. 1

$1.78^{235} \mathrm{U}$

$3.28^{235} \mathrm{U}$

b. Ref. 10

$3.38235 \mathrm{U}$
$37.5 \mathrm{MW} / \mathrm{T}$

$40 \mathrm{MW} / \mathrm{T}$
Flux

$3.25 \times 10^{14} \mathrm{n} / \mathrm{cm}^{2}-\mathrm{s}$

$4.07 \times 10^{13} \mathrm{n} / \mathrm{cm}^{2}-\mathrm{s}$

a. MWD $/$ MTU = megawatt day per metric ton or uranium. 


\section{TABLE VI}

RELEVANT FISSION PRODUCT GAMMA RAYS(Ref. 11,12)

\begin{tabular}{|c|c|c|c|c|c|}
\hline Nuclide & $\mathrm{T}_{\frac{1}{2}}$ & Ener gy (kev) & Branchin & atio $(q$ & (8) \\
\hline $95 \mathrm{zr}$ & 65.5. day & $\begin{array}{l}724.2 \\
756.7\end{array}$ & $\begin{array}{l}44.4 \\
54.6\end{array}$ & & \\
\hline${ }^{95} \mathrm{Nb}$ & 35.0 day & 764.5 & 100.0 & & \\
\hline $106_{\mathrm{Ru}-\mathrm{Rh}}$ & 369.0 day & $\begin{array}{r}511.9 \\
621.9 \\
1050.4 \\
1128.1 \\
1562.2 \\
2366.0\end{array}$ & $\begin{array}{l}20.6 \\
9.8 \\
1.5 \\
0.4 \\
0.17 \\
0.024\end{array}$ & from & $\begin{array}{c}106 \mathrm{Rh} \\
n \\
n \\
n \\
n\end{array}$ \\
\hline${ }^{134} \mathrm{Cs}$ & $2.06 \mathrm{yr}$ & $\begin{array}{r}569.4 \\
604.7 \\
795.8 \\
801.9 \\
1365.0\end{array}$ & $\begin{array}{r}15.4 \\
97.6 \\
85.4 \\
8.7 \\
3.3\end{array}$ & & \\
\hline${ }^{137} \mathrm{Cs}$ & $30.12 \mathrm{yr}$ & 661.6 & 85.0 & & \\
\hline${ }^{144} \mathrm{Ce}-\mathrm{Pr}$ & 284.4 day & $\begin{array}{r}133.5 \\
696.5 \\
1489.2 \\
2185.7\end{array}$ & $\begin{array}{c}11.0 \\
1.51 \\
0.29 \\
0.74\end{array}$ & $\begin{array}{l}\text { from } \\
\text { from }\end{array}$ & $\begin{array}{l}144 \mathrm{Ce} \\
144 \mathrm{Pr} \\
n \\
"\end{array}$ \\
\hline${ }^{154} \mathrm{Eu}$ & $8.6 \mathrm{yr}$ & $\begin{array}{r}123.0 \\
248.0 \\
591.8 \\
723.3 \\
759.0 \\
873.3 \\
996.4 \\
1008.0 \\
1274.5\end{array}$ & $\begin{array}{r}34.7 \\
6.3 \\
4.9 \\
19.7 \\
4.2 \\
11.7 \\
10.1 \\
17.4 \\
34.7\end{array}$ & & \\
\hline
\end{tabular}


FISSION PRODUCT GAMMA-RAY INTENSITIES AT I YR FROM REACTOR DISCHARGE

\section{$\underline{\gamma / M T U-S}$}

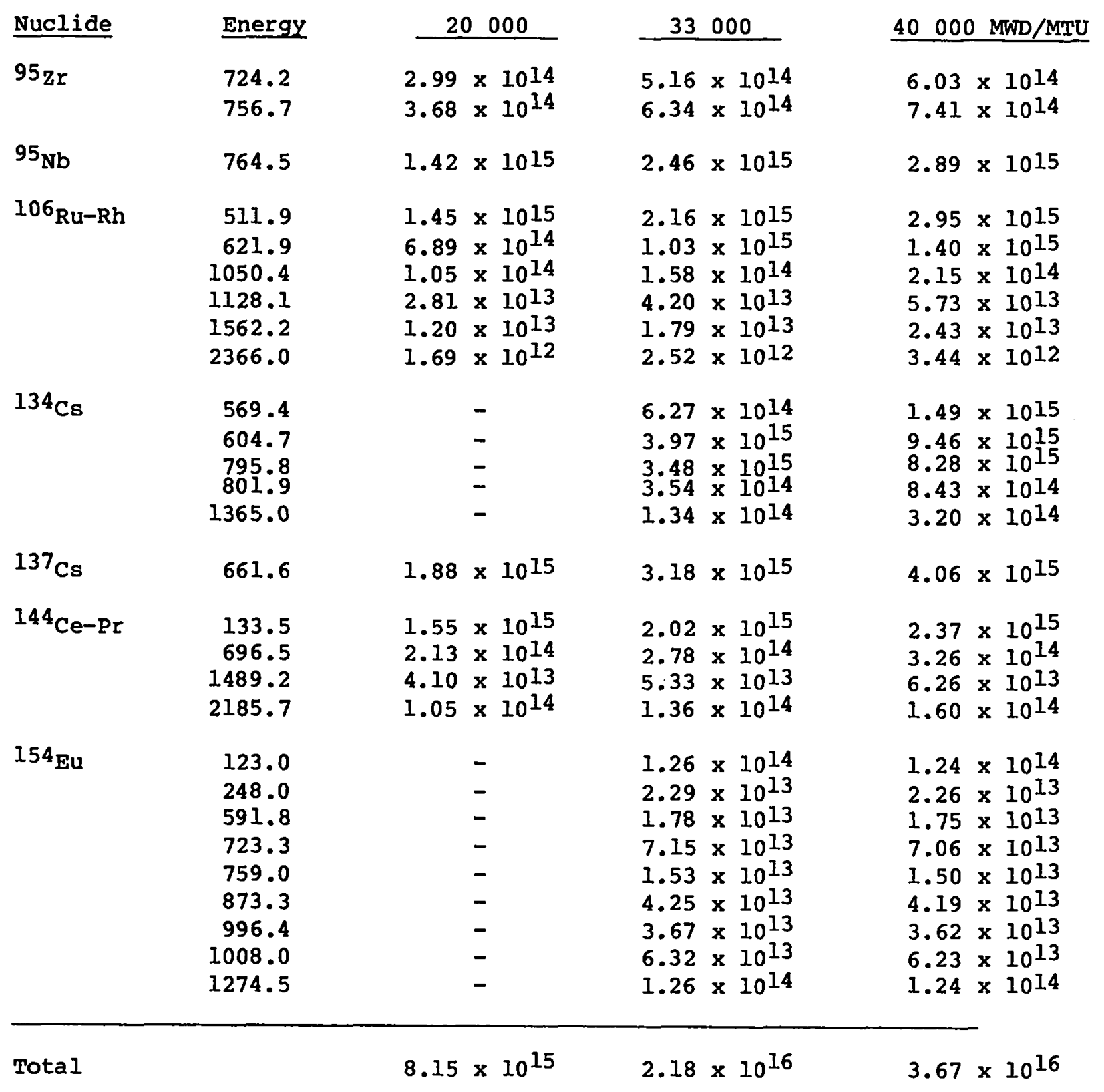




\section{TABLE VIII}

FISSION PRODUCT GAMMA-RAY INTENSITIES AT 4 YR FROM REACTOR DISCHARGE

\section{$\underline{Y / M T U-s}$}

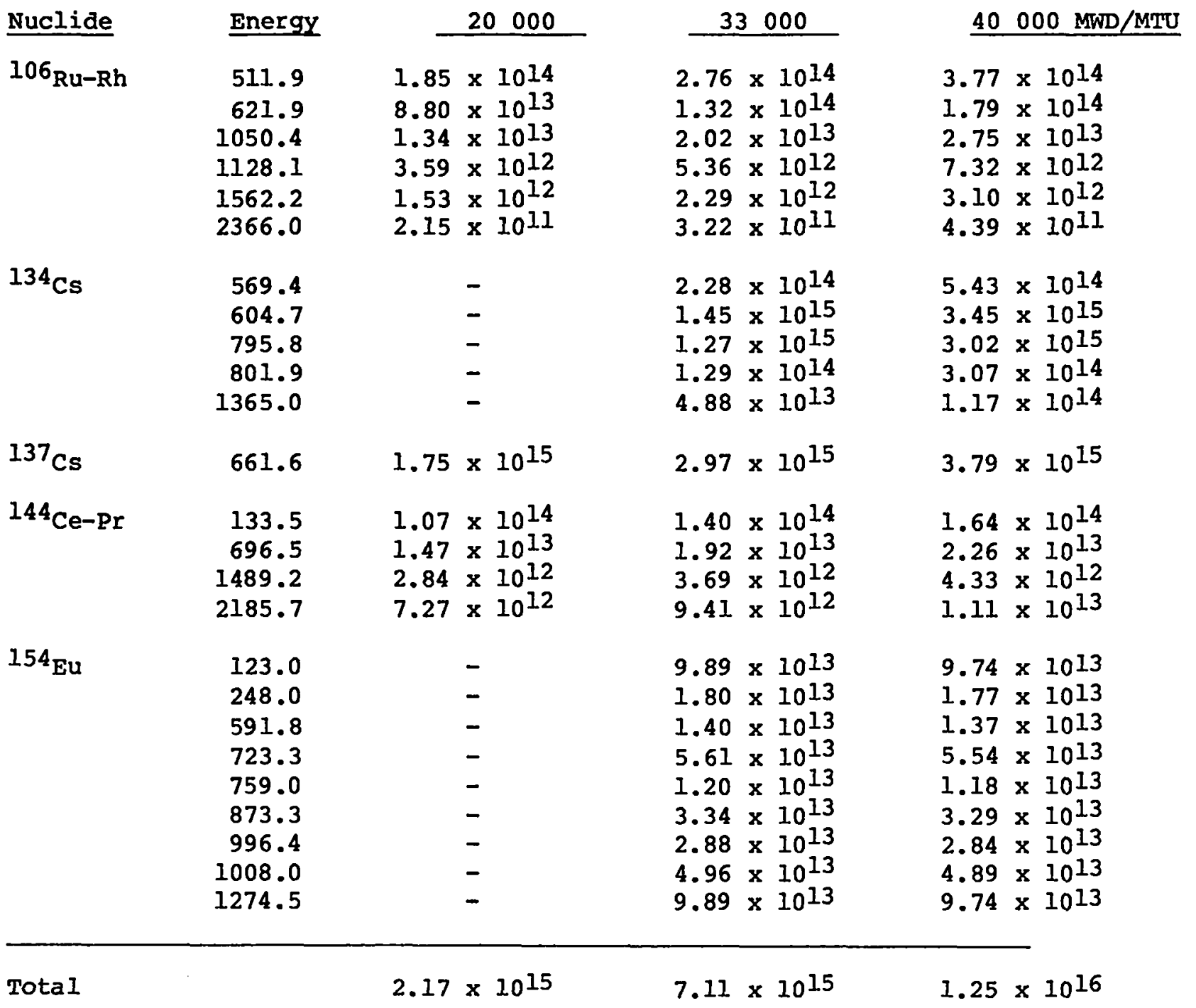


For the two higher burnup situations Table IX shows the major actinide levels in the irradiated fuel at $1 \mathrm{yr}$ from discharge. In addition to uranium and plutonium two isotopes of curium are listed here because they are major contributors to the neutron radiation from spent fuel.

\section{Cladding Gamma-Ray Levels}

The other major contribution to the gamma radiation field from spent fuel comes from the activation of the fuel cladding and element hardware. zircaloy is used for cladding material because it has a very low neutron absorption cross section and therefore does not significantly affect the neutron economy in the reactor. A side effect of this is that it does not activate to the extent that stainless steel materials do. Its major activation products (from the standpoint of gamma-ray emitters) are ${ }^{95} \mathrm{zr},{ }^{95} \mathrm{Nb}$, and ${ }^{125} \mathrm{Sb}$. The first two come from neutron absorption by $94 \mathrm{zr}$ an isotope which makes up approximately 17.4 of natural zirconium. This nuclide has a low thermal absorption cross section of about $0.05 \mathrm{~b} .{ }^{95} \mathrm{Nb}$ is the beta decay product

$$
{ }^{94} \mathrm{zr}+\mathrm{n} \rightarrow \gamma+{ }^{95} \mathrm{zr} \frac{-\beta}{65.5 \text { day }}{ }^{95} \mathrm{Nb} \frac{-\beta}{35.0 \text { day }}{ }^{95} \mathrm{Nb} \text { (stable) }
$$

of ${ }^{95} \mathrm{zr}$ and is also a gamma-ray emitter. The other activation product ${ }^{115} \mathrm{Sb}$ arises from neutron capture by ${ }^{124} \mathrm{Sn}^{-}$, tin being a minor constituent, about 1.45\%, of the zirconium alloy, zircaloy. ${ }^{124} \mathrm{Sn}$ has a concentration of approximately 5.68 in normal tin and has a thermal capture cross section of about $1.3 \mathrm{~b}$. The resulting nuclide ${ }^{125} \mathrm{Sn}(9.4$ days) is not especially gamma-ray active but its beta decay daughter, ${ }^{125} \mathrm{Sb}(2.71 \mathrm{yr})$ is a gamma-ray emitter.

The major activated material in the normal LWR fuel is stainless steel. This is true also for zircaloy clad fuels because the end fittings and fuel assembly hardware are always some form of stainless steel. For fuels clad with stainless steel the activation levels are even higher. The major activation product in stainless steel is ${ }^{60} \mathrm{Co}$ and to a lesser degree ${ }^{58} \mathrm{Co}$ and ${ }^{54} \mathrm{Mn}$. In all stainless steels there is some ${ }^{59} \mathrm{Co}$ which is the only isotope of natural cobalt and has a thermal capture cross section of about $37 \mathrm{~b}$. In reactor grade steels the level of ${ }^{59} \mathrm{Co}$ is in the range $0.1-0.28$. The direct neutron capture on ${ }^{59} \mathrm{Co}$ gives rise to ${ }^{60} \mathrm{Co}(5.263 \mathrm{yr})$ which is a strong gamma-ray emitter. The other two activation products, ${ }^{58} \mathrm{Co}$ (71.3 days) and ${ }^{54} \mathrm{Mn}$ (303 days) result from the $(n, p)$ reaction on ${ }^{58} \mathrm{Ni}$ and ${ }^{54} \mathrm{Fe}$. In reactor grade steels the level of ${ }^{58} \mathrm{Ni}$ is in the range $5.5-10.38$, and the level of ${ }^{54} \mathrm{Fe}$ is in the range $3.5-4.48$. 
TABLE IX

ACTINIDE LEVELS AT I YR FROM REACTOR DISCHARGE

g/MTU

33000

7940

$9.56 \times 10^{5}$

5030

3460

9116

2.43

18.3

$9.66 \times 10^{5} \mathrm{~g}$

$1.32 \times 10^{5} \mathrm{Ci}$
$40 \quad 000 \mathrm{MWD} / \mathrm{MTU}$

5506

$9.47 \times 10^{5}$

5251

4020

9710

3.05

75.4

Total Heavy Nuclide Mass

$9.58 \times 10^{5} \mathrm{~g}$

Total Heavy Nuclide

Acitivity

$1.43 \times 10^{5} \mathrm{Ci}$

Tables $X$-XIII pertain to fuel cladding and hardware activation for the same three irradiation situations as were considered in Tables V-VIII. Table $X$ presents typical cladding activities in $\mathrm{Ci} / \mathrm{MTU}$ at $\mathrm{I} \mathrm{yr}$ from reactor discharge. The activities are given per metric ton of uranium for easy comparison with the fission product activities and gamma-ray intensities in the earlier tables. They can be easily converted to activity or gamma-ray intensity per unit mass of cladding or hardware material using the information in the footnotes to Table $x$. The first two pertain to zircaloy clad fuel elements and their associated hardware. It is the sum of these two activities that would be found in the spent element. The last section refers to stainless steel clad fuel and contains the combined activity of the cladding and hardware. The apparent inconsistencies between the $20000 \mathrm{MWD} / \mathrm{MPU}$ and the higher burnup values for the cobalt and manganese activation levels may be partially due to different minor constituent concentrations in the stainless steels used. 
TABLE $X$

CLADDING ACTIVITIES AT 1 YR FROM REACTOR DISCHARGE

Zircaloy Cladding Activity

Nuclide

$20000 a$

$95 \mathrm{Nb}$

$95 \mathrm{zr}$

$125 \mathrm{Sb}$
Ci/MTU

$33000^{b}$

$40 \quad 000 \mathrm{MWD} / \mathrm{MTUC}$

$1.99 \times 10^{3}$

$3.02 \times 10^{3}$

$9.54 \times 10^{2}$

$1.36 \times 10^{3}$

$1.35 \times 10^{3}$

$3.91 \times 10^{3}$

Stainless Steel End Fittings and Hardware

$\underline{\mathrm{Ci} / \mathrm{MTU}}$
${ }^{60} \mathrm{Co}$
$9.18 \times 10^{2}$
$6.89 \times 10^{3}$
$9.82 \times 10^{3}$
${ }^{58} \mathrm{Co}$
$3.35 \times 10^{2}$
$1.97 \times 10^{2}$
${ }^{54} \mathrm{Mn}$
$2.25 \times 10^{3}$
$4.3 \times 10^{1}$

Stainless Steel Cladding and Hardware

$\underline{\mathrm{Ci} / \mathrm{MTU}}$
${ }^{60} \mathrm{Co}$
$5.26 \times 10^{3}$
$3.55 \times 10^{4}$
$5.77 \times 10^{4}$
${ }^{58}$ Co
$1.92 \times 10^{3}$
$1.01 \times 10^{3}$
${ }^{54} \mathrm{Mn}$
$1.29 \times 10^{4}$
$2.2 \times 10^{2}$

a. Ref. I Converted assuming $0.33 \mathrm{MTU}$ associated with $140 \mathrm{~kg}$ of $\mathrm{zircaloy}-2$ or $100 \mathrm{~kg}$ of stainless steel.

b. Ref. 10 Reference PWR element has $461.4 \mathrm{~kg}$ of Uranium, $108.4 \mathrm{~kg}$ of zircaloy, and $26.1 \mathrm{~kg}$ of stainless steel hardware. The activity of stainless steel cladding is estimated assuming $108.4 \mathrm{~kg}$ of stainless steel.

c. Ref. 5 Reference PWR element has $443 \mathrm{~kg}$ of uranium, $125 \mathrm{~kg}$ of zircaloy-4, and $25.7 \mathrm{~kg}$ of stainless steel hardware. 
Table XI gives the important parameters of the major gamma rays from these activation products. Tables XII and XIII show the gamma-ray intensities for $1 \mathrm{yr}$ and $4 \mathrm{yr}$ from reactor discharge. The format is the same as described above for Table $x$. These tables show that even for the $z$ ircaloy clad fuel the ${ }^{60} \mathrm{Co}$ is the major gamma radiation emanating from the cladding and hardware. They also show that for the fuel element considered as a whole the cladding and hardware activity is considerably below that of the contained fuel (ignoring for the moment gamma-ray attenuation). Compare, for instance, Table VII and Table XII. For Zircaloy clad fuel with $33000 \mathrm{MWD} / \mathrm{MTU}$ burnup the contained fission products produce $2.18 \times 10^{16} \mathrm{\gamma} / \mathrm{MTU}-\mathrm{s}$ while the cladding and hardware yield $6.64 \times 10^{14} \mathrm{\gamma} / \mathrm{MrU} / \mathrm{s}$ or only about 38 of the total gamma-ray production. This situation is reversed for the leached fuel hulls after all but $10^{-2}-10^{-3}$ of the original fuel content has gone into solution in the dissolver tank.

TABLE XI

RELEVANT CLADDING ACTIVATION GAMMA RAYS

\begin{tabular}{|c|c|c|c|c|}
\hline Nuclide & $T_{\frac{1}{2}}$ & & Energy $(\mathrm{keV})$ & Branching Ratio (8) \\
\hline $95 \mathrm{zr}$ & 65.5 & day & $\begin{array}{l}756.7 \\
724.2\end{array}$ & $\begin{array}{l}54.6 \\
44.4\end{array}$ \\
\hline${ }^{95} \mathrm{Nb}$ & 35.0 & day & 764.5 & 100 \\
\hline${ }^{125} \mathrm{sb}$ & 2.71 & yr & $\begin{array}{l}668.0 \\
634.0 \\
598.0 \\
462.0 \\
427.0\end{array}$ & $\begin{array}{r}1.9 \\
11.2 \\
19.2 \\
10.2 \\
31.0\end{array}$ \\
\hline${ }^{60} \mathrm{Co}$ & 5.263 & $y \mathrm{yr}$ & $\begin{array}{l}1332.5 \\
1173.2\end{array}$ & $\begin{array}{l}100.0 \\
100.0\end{array}$ \\
\hline${ }^{58} \mathrm{Co}$ & 71.3 & day & $\begin{array}{r}1674.9 \\
865.0 \\
810.5\end{array}$ & $\begin{array}{r}0.6 \\
1.4 \\
99.0\end{array}$ \\
\hline${ }^{54} \mathrm{Mn}$ & 303. & day & 834.9 & 100.0 \\
\hline
\end{tabular}


CLADDING ACTIVATION GAMMA-RAY INTENSITIES

AT 1 YR FROM REACTOR DISCHARGE

$x /$ MTU-s

Zircaloy Cladding Gamma-Ray Levels

Nuclide Energy (keV)

${ }^{95} \mathrm{zr}$

756.7

724.2

${ }^{95} \mathrm{Nb}$

764.5

668.0

634.0

598.0

462.0

427.0
$20 \quad 000$

$1.21 \times 10^{13}$

$9.86 \times 10^{12}$

$4.81 \times 10^{13}$

$\begin{array}{ll}- & 9.49 \times 10^{11} \\ - & 5.59 \times 10^{12} \\ - & 9.59 \times 10^{12} \\ - & 5.09 \times 10^{12} \\ - & 1.55 \times 10^{13}\end{array}$

$40 \quad 000 \mathrm{MWD} / \mathrm{MTU}$

$2.75 \times 10^{13}$

$2.23 \times 10^{13}$

$1.12 \times 10^{14}$

$2.75 \times 10^{12}$

$1.62 \times 10^{13}$

$2.78 \times 10^{13}$

$1.48 \times 10^{13}$

$4.48 \times 10^{13}$

Subtotal

$7.01 \times 10^{13}$

$1.45 \times 1014$

$2.68 \times 1014$

Stainless Steel End Fittings and Hardware

$\underline{Y / M T U-S}$

${ }^{60} \mathrm{Co}$

1332.5

$3.40 \times 1013$

$2.55 \times 10^{14}$

$3.63 \times 10^{14}$

1173.5

$3.40 \times 10^{13}$

$2.55 \times 10^{14}$

$3.63 \times 1014$

${ }^{58} \mathrm{Co}$

$$
\begin{array}{r}
1674.9 \\
865.0 \\
810.5
\end{array}
$$

$7.44 \times 1010$

$1.74 \times 10^{11}$

$4.37 \times 1010$

$1.02 \times 1011$

$1.23 \times 10^{13}$

$7.22 \times 1012$

${ }^{54} \mathrm{Mn}$

834.9

$8.33 \times 10^{13}$

$1.59 \times 1012$

Subtotal

$1.64 \times 1014$

$5.19 \times 10^{14}$

$7.26 \times 10^{14}$

Total

$2.34 \times 10^{14}$

$6.64 \times 10^{14}$

$9.94 \times 10^{14}$

Stainless Steel Cladding and Hardware

$\underline{Y / M T U-S}$

${ }^{60} \mathrm{Co}$

1332.5

$1.95 \times 1014$

$1.31 \times 10^{15}$

$1.31 \times 10^{15}$

$2.13 \times 10^{15}$

1173.2

$1.95 \times 10^{14}$

$2.24 \times 10^{11}$

${ }^{58} \mathrm{Co}$

1674.9

$4.26 \times 10^{11}$

865.0

$9.95 \times 10^{11}$

810.5

$7.03 \times 1.013$

$5.23 \times 10^{11}$

$3.70 \times 1013$

$54 \mathrm{Mn}$

834.9

$4.77 \times 10^{14}$

$8.14 \times 1012$

Total

$9.39 \times 10_{14}$

$2.67 \times 10_{15}$

$4.26 \times 1015$ 
CLADDING ACTIVATION GAMMA-RAY INTENSITIES

AT 4 YR FROM REACTOR DISCHARGE

\section{Zircaloy Cladding Gamma-Ray Levels}

Nuclide Energy (kev)

$125 \mathrm{Sb}$

668.

634 .

598.

462.

427.

$20 \quad 000$

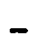

$-$

$\underline{\text { VMTU-s }}$

33000

$4.40 \times 10^{11}$

$40 \quad 000 \mathrm{MWD} / \mathrm{MTU}$

$1.28 \times 10^{12}$

$7.51 \times 10^{12}$

$2.59 \times 10^{12}$

$1.29 \times 10^{13}$

$6.86 \times 10^{12}$

$2.08 \times 10^{13}$

Sub total

$-\quad 4.45 \times 10^{12}$

$2.36 \times 10^{12}$

$7.19 \times 10^{12}$

$1.70 \times 10^{13}$

$4.94 \times 10^{13}$

Stainless Steel End Fittings $\quad \mathrm{Y} / \mathrm{MTU}-\mathrm{s}$
${ }^{60} \mathrm{Co}$
1332.5
$2.29 \times 10^{13}$
$1.72 \times 10^{14}$
$2.45 \times 10^{14}$
1173.2
$2.29 \times 10^{13}$
$1.72 \times 10^{14}$
$2.45 \times 10^{14}$

${ }^{54} \mathrm{Mn}$

834.9

$6.79 \times 10^{12}$

$1.30 \times 10^{11}$

Subtotal

$5.26 \times 10^{13}$

$3.44 \times 10^{14}$

$4.90 \times 10^{14}$

Total

$5.26 \times 10^{13}$

$3.61 \times 10^{14}$

$5.39 \times 10^{14}$

Stainless Steel Cladding and Hardware

${ }^{60} \mathrm{Co}$

$$
1332.5
$$

1173.2

${ }^{54} \mathrm{Mn}$

834.9

$3.89 \times 10^{13}$

$1.31 \times 10^{14}$

$1.31 \times 10^{14}$

$$
\begin{aligned}
& 8.82 \times 10^{14} \\
& 8.82 \times 10^{14}
\end{aligned}
$$

$1.43 \times 10^{15}$

$1.43 \times 10^{15}$

Total

$3.01 \times 10^{14}$

$1.76 \times 10^{15}$

$2.86 \times 10^{15}$ 
D. Neutron Levels

The irradiated LWR fuel is also a copious source of neutrons largely through the presence of intense spontaneous fission emitters. Table XIV lists neutron production rates for the most important nuclides in irradiated $\mathrm{NO}_{2}$ fuel. The two curium isotopes ${ }^{242} \mathrm{~cm}$ and ${ }^{244} \mathrm{~cm}$, which have half-lives of 162.8 days and $18.10 \mathrm{yr}$ respectively, have very high spontaneous fission activities and in any practical situation are the major source of neutrons in spent fuel.

Table XV shows the neutron production from oxide fuel irradiated to 33000 MWD/MTU (the same case as considered previously, Tables V-XIII) at 1 yr and 4 yr from reactor discharge. At 1 yr the total neutron rate is $2.81 \times 10^{8}$ $n / M T U-s$ of which 5.98 are $(\alpha, n)$ neutrons and only 2.28 are due to plutonium isotopes. At $4 \mathrm{yr}$ this has decayed to $1.93 \times 10^{8} \mathrm{n} / \mathrm{MTU}-\mathrm{s}$ of which only 2.98 are $(\alpha, n)$ neutrons and 3.28 are due to plutonium isotopes. The contribution from $24 I_{A m}(\alpha, n)$ has grown to nearly $0.5 \%$. Table XVI shows the neutron production per metric ton of uranium from fuel irradiated to $40000 \mathrm{MWD} / \mathrm{MTU}$ again for cooling times of $1 \mathrm{yr}$ and $4 \mathrm{yr}$. The total neutron rate at $1 \mathrm{yr}$ is

TABLE XIV

NEUTRON PRODUCTION RATES IN OXIDE FUEL

$\mathrm{n} / \mathrm{g}-\mathrm{s}$

Isotope

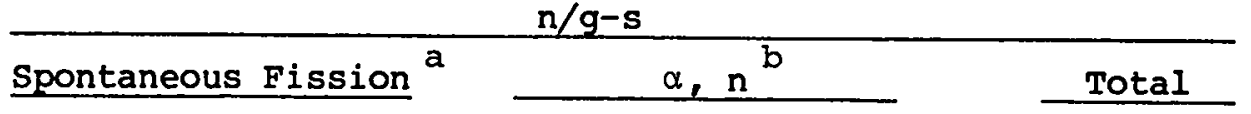

${ }^{238} \mathrm{Pu}$

$2.72 \times 10^{3}$

$1.84 \times 10^{4}$

$2.11 \times 10^{4}$

$240 \mathrm{Pu}$

$8.72 \times 10^{2}$

$2.01 \times 10^{2}$

$1.07 \times 10^{3}$

$242 \mathrm{Pu}$

$1.77 \times 10^{3}$

$1.77 \times 10^{3}$

$24 I_{\text {Am }}$

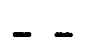

$3.64 \times 10^{3}$

$3.64 \times 10^{3}$

$242 \mathrm{~cm}$

$2.24 \times 10^{7}$

$4.75 \times 10^{6}$

$2.72 \times 10^{7}$

${ }^{244} \mathrm{Cm}$

$1.13 \times 10^{7}$

$1.03 \times 10^{5}$

$1.14 \times 10^{7}$

a Spontaneous fission half lives from C. M. Lederer and V. S. Shirley, Table of Isotopes, 7th Edition (John Wiley and Sons, Inc., New York, 1978).

b S. T. Hsue, Los Alamos Scientific Laboratory, personal communication, October 1978. 


\section{TABLE XV}

NEUTRON PRODUCTION FROM OXIDE FUEL (33 000 MWD/MTU)

(At 1 yr From Reactor Discharge)

$\begin{array}{ll}\text { Nuclide } & \frac{\mathrm{g} / \mathrm{MTU}}{238 \mathrm{Pu}} \\ { }^{240} \mathrm{Pu} & 1.35 \times 10^{2} \\ 242_{\mathrm{Pu}} & 2.32 \times 10^{3} \\ 241_{\mathrm{Am}} & 4.61 \times 10^{2} \\ 242 \mathrm{Cm} & 8.83 \times 10^{1} \\ 244 \mathrm{Cm} & 2.43 \\ & 18.3\end{array}$

$M T U^{-1}-S-1$

Total

(At 4 yr From Reactor Discharge)

pu Contribution Assumed Constant
$241_{\text {Am }}$
$2.46 \times 10^{2}$
- -
$8.95 \times 10^{5}$
${ }^{244} \mathrm{Cm}$
16.3
$1.84 \times 10^{8}$
$1.68 \times 10^{6}$
Total

$\overline{1.88 \times 10^{8}}$

$9.52 \times 10^{8} \mathrm{n} / \mathrm{MTU}-\mathrm{s}$ with 2.98 due to $(\alpha, n)$ neutrons and 0.938 due to plutonium isotopes. At 4 yr the total is $7.75 \times 10^{8}$ with $1.78(\alpha, n)$ and 1.158 from plutonium.

For high burnup these tables show the neutron emission from spent fuel to be of the order of $10^{8}-10^{9} \mathrm{n} / \mathrm{MrU}-\mathrm{s}$. In most practical situations the neutrons would be largely from spontaneous fission events $P 90 \%$ ) and predominately from the curium isotopes (>958). Only at very low burnup or long cooling time would the plutonium be expected to contribute appreciably to the neutron emission. As an example consider the $33000 \mathrm{MWD} / \mathrm{MTU}$ case. It would be more than $90 \mathrm{yr}$ before the ${ }^{244} \mathrm{Cm}$ has decayed to a level where its neutron output is equal to that of the combined plutoniun isotopes. 
The Tables V-XVI when taken together summarize the radiation environment which would be expected from typical IWR fuel irradiated to $20000-40000$ MWD/MTU. The total activities and gamma-ray and neutron intensities for the three cases considered are summarized in Table XVII.

\section{TABIE XVI}

NEUTRON PRODUCTION FROM OXIDE FUEL ( $40000 \mathrm{MWD} / \mathrm{MTU})$

(At 1 yr From Reactor Discharge)

Nuclide
$238 \mathrm{Pu}$
$240 \mathrm{Pu}$
$242 \mathrm{Pu}$
$241_{\mathrm{Am}}$
$242 \mathrm{Cm}$
$244 \mathrm{Cm}$

Total

$\frac{\mathrm{g} / \mathrm{MTU}}{2.58 \times 10^{2}}$
$2.31 \times 10^{3}$
$5.49 \times 10^{2}$
$8.25 \times 10^{1}$
3.05
75.4

MTU-1-S-I

\begin{tabular}{cc}
\hline$n(S F)$ & $\frac{n(\alpha, n)}{n}$ \\
$7.02 \times 10^{5}$ & $4.75 \times 10^{6}$ \\
$2.01 \times 10^{6}$ & $4.64 \times 10^{5}$ \\
$9.72 \times 10^{5}$ & -- \\
-- & $3.00 \times 10^{5}$ \\
$6.83 \times 10^{7}$ & $1.45 \times 10^{2}$ \\
$8.52 \times 10^{8}$ & $7.77 \times 10^{6}$ \\
$9.24 \times 10^{8}$ & $2.78 \times 10^{7}$ \\
$9.52 \times 10^{8} \mathrm{n} / \mathrm{MTU}-\mathrm{s}$
\end{tabular}

(At 4 yr From Reactor Discharge)

Pu Contribution Assumed Constant

\begin{tabular}{lccc}
$241_{\mathrm{Am}}$ & $2.40 \times 10^{2}$ & - & $8.74 \times 10^{5}$ \\
$24{ }^{2} \mathrm{Cm}$ & 0.029 & $6.43 \times 10^{5}$ & $1.36 \times 10^{5}$ \\
${ }^{244} \mathrm{Cm}$ & 67.1 & $7.58 \times 10^{8}$ & $6.91 \times 10^{6}$ \\
\cline { 2 - 2 } & & $7.62 \times 10^{8}$ & $1.31 \times 10^{7}$ \\
Total & &
\end{tabular}


SUMMARY OF SPENT FUEL ACTIVITY (1 YR COOLING TIME)

\begin{tabular}{|c|c|c|c|c|}
\hline & $20000^{a}$ & $33000^{\mathrm{b}}$ & $40000^{\mathrm{C}}$ & MWD/MTU \\
\hline Total Fission Product & $1.16 \times 10^{6}$ & $2.30 \times 106$ & $2.91 \times 106$ & $\mathrm{Ci} / \mathrm{MTU}$ \\
\hline $\begin{array}{l}\text { Fission Product } \\
\text { Gamma Intensity }\end{array}$ & $1.15 \times 1016$ & $2.18 \times 1016$ & $2.36 \times 10^{16}$ & $Y / M T U-s$ \\
\hline $\begin{array}{l}\text { Cladding and } \\
\text { Hardware Activity }\end{array}$ & $1.03 \times 10^{4}$ & $1.96 \times 104$ & $3.11 \times 104$ & $\mathrm{Ci} / \mathrm{MTU}$ \\
\hline $\begin{array}{l}\text { Cladding Gamma } \\
\text { Intensity }\end{array}$ & $2.52 \times 10^{14}$ & $6.64 \times 10^{14}$ & $9.94 \times 10^{14}$ & $\gamma /$ MTU-s \\
\hline Neutron Intensity & -- & $2.81 \times 10^{8}$ & $9.52 \times 10^{8}$ & $\mathrm{n} / \mathrm{MTU}-\mathrm{s}$ \\
\hline tonium Mass & - & 9116 & 9710 & g/MTU \\
\hline
\end{tabular}

a A metric ton of uranium is associated with $424 \mathrm{~kg}$ of zircaloy-2 and stainless steel end fittings. The activity and intensity values here have been corrected to account for the nuclides not stated in Ref. 1.

b A metric ton or uranium is associated with $235 \mathrm{~kg}$ of zircaloy and $56.6 \mathrm{~kg}$ of stainless steel.

C A metric ton of uranium is associated with $282 \mathrm{~kg}$ of zircaloy-4 and 58.0 $\mathrm{kg}$ of stainless steel.

\section{E. Example: Basket of Leached Hulls}

The above discussion and tables have dealt mostly with the radiation from the spent fuel before it enters the chop-and-leach process. Before concluding this chapter it would be informative to consider the radiation from an actual basket of leached hulls. The example considered will be one-half of a PWR fuel element such as fits in the dissolver basket at the Tokai fuel reprocessing plant. The sample burnup is $33000 \mathrm{MWD} / \mathrm{MTU}$, so the data presented below is based on Ref. 10. The original charge to the dissolver at 1 yr from reactor discharge would have the following characteristics:

$\begin{array}{lll}\text { Uranium content } & : & 231 \mathrm{~kg} \\ \text { Plutonium content } & : & 2110 \mathrm{~g} \\ \text { Zircaloy content } & : & 54.2 \mathrm{~kg} \\ \text { Stainless steel content } & : \quad 13.1 \mathrm{~kg} \\ \text { Fission product activity } & : \quad 5.31 \times 10^{5} \mathrm{Ci} \\ \text { Fission product intensity } & : \quad 5.04 \times 10^{15} \mathrm{\gamma} / \mathrm{s}\end{array}$



Cladding activity
: $4.53 \times 10^{3} \mathrm{Ci}$
Cladding $\gamma$ intensity
: $\quad 1.53 \times 10^{14} \mathrm{r} / \mathrm{s}$
Neutron activity
: $6.49 \times 10^{7} \mathrm{n} / \mathrm{s}$

If a fuel residue of 0.58 of the original charge is assumed, then the characteristics of the basket of leached hulls which leaves the dissolver would be as follows:

$\begin{array}{lll}\text { Uranium content } & : & 1.2 \mathrm{~kg} \\ \text { Plutonium content } & : & 10.5 \mathrm{~g} \\ \text { Fission product activity } & : & 2.66 \times 10^{3} \mathrm{Ci} \\ \text { Fission product } \gamma \text { intensity } & : & 2.52 \times 10^{13} \mathrm{\gamma} / \mathrm{s} \\ \text { Cladding activity } & : & 4.53 \times 10^{3} \mathrm{Ci} \\ \text { Cladding } \gamma \text { intensity } & : & 1.53 \times 10^{14} \mathrm{\gamma} / \mathrm{s} \\ \text { Neutron activity } & : \quad 3.25 \times 10^{5} \mathrm{n} / \mathrm{s} \\ \text { Total } \gamma \text { intensity } & : 1.78 \times 10^{14} \mathrm{\gamma} / \mathrm{s} \\ \text { Intensity of }{ }^{144} \mathrm{Pr}(2186 \mathrm{keV}) & : 1.57 \times 10^{11} \mathrm{\gamma} / \mathrm{s} .\end{array}$

The intensity of the $2186-\mathrm{keV}$ gamma ray from ${ }^{144} \mathrm{Ce}-\mathrm{Pr}$ is included in this listing because it is the signature most used by existing hull measurement systems. It is not a strong line, composing only about 0.098 of the total gamma radiation from the hulls. The intensity of any other line can be obtained by multiplying the appropriate value in Table VII or VIII by $1.16 \times 10^{-3}$. This listing demonstrates the problem of interference from the cladding radiation. Here the total cladding gamma-ray intensity is nearly 6 times higher than the total fission product gamma-ray intensity, and the major cladding activity comes from the high-energy lines of ${ }^{60} \mathrm{Co}$.

After a cooling time of $4 \mathrm{yr}$ the hulls from the same original fuel would look like:

$\begin{array}{lll}\text { Fission product activity } & : & 8.0 \times 10^{2} \mathrm{Ci} \\ \text { Fission product } \gamma \text { intensity } & : & 8.21 \times 10^{12} \mathrm{\gamma} / \mathrm{s} \\ \text { Cladding activity } & : & 1.68 \times 10^{3} \mathrm{Ci} \\ \text { Cladding } \gamma \text { intensity } & : \quad 8.34 \times 10^{13} \mathrm{\gamma} / \mathrm{s} \\ \text { Neutron activity } & : & 2.23 \times 10^{5} \mathrm{n} / \mathrm{s} \\ \text { Total } \gamma \text { intensity } & : & 9.16 \times 10^{13} \mathrm{\gamma} / \mathrm{s} \\ \text { Intensity of }{ }^{144} \operatorname{Pr}(2186) & : & 1.09 \times 10^{10} \mathrm{\gamma} / \mathrm{s}\end{array}$


with the uranium and plutonium content remaining constant. Note that the 2186keV activity decays away much faster than the total gamma-ray flux. This line now accounts for only 0.0128 of the total ganma activity.

The situation becomes even worse if the fuel is clad in stainless steel rods. The following listing for $1 \mathrm{yr}$ cooling time shows the cladding activity (the fission product activity remains the same as does $\mathrm{U}$ and $\mathrm{Pu}$ content):

$\begin{array}{lll}\text { Cladding activity } & : & 6.42 \times 10^{4} \mathrm{Ci} \\ \text { Cladding } \gamma \text { intensity } & : & 6.17 \times 10^{14} \mathrm{\gamma} / \mathrm{s} \\ \text { Total } \gamma \text { intensity } & : & 6.42 \times 10^{14} \mathrm{\gamma} / \mathrm{s} .\end{array}$

Now the 2186-kev line accounts for only 0.0248 of the total gamma-ray activity. At 4 yr this basket of hulls would have:

$\begin{array}{lll}\text { Cladding activity } & : & 1.36 \times 10^{4} \mathrm{Ci} \\ \text { Cladding } \gamma \text { intensity } & : & 4.07 \times 10^{14} \mathrm{\gamma} / \mathrm{s} \\ \text { Total } \gamma \text { intensity } & : & 4.15 \times 10^{14} \mathrm{\gamma} / \mathrm{s} .\end{array}$

Now the $2186-\mathrm{keV}$ line accounts for only 0.00268 of the total gamma activity, and the cladding gamma-ray activity accounts for 988 of the total gamma radiation. These lists illustrate the problem of using fission product gamma rays to measure $\mathrm{Pu}$ content in this difficult radiation environment.

This finishes the description of the typical hull characteristics and the radiation environment which can be expected when attempting to measure leached hulls. The various tables can be used when studying or designing hull measurement systems and will be referred to throughout the rest of the report. The characteristics of the leached hull example given above will be used as a basis for much of the technique evaluation which now follows.

Before ending this chapter a brief word is in order regarding the accuracy of the calculational methods which provide the basis of the data presented in the Tables V-XVII and the hull example. There are a large number of burnup codes available which could be used to predict fission product and actinide concentrations as a function of reactor operating history. A code such as ORIGEN, which produced much of the data given here, or CINDER is useful because it calculates everything including cladding and hardware activation and includes nearly all isotopes imaginable. The accuracy of these codes is not 
well studied. Where comparisons have been made between experimental measurements and theoretical prediction, they have usually considered only the actinide levels. For plutonium concentrations, for instance, the isotopes 239-241 are usually predicted to within a few percent. ${ }^{238} \mathrm{Pu}$ and ${ }^{242} \mathrm{Pu}$ are less well predicted $(>, 10 \%)$. There are virtually no comparisons found in the literature which deal with fission product levels. A good discussion of the available techniques and codes for predicting fission product and actinide levels is given in Ref. 13. The experience with hull measurements at windscale has shown good agreement for the ratio ${ }^{144} \mathrm{Pr} / \mathrm{U}$ between values measured in the dissolver solution and those predicted by reactor codes such as ORIGEN. ${ }^{14}$ This is of particular interest to problems under consideration here. 


\section{MEASUREMENT OF FISSION PRODUCT GAMMA RAYS}

\section{A. Introduction}

The subject of this chapter is the measurement of leached hull fuel residue via the indirect measurement of fission product gamma rays. The most used and discussed signature is by far the $2185.7-\mathrm{keV}$ gamma ray from ${ }^{144} \mathrm{Ce}-{ }^{144} \mathrm{pr}$. Consequently the major part of this discussion is oriented toward the use of this signature. However, the possibility of using other fission product gamma rays is also discussed. This applies especially to hulls from fuel with a very long cooling time where the ${ }^{144} \mathrm{Ce}$ has decayed below the practical detection limit.

The major topics discussed are the practical considerations for measuring the 2186-kev line (e.g., detector choice, shielding, collimation), the correction for hull attenuation, the relation of ${ }^{144} \mathrm{Ce}-{ }^{144} \mathrm{Pr}$ content to fuel residue (i.e., calibration), and finally the reliability of the signature. This last subject is discussed in detail because it is crucial to the applicability of this measurement technique. All techniques which rely on the measurement of fission product gamma rays are indirect and demand that a measurable or calculatable relation between the fuel residue and the measured fission products can be proven to exist.

Finally a brief list of the facilities applying this technique is given at the end of the chapter. More detailed reviews of user instrumentation and experience are presented in the later chapters.

\section{B. Characteristics of Fission Product signatures}

The most used signature is the $2185.7-\mathrm{keV}$ gamma ray of ${ }^{144} \mathrm{Ce}^{144} \mathrm{Pr}$. ${ }^{144} \mathrm{Ce}$ is a direct fission product with a thermal fission yield of 5.398 for ${ }^{235} \mathrm{U}$ and 3.808 for ${ }^{239} \mathrm{Pu} .{ }^{11}$ This nuclide beta-decays to ${ }^{144} \mathrm{Pr}$ which is the actual source of the $2185.7-\mathrm{keV}$ line (see Table VI).

$$
\stackrel{\text { Fission }}{\longrightarrow}{ }^{144} \mathrm{Ce} \underset{284.4 \text { days }}{\longrightarrow}{ }^{144} \mathrm{Pr} \frac{\beta-}{17.3 \mathrm{~min}}{ }^{144} \mathrm{Nd} \underset{2.1 \times 10^{15} \mathrm{yr}}{\longrightarrow}{ }^{140} \mathrm{Ce} \text { (stable) }
$$

The subsequent beta-decay of ${ }^{144} \mathrm{Pr}$ has a half life of $17.3 \mathrm{~min}$ so it is for all practical situations in equilibrium with ${ }^{144} \mathrm{Ce}$. The highest energy gamma ray which comes directly from ${ }^{144} \mathrm{Ce}$ is at $133.5 \mathrm{keV}$ (118), however this energy is much too low to be useful. While at least 10 gamma rays have been identified in the decay spectrum of ${ }^{144} \mathrm{Pr}$ only the three listed in Table VI 
have an appreciable intensity. The $2185.7-\mathrm{keV}$ gamma ray is nearly the highest energy line in the typical fission product spectrum and it is principally for this reason that it is so frequently chosen as the fuel residue indicator for a leached hull monitor.

The only direct interferences to this line come from ${ }^{106} \mathrm{Ru}-{ }^{106} \mathrm{Rh}$ which has approximately 78 identified gamma rays between $327.7 \mathrm{keV}$ and $3055.5 \mathrm{keV}$. Most of the high-energy lines are of considerably lower intensity than the $2186-\mathrm{keV}$ line of ${ }^{144} \mathrm{Pr}$. The following list gives the major lines of ${ }^{106} \mathrm{Rh}$ $\left(29.80\right.$ s) which might cause a direct interference to the $2186-\mathrm{keV}$ activity. ${ }^{15}$

\begin{tabular}{cr} 
Energy (keV) & Branching Inte \\
\cline { 2 - 2 } 1988.1 & 0.027 \\
2112.1 & 0.040 \\
2192.7 & 0.005 \\
2309.5 & 0.006 \\
2315.9 & 0.007 \\
2365.6 & 0.026 \\
2390.0 & 0.007 \\
2405.5 & 0.017 \\
2438.6 & 0.005
\end{tabular}

Tables VII and VIII show the that the ratio of the $2366-\mathrm{keV}\left({ }^{106} \mathrm{Rh}\right)$ line to the $2186-\mathrm{keV}\left({ }^{144} \mathrm{Pr}\right)$ line is about 1.98 at $I \mathrm{yr}$ and 3.48 at $4 \mathrm{yr}$ for fuel with $33000 \mathrm{MWD} / \mathrm{MTU}$ burnup.

Using a high-resolution germanium detector the ${ }^{144} \mathrm{Pr}$ line is easily resolved from any of the lines in the above list. However if a NaI detector is used with a typical resolution of approximately $110 \mathrm{keV}$ FWHM, the lines 1988-2366 would interfere with the $2186-\mathrm{keV}$ peak from ${ }^{144} \mathrm{pr}$. It is unlikely that any of these would be distinguishable as separate spectral features but together they would constitute a contribution to the peak of interest varying from about 68 at $1 \mathrm{yr}$ to 128 at $4 \mathrm{yr}$. This is a small enough correction that it could probably be ignored or theoretically subtracted.

A more important interference is caused by pileup from the very intense radiation at lower energies. The $2186-\mathrm{keV}$ gamma ray is only a very small part of the total gamna-ray activity. The example given earlier (II.E) shows that it constitutes on $l_{Y}$ about 0.098 and 0.0128 of the total leached hull gamma-ray activity at $1 \mathrm{yr}$ and $4 \mathrm{yr}$ respectively if a fuel residue of 0.58 of the original fuel content is assumed. The earlier tables show that the major gamma rays are the $1173-$ and $1332-\mathrm{keV}$ emission from ${ }^{60} \mathrm{Co}$. For the example (33 $000 \mathrm{MWD} / \mathrm{MTU}$ ) they constitute 668 of the total activity at I yr and 868 at 
$4 \mathrm{yr}$. In addition to the two intense photopeaks they give rise to an intense Compton distribution which extends well above $1000 \mathrm{keV}$. This combines with the radiation from other fission products and cladding activation products to make up the very intense gamma radiation below $1400 \mathrm{keV}$. These gamma rays can sum in the counting system to give a semicontinuous background which extends to $2186 \mathrm{keV}$ and beyond. It is this effect which probably ultimately determines the limit of detectability for ${ }^{144} \mathrm{Pr}$ and the maximum practical fuel cooling time for which the signature is useful.

A simplified model was used to calculate this pulse pileup and estimate the maximum practical cooling times. Calculations were carried out for both a NaI and a high resolution germanium detector. The simple spectrum model assumed full energy peaks from ${ }^{144} \mathrm{Pr}$ at $2186 \mathrm{keV}$ and ${ }^{60} \mathrm{Co}$ at $1332 \mathrm{keV}$ and $1173 \mathrm{keV}$ plus a uniform low energy spectrum extending to $1120 \mathrm{keV}$, the compton edge of the 1332-kev gamma ray. This low energy continuum contains fission product and activation product gamma rays but its major contributor is the compton distribution from ${ }^{60} \mathrm{Co}$. The following parameters were assumed:

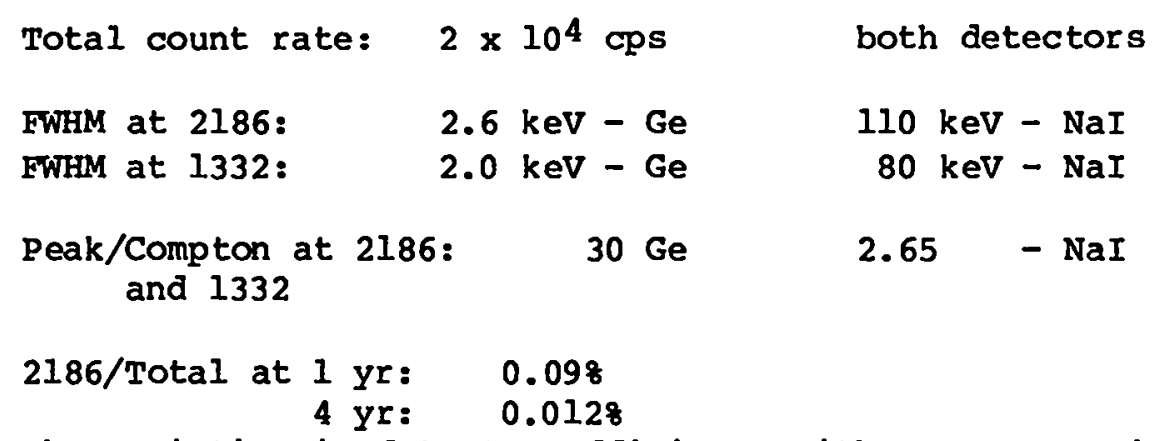

The variation in detector efficiency with energy was ignored.

$15 \mathrm{~cm} \mathrm{~Pb}$ filter providing selective attenuation factor $1250-\mathrm{keV} / 2186-\mathrm{keV}=0.066$

Amplifier pulse width: $10 \mu \mathrm{s}$ Ge $4 \mu \mathrm{s}$ - NaI

The 15-cm-thick lead filter was necessary to reduce the total count rate to approximately $2 \times 10^{4} \mathrm{cps}$ assuming a basket-to-detector distance of $2 \mathrm{~m}$ and collimation restricting the detector to viewing $10 \%$ of the basket contents. This filter has the desirable feature that it selectively attenuates the lower energy ${ }^{60}$ Co and fission product gamna radiation to the benefit of the 2186-kev activity. The mass attenuation coefficient of lead for $2186-\mathrm{keV}$ radiation is approximately $0.044 \mathrm{~cm}^{2} / 9$ whereas for the ${ }^{60}$ Co gamma rays it is approximately $0.060 \mathrm{~cm}^{2} / \mathrm{g}$. This filter is essential, and it may be 
desirable to increase its thickness over the $15 \mathrm{~cm}$ used for this example. Depleted uranium metal might also be considered as the filter material since it has a slightly better selective attenuation coefficient $\left[\left(\mu_{1250^{-\mu}} 2186\right)\right.$

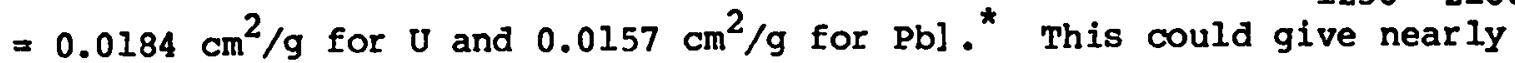
a 508 improvement in signal to background. It also has a significantly higher density ( 18.7 vs $11.3 \mathrm{~g} / \mathrm{cm}^{3}$ ) which would permit a more compact filter.

Using the above parameters and spectrum model, the $2186-\mathrm{keV}$ peak count rate and two-pulse pileup rate were calculated. The results of these calculations are presented in Table XVIII. This precision estimate for a 1000-s count is based just on the numbers in the table assuming pileup to be the major contributor to background under the full energy peak. No account is taken here of ambient background or the small interference due to ${ }^{106} \mathrm{Rh}$ discussed earlier. These would essentially affect only the NaI detector. The table shows one of the advantages of using the high resolution detector, namely a much more favorable signal-to-background ratio especially at long cooling times. It also indicates that for fuel cooled more than 5-6 yr the 2186-keV activity has decayed below the limit of detectability. The situation may be improved somewhat with more selective filtering and also by using electronic means to reduce pileup in the system. The use of electronic pileup rejection schemes would seem highly desirable for this measurement problem.

This estimate of the time limit on use of the $2186-\mathrm{keV}$ signature is consistent with the reported English experience. Their NaI hull monitor has been used on fuel with up to $3 \mathrm{yr}$ cooling, and they estimate that fuel with up to 5 yr cooling could still be measured. ${ }^{14}$ The use of a germanium detector would extend this somewhat as would the other factors mentioned above. There is, however, some finite time limit here which will not be too much beyond the 5-6 yr indicated just due to the short half-life of the ${ }^{144}$ Ce fission product (284 days) as compared with the other longer lived emitters such as ${ }^{60} \mathrm{co}$ $(5.26 \mathrm{yr})$ and ${ }^{137} \mathrm{Cs}(30 \mathrm{yr})$. It should be noted that the data

* Actually the largest difference in mass attenuation coefficient occurs for

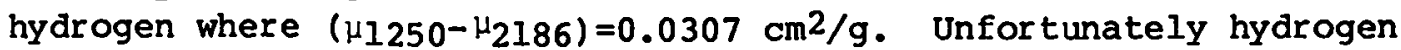
doesn't occur in materials with sufficient concentration or density to be useful. For polyethylene $\left(\mathrm{CH}_{2}\right)$ this difference is $0.0173 \mathrm{~cm}^{2} / \mathrm{g}$. 
presented in Table XVIII and the related discussion pertain to the example with zircaloy cladding. Pileup levels would be very much higher if stainless steel cladding hulls are considered because the ${ }^{60}$ Co gama radiation would be nearly 5 times more intense.

C. Possible Signatures for Very Long Cooling Times.

After the $2186-\mathrm{keV}$ line has decayed below detectability, it is obvious to consider the use of other fission product gamma rays. There are several intense lines from longer-lived fission products which can be considered. These are all of lower energy so they are attenuated more severely and are mostly below the ${ }^{60}$ co energies so are in a spectral region of very high compton background. Considering the intensity levels at 4 yr cooling time presented in Table VIII the following gamma rays might be considered for long cooling time fuel residue indicators:

$\begin{array}{lll}134 \mathrm{Cs}: & 2.06 \mathrm{yr} & : 604.7 \mathrm{keV} \\ & & : 795.8 \\ & & : 1365.0 \\ 137 \mathrm{Cs}: & 30.12 \mathrm{yr} & : 661.6 \\ 154 \mathrm{Eu}: & 8.6 \mathrm{yr} & : 1008 . \\ & & : 1274.5 \\ 106 \mathrm{Ru}-\mathrm{Rh}: 369 \text { day } & : 621.9 \\ & & : 1050.4 \\ & & : 1562.2\end{array}$

TABLE XVIII

ESTIMATE OF PULSE PILEUP INTERFERENCE TO 2186-keV PEAR

(Basket Containing Hulls From $\frac{1}{2}$ PWR Fuel Element)a $33000 \mathrm{MWD} / \mathrm{MTU}$

\begin{tabular}{|c|c|c|c|c|c|c|}
\hline \multirow{2}{*}{$\begin{array}{c}\text { Cooling } \\
\text { Time } \\
\text { (yr) }\end{array}$} & \multicolumn{3}{|c|}{ NaI } & \multicolumn{3}{|c|}{$\mathrm{Ge}$} \\
\hline & $\begin{array}{l}2186-\mathrm{keV} \\
\text { (cps) } \\
\end{array}$ & $\begin{array}{l}\text { Pileup } \\
\text { (cps) } \\
\end{array}$ & $\begin{array}{l}\text { Precisiona } \\
\text { (8) }\end{array}$ & $\begin{array}{l}2186-\mathrm{keV} \\
\text { (cps) } \\
\end{array}$ & $\begin{array}{l}\text { Pileup } \\
\text { (cps) }\end{array}$ & $\begin{array}{c}\text { Precision } \\
\frac{(8)}{}\end{array}$ \\
\hline 1 & 37.1 & 125.2 & 1.2 & 11.0 & 3.16 & 1.4 \\
\hline 4 & 4.96 & 144.3 & 7.9 & 1.48 & 3.69 & 5.5 \\
\hline 5 & 2.32 & 144.3 & 17. & 0.69 & 3.69 & 10 \\
\hline 6 & 1.09 & 144.3 & 35 & 0.32 & 3.69 & 20 \\
\hline 7 & 0.51 & 144.3 & 75 & 0.15 & 3.69 & 42 \\
\hline
\end{tabular}

a Fuel residue assumed to be 0.58 of initial charge.

b This is the counting statistical precision for a 1000-s count. 
The ${ }^{106} \mathrm{Ru}-\mathrm{Rh}$ might not normally be considered because its half life is really not significantly longer than the 284.4 day half life of ${ }^{144} \mathrm{Ce}-\mathrm{Pr}$. Also ${ }^{106} \mathrm{Ru}$ has much different fission yields for ${ }^{235} \mathrm{U}(0.48)$ and ${ }^{239} \mathrm{Pu}$ (4.38) and the $\mathrm{Pu} / \mathrm{J}$ ratio varies across a fuel pin. It is included here because the Japanese have reported using it for measurement of old hulls at Tokai. ${ }^{3}$ The applicability of these various lines was investigated using as an example the PWR fuel with $33000 \mathrm{MWD} / \mathrm{MTU}$ burnup after a cooling time of $10 \mathrm{yr}$. The expected gamma-ray intensities are obtained from Table vIII after making the appropriate decay corrections. These intensities ( $\gamma / \mathrm{MTU}-\mathrm{s})$ are presented in Table XIX along with the expected intensities in the hypothetical basket of hulls from $\frac{1}{2}$ PWR element with a 0.58 fuel residue. The intensity of the ${ }^{144} \mathrm{Pr}$ line is included in the table for comparison purposes; it is too weak to be detected. The intensity of the ${ }^{60} \mathrm{Co}$ lines is also included since they form the major background for the other radiations.

The same spectral model as used earlier in section III.B was used here to study the detectability of the various gamma rays. Because of its obvious advantages in this crowded spectral region, the only detector considered was a high-resolution germanium detector. This detector was assumed to have the following performance as regards resolution and peak/Compton:

\begin{tabular}{rlc}
$\begin{array}{c}\text { Energy } \\
(\mathrm{keV})\end{array}$ & $\begin{array}{c}\text { FWHM } \\
(\mathrm{keV})\end{array}$ & Peak/Compton \\
\cline { 1 - 1 } 2186 & & \\
1250 & 2.6 & 30 \\
800 & 2.0 & 30 \\
662 & 1.6 & 50 \\
600 & 1.46 & 60 \\
& 1.4 & 65
\end{tabular}

As before the total count rate in the detector was assumed to be $2 \times 10^{4} \mathrm{cps}$ and the amplifier pulse width $10 \mu \mathrm{s}$.

The selective filter situation becomes a bit more complicated in this case because most of the gamma rays under consideration are of lower energy than the interfering ${ }^{60} \mathrm{Co}$ radiation. In this situation any filter degrades the signal-to-background ratio. In fact with the same 15-cm lead filter used earlier the only potentially useful lines are those at $1275-\mathrm{kev}\left({ }^{154} \mathrm{Eu}\right)$ and $1365-\mathrm{keV}\left({ }^{134} \mathrm{Cs}\right)$ and the latter is somewhat doubtful. The obvious solution is to omit the selective filter in which case most of the above lines are 
potentially useful. However, without the filter it is difficult to reduce the count rate to the desired level $\left(2 \times 10^{4}\right)$. This can be achieved only with an impractically large basket-to-detector distance (10's of meters) or with very fine collimation (millimeters). This latter approach has been taken by the Japanese. With no filter (assuming appropriate collimation to achieve a reasonable count rate) the analysis predicts the approximate count rates given in Table Xx. This indicates that the following gamma rays are potentially useful for hull residue indicators with fuel cooled $10 \mathrm{yr}$ or more:

$$
\begin{array}{ll}
134 \mathrm{Cs}: & 604.7 \text { and } 795.8 \mathrm{keV} \\
137 \mathrm{Cs}: & 661.6 \mathrm{keV} \\
154 \mathrm{Eu}: & 1274.5 \mathrm{keV} .
\end{array}
$$

These nuclides have sufficiently long half lives so that fuels with even longer cooling times should be measurable. It is not clear that the very restrictive collimation required is desirable, but this does seem like a possible solution to the measurement of very old fuel hulls. It would seem desirable to have changeable collimators and filters for different age fuels to take advantage of the $2186-\mathrm{keV}$ line when it is measurable.

A different approach is also possible using a filter material other than lead which has a more slowly changing attenuation coefficient below $1332 \mathrm{keV}$. One possibility is iron or steel which is still dense enough to provide a reasonably compact filter. Assuming a source-to-detector distance of $2 \mathrm{~m}$ and a 108 vertical collimation the necessary lead filter at $10 \mathrm{yr}$ is approximately 13-cm-thick and the necessary steel filter is $21 \mathrm{~cm}$ thick. Table XXI lists the mass attenuation coefficient for lead and steel and the selective filtering coefficient for the two filters in question. ${ }^{16}$ while the steel filter (or any filter for that matter) adversely affects the lower energy gamma rays, its effect is clearly much less severe. The impact of these filters on the spectrum is shown in Table XXII which gives the percentage of the total detected gamma rays represented by the lines in question for the three filtering conditions: no filter, $15-\mathrm{cm} \mathrm{Pb}$ and $21-\mathrm{cm} \mathrm{Fe}$.

Finally Table XXIII is the equivalent of Table XX for the 21-cm steel filter, namely it shows the estimated count rates for the gamma rays of interest in the sample basket. Comparing the two tables it is clear that the 
TABLE XIX

SELECTED GAMMA-RAY INTENSITIES AT 10 YR (33000 MWD/MTU)

\begin{tabular}{|c|c|c|c|}
\hline Nuclide & $\begin{array}{l}\text { Energy } \\
\text { (kev) } \\
\end{array}$ & $\begin{array}{l}\text { Intensity } \\
\text { ( } / \text { MTU-s) }\end{array}$ & $\begin{array}{c}\text { Example Intensity } \\
(\gamma / s) \\
\end{array}$ \\
\hline \multirow[t]{3}{*}{${ }^{134} \mathrm{Cs}$} & 604.7 & $1.93 \times 10^{14}$ & $2.23 \times 10^{11}$ \\
\hline & 795.8 & $1.69 \times 10^{14}$ & $1.95 \times 10^{11}$ \\
\hline & 1365.0 & $6.48 \times 10^{12}$ & $7.48 \times 10^{9}$ \\
\hline${ }^{137} \mathrm{Cs}$ & 661.6 & $2.59 \times 10^{15}$ & $2.99 \times 10^{12}$ \\
\hline \multirow[t]{2}{*}{${ }^{154} \mathrm{Eu}$} & 1008 & $3.06 \times 10^{13}$ & $3.53 \times 10^{10}$ \\
\hline & 1274.5 & $6.10 \times 10^{13}$ & $7.05 \times 10^{10}$ \\
\hline \multirow[t]{3}{*}{${ }^{106} \mathrm{Ru}-\mathrm{Rh}$} & 621.9 & $2.15 \times 10^{12}$ & $2.49 \times 10^{9}$ \\
\hline & 1050.4 & $3.29 \times 10^{11}$ & $3.80 \times 10^{8}$ \\
\hline & 1562.2 & $3.73 \times 10^{10}$ & $4.31 \times 10^{7}$ \\
\hline${ }^{144} \mathrm{Ce}-\mathrm{Pr}$ & 2185.7 & $4.51 \times 10^{10}$ & $5.21 \times 10^{7}$ \\
\hline \multirow[t]{2}{*}{${ }^{60} \mathrm{Co}$} & 1173.2 & $7.80 \times 10^{13}$ & $1.80 \times 10^{13}$ \\
\hline & 1332.5 & $7.80 \times 10^{13}$ & $1.80 \times 10^{13}$ \\
\hline \multirow{2}{*}{\multicolumn{2}{|c|}{$\begin{array}{l}\text { Total Fission Product } \\
\text { Total Cladding }\end{array}$}} & $3.26 \times 10^{15}$ & $3.77 \times 10^{12}$ \\
\hline & & $1.60 \times 10^{14}$ & $3.70 \times 10^{13}$ \\
\hline \multicolumn{2}{|c|}{ Total Gamna } & $3.42 \times 10^{15}$ & $4.07 \times 10^{13}$ \\
\hline
\end{tabular}

a The example is a basket containing hulls from $\frac{1}{2}$ PWR fuel element with a fuel residue of 0.58 . 
ESTIMATED COUNT RATES FOR SELECTED GAMMA RAYS IN HULL BASKET EXAMPLE (10 yr, No Filter)

\begin{tabular}{|c|c|c|c|c|}
\hline Nuclide & $\begin{array}{l}\text { Ener gy } \\
\text { (keV) } \\
\end{array}$ & $\begin{array}{l}\text { Peak } \\
\text { (cps) } \\
\end{array}$ & $\begin{array}{l}\text { Background } \\
\text { (cps) }\end{array}$ & $\begin{array}{c}\text { Precision (1000s) } \\
(8)\end{array}$ \\
\hline \multirow[t]{2}{*}{$134 \mathrm{Cs}$} & 604.7 & 20.3 & 80.1 & 1.7 \\
\hline & $\begin{array}{r}795.8 \\
1365.0\end{array}$ & $\begin{array}{l}11.8 \\
0.09\end{array}$ & $\begin{array}{l}91.6 \\
18.3\end{array}$ & $7^{2.9}$ \\
\hline $137 \mathrm{Cs}$ & 661.6 & 240 . & 83.5 & 0.3 \\
\hline $154 \mathrm{Eu}$ & $\begin{array}{l}1008 \\
1274.5\end{array}$ & $\begin{array}{l}1.50 \\
1.96\end{array}$ & $\begin{array}{l}103 . \\
20.2\end{array}$ & $\begin{array}{l}22 \\
7.9\end{array}$ \\
\hline $106 \mathrm{Ru}-\mathrm{Rh}$ & $\begin{array}{r}621.9 \\
1050.4\end{array}$ & $\begin{array}{l}0.22 \\
0.015\end{array}$ & $\begin{array}{l}80.1 \\
103 .\end{array}$ & 130 \\
\hline${ }^{144} \mathrm{Ce}-\mathrm{Pr}$ & 2185.7 & 0.001 & 4.5 & - \\
\hline
\end{tabular}

\section{TABLE XXI}

PROPERTIES OF LEAD AND STEEL FILTERS

Energy

(keV)

2186

1562

1365

1250

1000

800

662

600

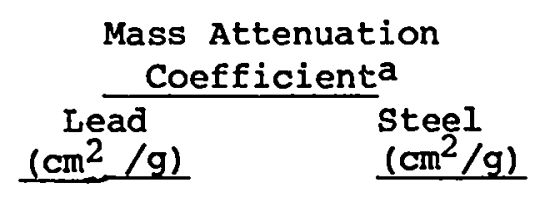

\subsection{3}

0.0517

0.0559

0.060

0.069

0.086

0.107

0.120
0.0412
0.0494
0.0516
0.0542
0.0596
0.0665
0.0728
0.0762
Selective Filtering coefficientb

Lead

\section{$\underline{\text { Steel }}$}

$\begin{array}{cc}15.2 & 8.30 \\ 4.11 & 2.19 \\ 2.02 & 1.52 \\ 1.00 & 1.00 \\ 0.22 & 0.42 \\ 0.012 & 0.135 \\ 3.5 \times 10^{-4} & 4.85 \times 10^{-2} \\ 3.66 \times 10^{-5} & 2.79 \times 10^{-2}\end{array}$

a Reference 16 .

b This coefficient is defined as $\exp \left[\left(\mu_{1250}-\mu_{E}\right) \rho \mathrm{X}\right]$ where $\rho=11.35$ $\mathrm{g} / \mathrm{cm}^{3}$ for lead and $7.75 \mathrm{~g} / \mathrm{cm}^{3}$ for steel and $\mathrm{x}=15 \mathrm{~cm}$ for lead and $21 \mathrm{~cm}$ for steel. 
TABLE XXII

IMPACT OF VARIOUS FILTERS

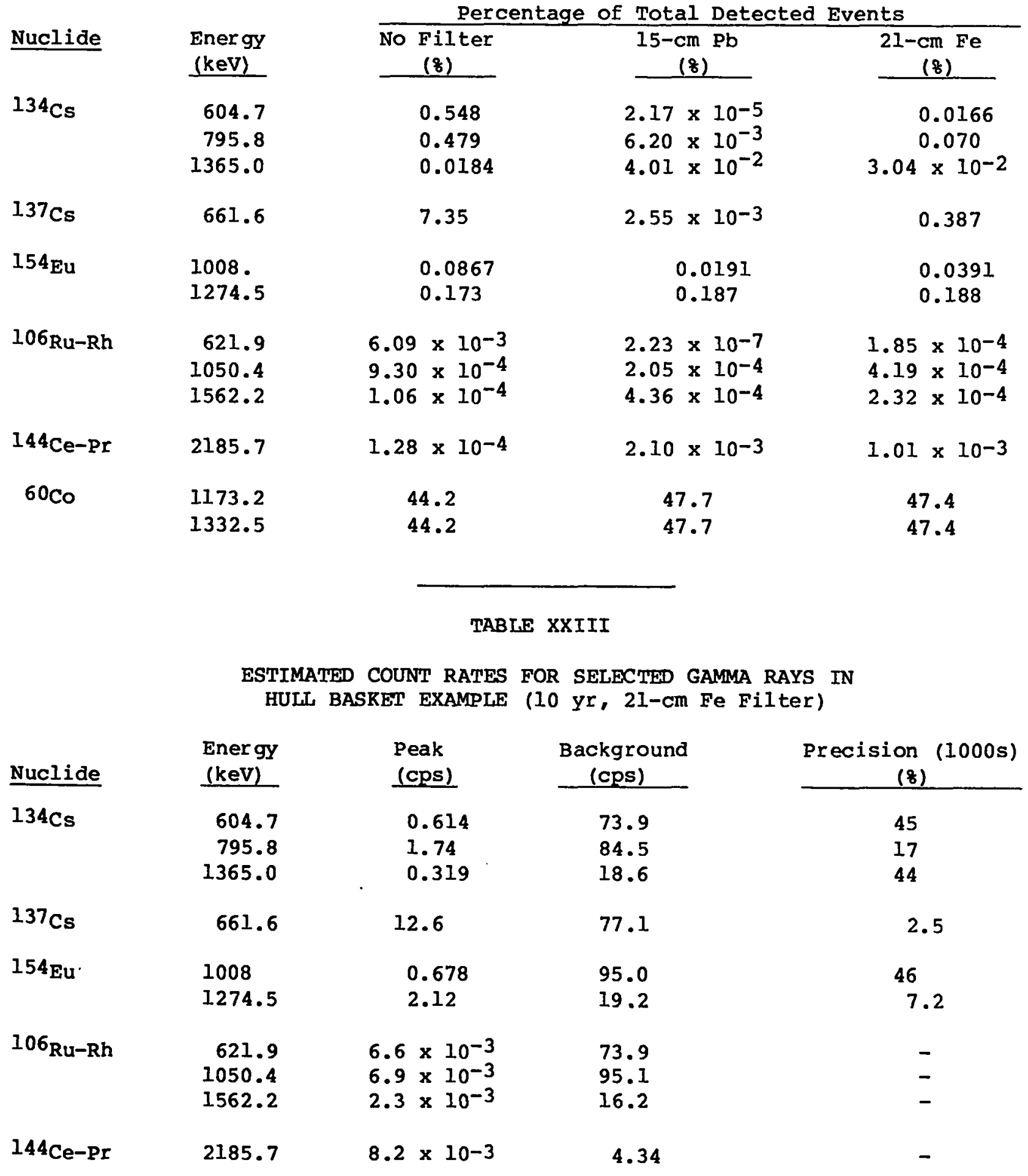


low energy lines are reduced in relative intensity, however, several of them are still potential hull residue indicators:

$$
\begin{array}{ll}
{ }^{134} \mathrm{Cs}: & 795.8 \mathrm{kev} \\
{ }^{137} \mathrm{Cs}: & 661.6 \mathrm{keV} \\
{ }^{154} \mathrm{Eu}: & 1274.5 \mathrm{keV} .
\end{array}
$$

They are not quite as favorable as in the no filter situation but it may be that it is easier to use the more open collimation and just switch filters to change from counting new to old fuel hulls.

Before leaving this subject it is worthwhile to mention one other characteristic of these lower energy fission product gamma rays. In addition to being subject to more attenuation (which is discussed next), they come from nuclides which may migrate more readily in spent fuels. The migration of fission products in irradiated fuel materials has been extensively studied but is a complex problem and still only incompletely understood. More work has been done to study migration in fast reactor fuels (FBR) than in Light water Reactor (LWR) fuels. The FBR studies show that ${ }^{144} \mathrm{Ce}$ and ${ }^{154} \mathrm{Eu}$ do not migrate significantly either radially or axially relative to the fuel material. They also show ${ }^{106} \mathrm{Ru},{ }^{134} \mathrm{Cs}$, and ${ }^{137} \mathrm{Cs}$ to migrate significantly in both directions. At present there are insufficient studies to generalize this with certainty to LWR fuels. ${ }^{11}$ In some cases this migration may not be troublesome, but it may result in fission product concentrations in the cladding hulls which are not representative of the fuel as a whole. This latter situation would mean that the reliability of the fission product signature was questionable and would make calibration of the monitor difficult.

D. Detector Choice, Shielding, Geometry

The detector of choice as indicated from the preceding discussion is clearly the high-resolution germanium detector. The vastly improved resolution (FWHM as low as $1.65 \mathrm{keV}$ at $1332 \mathrm{keV}$ versus $\sim 80 \mathrm{keV}$ for NaI) is an advantage even for detection of the ${ }^{144} \mathrm{Ce}-\mathrm{Pr} 1$ ine at $2186 \mathrm{keV}$ which is relatively interference free and in a low background part of the spectrum. The higher resolution means a much higher signal-to-background ratio which extends the usefulness of the signature to longer cooling times. 
When lower-energy fission product gamma rays are used to measure very old fuel hulls the high-resolution detector becomes even more important because of the high Compton continuum from ${ }^{60} \mathrm{Co}$ and the many closely-spaced gamma rays between about 400 and $1000 \mathrm{keV}$. There are no resolved peaks in this region using a NaI detector only several rather complex multiplets which though not impossible are very difficult to analyze into individual components.

The desired specifications for the germanium detector are reasonably broad and easy to meet. Its size need only be moderate, probably 108 or greater relative efficiency (at $1332 \mathrm{keV}$ relative to $3 \times 3 \mathrm{NaI}$ in the usual manner) in order that it have reasonable thickness for detecting 2186-kev gamma rays. While every bit of resolution helps, the detector need not have the absolute best resolution available. The major lines of interest are relatively interference free even with the average performance detectors available from most manufacturers (perhaps FWHM $=1.8-2.0 \mathrm{keV}$ at $1332 \mathrm{keV}$ ). Such a detector has actually slightly higher performance than that chosen for the example in sections $B$ and $C$ above. Because only modest resolution is required and because all the potentially interesting radiations are above about $500 \mathrm{kev}$, there is really no need to use a detector with a cooled FEr in the first stage of the preamp. The room temperature preamp is subject to less chance of failure, which is a desirable feature in any routine plant operation. Historically there has been a reluctance on the part of plant operators to use germanium detectors due to their need for regular liquid nitrogen replenishment and alleged higher maintenance. The liquid nitrogen cooling is a necessary inconvenience for their operation, but beyond this there is really no cause for worry. Modern germanium detectors are very rugged instruments which function continuously for years with little or no maintenance.

The above discussion is not to say that NaI detectors cannot be used but rather to discuss the definite advantages to using a higher resolution detector. NaI scintillation detectors are indeed the only detectors which have been used to date in routine hull measurement applications. They are cheaper and may have advantages in installations where the detector must be located inside the shield walls around the dissolver cell.

Most measurements of the $2186-\mathrm{keV}$ peak with NaI have been attempted with simple single channel analyzer and scaler electronics often without explicit corrections for the pileup background under the peak. Such a system can be made to work reasonably well if extreme care is taken in calibrating the 
device. It is, however, more desirable to use a multichannel analyzer to view the whole spectrum and make some corrections for pileup under the full energy peak. When gamma rays below $1000 \mathrm{keV}$ are measured, the multichannel analyzer is mandatory for any spectral analysis. Obviously the data collection and analysis from the germanium detector assumes a good computer- or microprocessor-based multichannel analyzer system.

When designing a leached hull monitor considerable attention must be given to the detector shielding. The largest source of radiation is from the hull basket itself. However, this instrument must usually function near or even inside the dissolver cell so there may well be other sources of radiation nearby which must be adequately shielded out.

A brief discussion of shielding requirements is given here, though, naturally each facility will have its own unique design requirements. The main shielding materials will be the concrete walls of the dissolver cell and additional lead added to shield the detector. A simple argument will be used here assuming the major radiation to be shielded is from ${ }^{60}$ Co (average energy $1250 \mathrm{keV}$ ) and using a simple exponential attenuation (removal cross section) to compute the shielding factors. When actually designing a shield buildup theory should be used to estimate shielding. Furthermore, the shield should be dimensioned conservatively in view of the high radiation levels involved. For an example of an actual system the report on the windscale hull monitor (Ref. 1) gives a good description of the design and testing of detector shielding.

The example basket used previously ( $\frac{1}{2}$ PWR element, 33000 MWD/MTU, I yr) can serve here to estimate the shielding thicknesses required. This basket of hulls has a total gamma-ray activity of $1.78 \times 10^{14} \mathrm{r} / \mathrm{s}$ after leaching. If the detector is located $2 \mathrm{~m}$ away from the basket center and has an average cross sectional area of $20 \mathrm{~cm}^{2}$, the unattenuated flux at the detector would be approximately $7.08 \times 10^{9} \mathrm{r} / \mathrm{s}$. For the intervening shielding to reduce this level to $10 \mathrm{r} / \mathrm{s}$ requires a thickness of approximately $30 \mathrm{~cm}$ of lead or $120 \mathrm{~cm}$ of concrete. " It is obviously highly desirable to locate the

$\star$

The mass attenuation coefficient and density of lead are taken as 0.060 $\mathrm{cm}^{2} / \mathrm{g}$ (at $1250 \mathrm{keV}$ ) and $11.35 \mathrm{~g} / \mathrm{cm}^{3}$. For concrete these are 0.058 $\mathrm{cm}^{2} / \mathrm{g}$ and $3.0 \mathrm{~g} / \mathrm{cm}^{3}$. 
detector outside the cell wall. If this wall is $70-\mathrm{cm}$-thick concrete, the additional lead shielding required is approximately $12 \mathrm{~cm}$. The wall thickness involved at the windscale plant is approximately $120 \mathrm{~cm}$, so minimal extra lead shielding is required here. * The wall thickness involved at the Tokai plant appears to be approximately $70 \mathrm{~cm}$ thick and the basket-to-detector distance approximately $120 \mathrm{~cm} .17$ The hulls from $\frac{1}{2}$ PWR fuel element (the example under consideration) fit here into a basket of diameter approximately $22 \mathrm{~cm}$ and height $1.3 \mathrm{~m}$. To reduce the overall background level at the detector from the basket to $10 \mathrm{cps}$ requires approximately $13 \mathrm{~cm}$ of lead or to $100 \mathrm{cps}$ requires approximately $9 \mathrm{~cm}$ of lead. Of course the burnup level considered here is quite high and the cooling time short. If only lower burnup fuel and longer cooling times will be seen the radiation level and required shielding thickness would be lower.

Finally some general rules are given regarding measurement geometry, i.e., source-to-detector distance, collimation, basket rotation, and filtering. In all practical situations the source-to-detector distance will be dictated at least in part by the actual cell design and will not be a free variable to the hull monitor designer. There are probably two major considerations when choosing the source-to-detector distance. The first is to have sufficient separation so that the response from different parts of the hull basket is reasonably constant. Since in almost all situations very restrictive vertical collimation is used, the determining parameter is the basket diameter. If the basket can be rotated, the maximum response variation due to $1 / r^{2}$ effects will be less than $\pm 10 \%$ if the distance between the sample and the detector is equal to or greater than three to four times the radius of the sample (hull basket). This applies only to $1 / \mathrm{r}^{2}$ effects; variations due to hull attenuation can not be reduced by simply changing source-to-detector distance.

In practical numbers this rule would dictate a minimum separation of 30-40 $\mathrm{cm}$ at the Tokai plant and 60-80 $\mathrm{cm}$ at the Windscale plant (actually at windscale the basket is not rotated but is between two detectors so a larger spacing is advisable). From the standpoint of reducing geometrical response variations it is of very little use to increase the sample-to-detector

Actually they use two NaI detectors, one outside the cell wall and the other inside. The latter has a very thick lead shield. 
distance beyond these values. Of course other considerations such as count rate limitation and existing cell dimensions will also determine the location of the detector.

The second consideration concerns the selective filter placed in front of the detector as discussed in section $B$ above. This filter is necessary for the measurement of the $2186-\mathrm{keV}$ line because it selectively attenuates the lower energy radiation $\left({ }^{60} \mathrm{Co}\right)$ increasing the detectability of the desired line. Moving the detector closer to the basket allows the use of a thicker filter which increases the selective filtering factor. The first example used in section $B$ had a 15-cm-thick Pb filter which enhanced the 2186-keV line a factor of 15 with respect to the total gamma count rate. If the detector were moved to $1 \mathrm{~m}$, the filter would have to be increased to $17 \mathrm{~cm}$ which would enhance the 2186 line a factor of 22 times. If it were moved to $0.5 \mathrm{~m}$ the required filter would become $19 \mathrm{~cm}$ and the selective filtering factor nearly 32. Obviously there is a limit to this and the above argument is oversimplified, however, the discussion should indicate what must be considered when choosing a detector location and selective filter. For further discussion of the filter design refer back to sections $B$ and $C$.

The basket should be rotated if at all possible. Unfortunately this may often be difficult because the hull basket is large and heavy (see Table III) and is located inside the thick shield walls of the dissolver cell or cell annex. Revolving the sample serves in effect to homogenize the sample somewhat in the radial dimension and reduces variations due to source location within the basket. If this is not feasible, the next best thing is to use two detectors, $180^{\circ}$ apart, with the sample fixed in the center.

Nearly all practical situations will require a degree of vertical collimation to achieve a workable count rate and limit variations from $1 / \mathrm{r}^{2}$ effects (most dissolver baskets or transfer baskets are quite tall, 1-2 m). This collimation requires that a scanning mechanism be provided to move the basket in front of the collimator slit. For measurement of the $2186-\mathrm{keV}$ gamma ray it would seem best to use a fairly open collimation ( 108 ) with selective filters to limit count rate. The scan may be either continuous or stepwise, there being no particular advantages or disadvantages to recommend one over the other. If only low energy lines are to be measured, it is advantageous to omit the filter and achieve count rate limitation with a very narrow collimator. This point is more fully discussed in section $C$. 


\section{E. Attenuation}

The magnitude of gamma-ray attenuation within the basket of leached hulls is considered in this section. In most gamma-ray assay involving bulk samples this is the limiting factor determining measurement accuracy. It must be carefully and adequately corrected before the measured gamma-ray flux escaping from the surface of the sample can be reliably related to the contained quantity of the emitting isotope. The situation is not as critical here because the high energy fission product gamma rays have significantly higher penetrability in dense matter than the gamma rays from ${ }^{235} \mathrm{U}$ and ${ }^{239} \mathrm{Pu}$.

The most obvious part of the attenuation is that due to 50-150 $\mathrm{kg}$ of zircaloy or stainless steel pieces in the basket. If the average hull dimension is very much smaller than the basket diameter, and if the fuel residue is assumed to be fairly uniformly distributed throughout the hulls, the hull attenuation can be treated as coming from a homogeneous Fe or $\mathrm{zr}$ and fuel mixture and the actual hull shape can be ignored. Table XXIV shows that for the energies of interest here stainless steel and zircaloy have essentially the same mass attenuation coefficient. ${ }^{28}$ It is helpful to prepare several graphs illustrating the dependence of attenuation on parameters such as basket diameter, gamma-ray energy and average hull density. The parameter of interest here might be called the gamma-ray leakage from the basket surface, i.e., the fraction of the gamma rays emitted by the fuel residue left on the hull pieces which escapes unscattered from the hull container. This can be approximated quite accurately using the simple formula: ${ }^{19}$

$$
\text { Leakage }=\left(1-e^{-0.82 \mu \rho D}\right) /(0.82 \mu \rho D)
$$

where

$$
\begin{array}{ll}
0 & \leqslant \text { leakage } \leqslant 1.0 \\
\mu & =\text { mass attenuation coefficient } \\
\rho & =\text { average hull density } \\
D & =\text { basket diameter. }
\end{array}
$$

Figure 1 shows the fraction of $2186-\mathrm{keV}$ gamma rays which escape from baskets of 20-, 38-, and 50-cm diameter as a function of the average hull density within the basket. Refer to Table IV to see the range of hull densities reported in the literature. The vertical lines at 0.8 and $1.3 \mathrm{~g} / \mathrm{cm}^{3}$ are included to indicate the range of reported hull densities. The graph shows 
MASS ATTENUATION COEFFICIENT FOR ZIRCALOY AND STAINLESS STEEL (Reference 18)

$\begin{array}{ccc}\text { Energy }(\mathrm{keV}) & \mathrm{Zr}(40)\left(\mathrm{cm}^{2} / \mathrm{g}\right) & \mathrm{Fe}(26)\left(\mathrm{cm}^{2} / \mathrm{g}\right) \\ 3000.0 & 0.0362 & 0.0360 \\ 2500.0 & 0.0384 & 0.0388 \\ 2185.7 & 0.0401 & 0.0409 \\ 2000.0 & 0.0412 & 0.0424 \\ 1500.0 & 0.0465 & 0.0486 \\ 1274.5 & 0.0505 & 0.0527 \\ 1000.0 & 0.0572 & 0.0594 \\ 800.0 & 0.0645 & 0.0662 \\ 661.6 & 0.0714 & 0.0724 \\ 600.0 & 0.0753 & 0.0758\end{array}$

that the leakage of $2186-\mathrm{keV}$ gamma rays from both the windscale and the Tokai hull baskets is of the order of 60-708. This is quite high by virtue of the high energy gamma ray involved. The graph includes only the attenuation of the contained hulls; it does not include the attenuation of the hull basket walls. This latter attenuation is a constant which is easily handled in the calibration procedure. For an estimate of its magnitude use the 19-mm wall thickness of the Windscale basket. At $2186-\mathrm{keV}$ its transmission is approximately 0.55. Actually this number is to low because all dissolver baskets would be full of holes to promote good circulation and drainage of the dissolver solution and any rinse solutions.

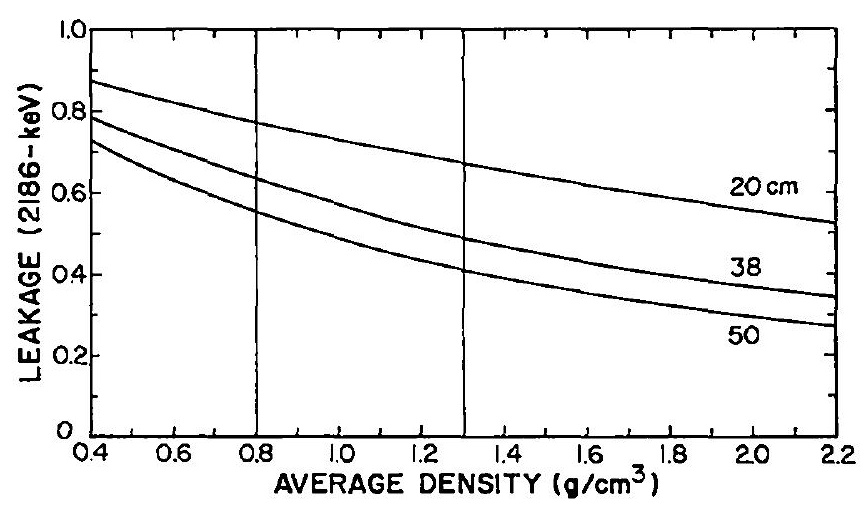


Figure 2 is useful when considering the measurement of lower energy gamma rays for very old fuel hulls. For a fixed basket diameter of $20 \mathrm{~cm}$ it shows the leakage as a function of gamma-ray energy for several different hull densities. These curves are rather flat because the mass attenuation coefficient of all materials changes only slowly above $800-1000 \mathrm{keV}$; in fact it levels off and begins to rise slowly with the increase of the pair production cross section. Consider the curve for $1.4 \mathrm{~g} / \mathrm{cm}^{3}$ (typical of the Tokai facility). The leakage changes from approximately 658 at $2186 \mathrm{keV}$ to 498 at $661.6 \mathrm{keV}$. This change is really quite small and indicates that the ${ }^{137} \mathrm{Cs}$ gamma ray still has a rather high penetrability. Its use as a hull residue indicator is not ruled out by attenuation considerations.

A correction for this bulk attenuation must be made as part of the assay procedure. A common procedure in other gamma assay situations is to measure the transmission of an external gamma-ray source through the sample to determine the average linear attenuation coefficient for the sample. This might be done here using, for example, the $1836-\mathrm{keV}$ gamma ray from an ${ }^{88} \mathrm{y}$ source (this probably has too short a half life, 106.6 days, to be practical). However, it doesn't really seem warranted. A calculated correction based on the hull weight and fill height (i.e., effective density) would seem more than adequate for a leached hull measurement. In fact it would probably be acceptable to simply compute an average correction for each type of fuel hull. For example suppose the mean density were $1.5 \mathrm{~g} / \mathrm{cm}^{3}$ with an observed variability of \pm 108 . For measurements of the $2186 \mathrm{keV}$ gamma ray Fig. I would predict a leakage of $64 \pm 3 \%$. This level of variability could reasonably be ignored for leached hull measurements.

Another source of attenuation is the fuel residue itself. If this is distributed evenly in particles or deposits of very small dimension ( $1 \mathrm{~mm}$ ), the additional attenuation is negligible. If the residue were more in the form of undissolved pellets, the attenuation might be significant. Unfortunately it would be very difficult in any practical situation to evaluate this effect. To consider the possible magnitude of this effect Fig. 3 shows the gamma-ray leakage at 2186- and $662-\mathrm{keV}$ for a cylindrical particle of density $10 \mathrm{~g} / \mathrm{cm}^{3}$. This is a very approximate and simplified calculation which takes no account of the radiating particle's probable irregular shape, but should provide a feeling for the order of magnitude of this effect. Assuming the worst case would be an undissolved pellet of diameter $12 \mathrm{~mm}$, Fig. 3 would estimate 


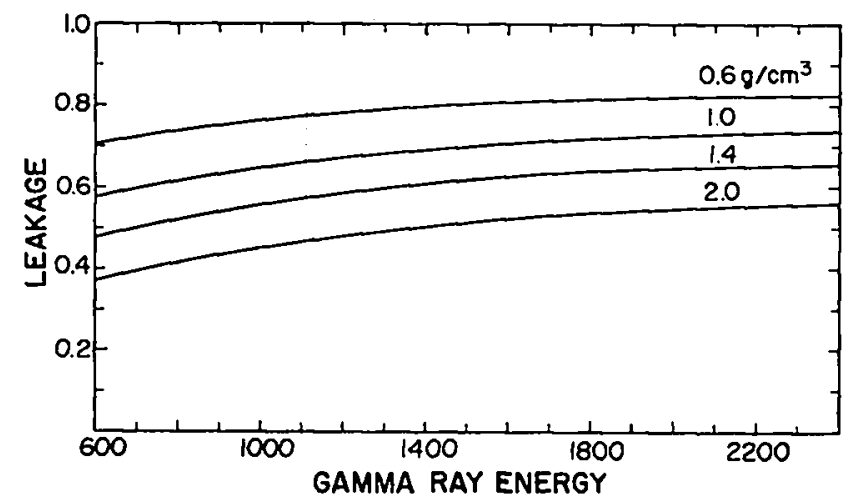

Fig. 2.

Gamma-ray leakage as a function of energy for a fixed basket diameter of $30 \mathrm{~cm}$ and average hull densities of $0.6,1.0,1.4$, and $1.6 \mathrm{~g} / \mathrm{cm}^{3}$.

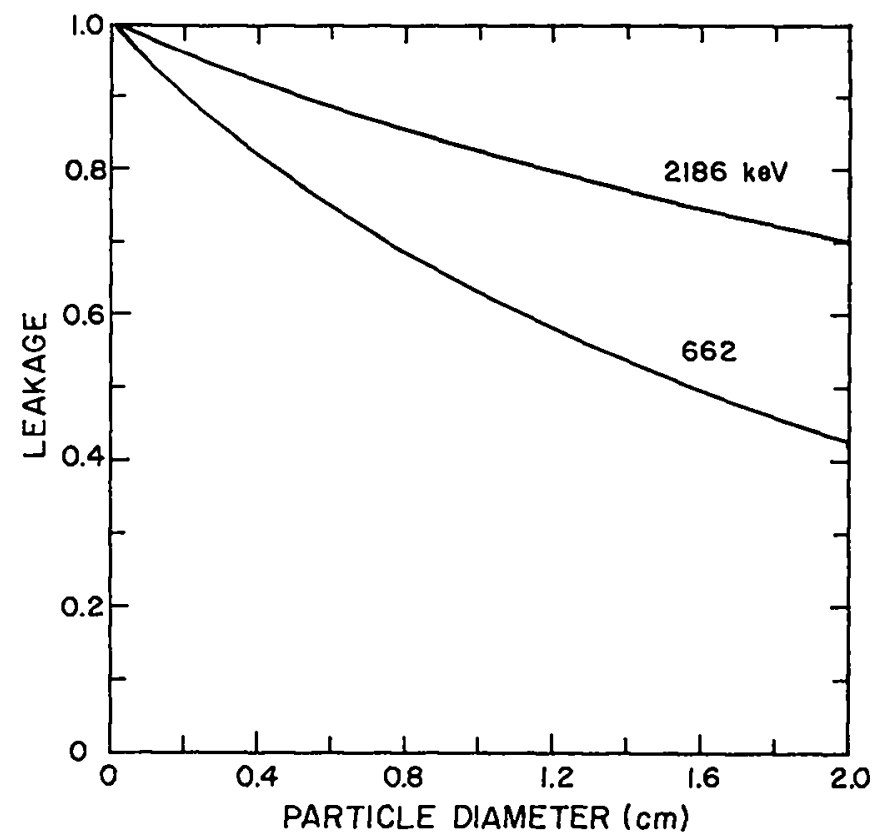

Fig. 3.

This shows approximate self-attenuation in the source particle. Number given is gamma-ray leakage at 2186 and $662-\mathrm{keV}$ for an irradiating particle of density $10 \mathrm{~g} / \mathrm{cm}^{3}$.

gamma-ray leakage from the particle as 808 at $2186 \mathrm{keV}$ and $58 \%$ at $662 \mathrm{keV}$. It would seem that the actual entrained particle dimension should be much less than $12 \mathrm{~mm}$. If this were the case it would be legitimate to ignore this effect. If it were not so, any correction would be difficult or impossible and would probably represent an error to the measurement.

\section{F. Calibration Procedures}

Many potential calibration procedures exist. The present discussion is not meant to be exhaustive but rather to indicate some of the different procedures in use. The first step is the relatively straightforward calibration for quantity of ${ }^{144} \mathrm{Ce}-\mathrm{Pr}$ or other fission product. Actually in some procedures this is bypassed and the ratio of leached hull activity to the undissolved fuel activity is taken to be the fraction of the original fuel change remaining undissolved with the hulls. The second step is the determination of the relation between fission product content and the fuel residue.

The calibration for ${ }^{144} \mathrm{Ce}-\mathrm{Pr}$ or other fission product is quite straightforward. The only essential item is a calibrated source of the fission product 
Indicator being used. Such sources are readily available from normal calibration source suppliers. The other useful item, though not essential, is a test basket of clean hulls with some prevision for source insertion such as pipes at several radial positions. This test basket allows experimental measurement of response variation with position, average attenuation of the hulls and basket wall, and attenuation of different filter combinations. All of this can in principle be calculated with reasonable accuracy. However, the calculation, especially for NaI may be quite difficult and the direct measurement may be more credible. A good description of what might be involved in a rather complete calibration procedure can be found on pages 8-12 of the report on the windscale leached hull monitor. ${ }^{1}$

The general procedures will be discussed here for the second part of the calibration procedure, namely the determination of the relation between fuel residue and fission product content. These are the measurement of the ${ }^{144} \mathrm{Pr} /$ $(U, \mathrm{Pu})$ ratio in the dissolver solution, the calculation of these ratios using burnup codes such as ORIGEN, and the before and after dissolution measurement mentioned above.

By measuring the ${ }^{144} \mathrm{Pr} / \mathrm{U}$ and $\mathrm{U} / \mathrm{Pu}$ ratios in the dissolver solution it is possible to interpret the ${ }^{144} \mathrm{Pr}$ level measured in the leached hull basket. The dissolver solution must be sampled after each leach cycle anyway so this doesn't even add another sample-taking to the plant operation. In principle the other fission products (other than ${ }^{144} \mathrm{Ce}-\mathrm{Pr}$ ) could also be determined here. The ${ }^{144} \mathrm{Pr}$ might be determined by a radio-chemical and gama-spectrometric technique and the uranium by Davies-Gray titration. The uranium and plutonium might also be determined by isotope dissolution mass spectrometry. The major assumption made here is that the ${ }^{144} \mathrm{Pr} / \mathrm{O}$ ratio is the same in the dissolver solution as in the leached hulls. The validity of this assumption will be discussed in the next section on reliability.

The ${ }^{144} \mathrm{Pr} / \mathrm{U}$ ratio (or other fission product ratio) can be calculated using a burnup code such as ORIGEN. Here data such as presented in Chapter II are used to interpret the measured fission product levels and convert to grams of $U$ and Pu held up on the fuel hulls. The advantage of this is that it avoids the determination of the fission product content in the dissolver solution sample. The disadvantage has already been discussed at the end of Chapter II, namely the accuracy of these codes for predicting fission product levels remains largely unproven. It may be sufficiently accurate for the leached hull determination, but this needs to be demonstrated. 
The third procedure does not compute the quantity of ${ }^{144} \mathrm{Ce}-\mathrm{Pr}$ explicitly but rather measures its gamma activity prior to and after dissolution and assumes this ratio is equal to the fraction of the initial fuel charge rejected with the hulls. Similar to the first two procedures this assumes that the hull residue has the same composition as the contained fuel prior to dissolution. If the before measurement were to be made on the basket of chopped fuel pieces prior to dissolution and the after measurement made on the same basket after it leaves the dissolver, the procedure could in principle be as simple as counting one gamma-ray peak. In practice this might be difficult because the basket of undissolved fuel would contain a very much higher total gamma-ray activity (20-30 times or more) than the leached hulls. This could make the measurement of the two cases with a single counting geometry somewhat difficult but probably possible. A different approach is used at the French facility AT-I in La Hague. Here the ratio of the ${ }^{144} \mathrm{Pr}$ gamma activity to that of ${ }^{60} \mathrm{Co}$ or ${ }^{54} \mathrm{Mn}$ is measured from the spent fuel prior to shearing. ${ }^{6}$ The same ratio is measured in the hulls after dissolution. The quantity of cladding and structural material has presumably remained constant so the ${ }^{60} \mathrm{Co}$ or ${ }^{54} \mathrm{Mn}$ which come from these materials provide a good normalization. Also the ${ }^{60}$ co performs a reasonable attenuation correction. The gamma-ray leakage is certainly different (higher) in the basket of leached hulls than it is in the unleached spent fuel. Both the ${ }^{60} \mathrm{Co}$ and ${ }^{144} \mathrm{Pr}$ gamma rays will experience somewhat less attenuation in the leached hulls and while the mass attenuation coefficients are not identical at $1332-$ and $2186-\mathrm{kev}$, they are enough similar that the normalization to the ${ }^{60} \mathrm{Co}$ line serves as a reasonable attenuation correction. G. The Reliability of Fission Product Signatures

The use of any fission product gamma ray as a signature for the fuel residue rejected with leached hulls requires the assumption that the fission product involved quantitatively tracks the fuel through the dissolution process. In essence it must be created in such a way as to form a uniform mixture with the fuel, and it must remain so throughout the various dissolution and rinse cycles. Most of the fuel $(99+8)$ goes into the dissolver solution. The small residue that remains on the hulls must be quantitatively identical to the rest of the fuel. This is not exactly true. The limitations on this assumption are the subject of this section. The various potential problem areas are discussed first followed by a d scription of the evidence collected with existing hull monitoring systems as to the reliability of the fission product signatures. Finally several reported anomalies are discussed. 
The use of fission product signatures is complicated by the fact that fuel burnup is not uniform throughout the reactor core nor for that matter throughout a single fuel rod or even fuel pellet. Consider the measurement of a quantity of hulls derived from the dissolution of a single fuel element. Each of the three calibration techniques discussed in the previous section determines an average fission product/fuel ratio for the element. The chemical and radiochemical analysis of the dissolver solution yields the mean value of fission product/fuel because any variations have been homogenized during the dissolution. With the burnup calculation and the before-dissolution gamma intensity determination it would in principle be possible to obtain an axial profile of the fission product levels. However, in practice it would be too difficult to keep track of the original axial position of the many hull pieces. Hence some mean number is generated to serve as the calibration. The burnup varies considerably along the length of a given fuel element being highest at the center of the element. This variation can be 308 or more. If the fuel residue from a given element comes uniformly from all parts of the element, the mean calibration yields the correct value for the fuel residue. It seems quite possible, however, that the undissolved fuel could come from a minimum or maximum burnup position (where the fission product/fuel ratio is 10-208 more or less than the average) in which case a negative or positive error could result for an individual measurement. It may be hoped that over the course of many measurements this type of error would average out to zero. If there is no preferential position of origin for the fuel residue, this will certainly be the case. The origin of the fuel residue is not well studied nor understood so while this averaging seems reasonable it is difficult to verify. In addition to axial variations there can be radial burnup variations within a single fuel pellet. There is evidence, for example, that the burnup may be higher at the surface of the fuel rod than in the center. During the Mol III safeguards experiment, analysis of the chemical decladding solution at the Eurochemic reprocessing plant in Mol, Belgium showed that the contained uranium and plutonium had a significantly different isotopic composition than that of the fuel as a whole indicating a higher burnup at the surface. ${ }^{2}$ If the fuel residue on the hulls came preferentially from the surface of the fuel, this might cause an exror when the average calibration is used to interpret the measured fission product gamma-ray activity. 
Fission product migration is another potential source of error. If the measured fission product does not stay uniformly mixed with the fuel material, this could easily lead to errors in the measured fuel residue on the hulls especially if the residue does not originate with equal probability from all positions within the fuel. If fission products are volatile, they may migrate from their position of formation due to temperature gradients within the fuel. Radial migration is usually larger because the radial temperature gradient is much larger than the axial gradient. Fission product migration is a complex phenomenon depending on fuel density, oxygen-to-metal ratio, temperature, and temperature gradient. As mentioned earlier, studies of FBR fuel have shown that ${ }^{144} \mathrm{Ce}$ and ${ }^{154} \mathrm{Eu}$ do not migrate significantly making them attractive candidates for hull residue indicators. These studies also show ${ }^{106} \mathrm{Ru},{ }^{134} \mathrm{Cs}$, and ${ }^{137} \mathrm{Cs}$ to migrate significantly making them less attractive. The two cesium isotopes tend to migrate toward cooler regions near the cladding surface and interpellet gaps; however, having different iodine precursors they migrate differently. While the FBR experience can not be generalized with certainty to LWR fuel, it does raise some concern as to the reliability of the ruthenium or cesium indicators.

Another potential source of error is fission product retention by the fuel rod cladding. This might occur if the fission product precursor from a fission near the fuel surface recolled with sufficient energy to imbed itself in the cladding. This certainly occurs to some extent; the crucial question is whether it is significant enough to cause error in the hull residue determination. If the fission product in question were preferentially retained by the cladding, this would cause a positive error in the hull measurement because the fission product/fuel calibration obtained from the fuel as a whole would be lower than the effective ratio for the cladding hulls. Looked at a different way the leached hulls would contain a fission product source which was unassociated with any retained fuel material.

All of the above are potential problems for a fission product based hull mesurement (gamma ray or neutron) and should be considered in any detailed study of a hull measurement system. In practical situations the significance of each may be quite difficult to ascertain. For the purposes of this report the best approach is to consider the experience obtained from existing hull measurement systems. The bulk of this experience comes from the windscale plant in the United Ringdom. 
The possibility of fission product retention by the cladding was investigated theoretically and experimentally at windscale. For a detailed discussion of this work see pages 18-19 of Ref. 1. Assuming a uniform fission rate throughout the fuel and using reported fission fragment ranges, they calculate the percentage recoil into the cladding to be 0.0648 for ${ }^{144} \mathrm{Ce}$ and 0.0848 for ${ }^{106} \mathrm{Ru}$. The percentage recoil is expressed relative to the fission product content of the original fuel. They felt this computation was oversimplified because it did not take into account the actual nonuniform fission density in the fuel. In particular the ${ }^{238} \mathrm{U},{ }^{235} \mathrm{U}$, and ${ }^{239} \mathrm{pu}$ fission and absorption cross sections have many strong resonances in the epithermal neutron energy region. The epithermal component of the reactor neutron spectrum would be strongly absorbed at the surface of the fuel leading to an increased concentration of ${ }^{239} \mathrm{pu}$ there and a higher total fission rate than in the rest of the fuel. They concluded that the correct detailed computation was too difficult to perform since many of the necessary data of reactor spectra were not available. Instead they attempted to sample the hulls after leaching and chemically determine the ${ }^{144} \mathrm{Ce}$ and ${ }^{106} \mathrm{Ru}$ retention. Hull samples were taken f rom BWR, HWR, and WAGR fuels with burnups from 6000 to $15000 \mathrm{MWD} / \mathrm{MPU}$. The measured retention of ${ }^{144} \mathrm{Ce}$ varied from 0.0258 to 0.0968 with an average of $0.054 \%$. This is quite consistent with their theoretical value. If the hull residue were $0.5 \%$ of the original fuel charge, this would correspond to a positive bias of approximately 108 (relative). The ${ }^{106} \mathrm{Ru}$ results showed considerably more variability ranging from 0.098 to one value of 0.88 . The average (omitting this very high point) is 0.238 or about three times their theoretical value. Recall that the ${ }^{106} \mathrm{Ru}-\mathrm{Rh}$ can represent an interference to the NaI measurement of the $2186-\mathrm{keV}$ line of ${ }^{144} \mathrm{Pr}$ or it can be used as an independent hull residue indicator. The potentially high cladding retention indicated in these tests might, however, warn against its use as a hull residue indicator.

The relatively high ${ }^{106} \mathrm{Ru}$ retention could not be explained, so in addition to the chemical analyses they took Ge(Li) spectra of several baskets of hulls. These spectra were taken at points where the NaI measurements showed very little undissolved fuel. These measurements did not detect any evidence of high ${ }^{106} \mathrm{Ru}$ retention.

It would seem that these tests indicate, at least for the ${ }^{144} \mathrm{Ce}$ case, that fission product retention in the cladding is a small and manageable problem. It does need to be studied further, however. 
The most desirable test of hull measurement reliability would be to take a measured quantity of hulls and recover the fuel residue chemically as a verification. This has never been done directly but a close approximation has been carried out at windscale. A batch of hulls is inefficiently leached leaving perhaps $20 \mathrm{~kg}$ ( 5-108 of original charge) of fuel on the hulls. These hulls are monitored and the dissolver solution analyzed to determine the undissolved fuel residue. The hulls are then returned to a fresh dissolver tank and releached. Again the resulting hulls are monitored and the new dissolver solution analyzed. It is now possible to compare the fuel weight recovered in the second dissolver solution with the difference of the two hull measurements. This is a very direct test of the hull monitor accuracy. Such tests were carried out at windscale and the stated results are that the uranium measured by the hull monitor and that recovered in the second dissolver solution agree to better than 208 (more than adequate for a leached hull measurement). There were apparently some sampling difficulties which dissuaded them from publishing or releasing the actual results.

This would seem to be the ultimate test of a hull measurement system and the encouraging windscale results would seem to confirm the validity of the ${ }^{144} \mathrm{Ce}-\mathrm{Pr}$ hull residue signature and lay to rest most of the concerns over potential measurement problems expressed earlier. unfortunately this is only one test and not fully documented. It would be desirable to repeat these tests on other fuels and over a wide range of burnups. This is planned when the windscale plant is operating again. 14 It is to be hoped that this releach experiment could be conducted at other facilities in operation today. The only doubt that could remain after these experiments were carried out would involve the question of whether the fuel dissolved in the first inefficient leach (the early stages of the complete leach) were significantly different from that which froms the final fuel residue. This could be investigated somewhat by successively leaching a quantity of hulls and checking the dissolver solution analyses for any variation in the ${ }^{144} \mathrm{Ce}-\mathrm{Pr} / \mathrm{U}$ ratio.

One other piece of evidence is cited in the windscale report as supportive of the reported hull monitor accuracy. This involves overall process accountability but is not explained in detail. Fuel is processed on a compaign basis and accounting data are available for each campaign. There are two methods for input accounting and one is independent of hull losses. Over a long period of time these two methods agree to better than 0.18 on the total uranium input to 
the plant. This supports the previous conclusion that the possible sources discussed earlier are not significant. Similar confirmatory data may already exist at other operating facilities but it is not obvious from the literature that it has been analyzed in this way. The Japanese report (Ref. 3) contains considerable data on material balances throughout three reprocessing compaigns.

Before ending this section it is necessary to note two reports of measurements which might cast doubt on the applicability of fission product signatures to leached hull measurements (that is on the assumption that the hull residue has the same properties as the dissolver solution or the total fuel average). The first appeared as a brief note on p. 371 and p. 375 of Ref. 2 and concerns work done at the WAR plant in Germany. Results of measurements made at this facility showed a much higher $\mathrm{Pu} / \mathrm{O}$ ratio in the hull residue than that of the dissolver solution. This has not been described in the literature in any detail. According to one of the paper's authors the measurements in question involved the destructive analysis of dissolver solution samples (the WAK plant has never had a nondestructive hull monitor installed). 20 They releached several baskets of hulls and found a higher $\mathrm{Pu} / \mathrm{O}$ ratio in the releach solution than was found in the original solution. This is equivalent to the result reported earlier from the analysis of chemical decladding solution at the Eurochemic plant and is consistent with a number of things pointing to a higher plutonium concentration near the clad-fuel interface. No discussion is given of the level of this effect nor of its significance to leached hull measurements.

The second report involves some hot cell measurements performed on LWR fuel samples at Oak Ridge National Laboratory. ${ }^{21}$ The work was done to study various aspects of LWR fuel reprocessing using fuel samples with burnups of 7000-31000 MWD/MTU. One of the problems studied was the dynamics of the dissolution of fuel in the small pieces which would result from the shearing operation. On two occasions a section of leached cladding was dissolved in hydrofluoric acid to determine the quantities of various isotopes that remain with the leached hulls. Both measurements showed fission product activity to be 100 times that of the retained actinides, the fission product retention being due to recoil of fission fragments from the surface of the fuel into the cladding. This is consistent with the results reported from windscale, namely very little $\mathrm{U}$ or $\mathrm{Pu}$ is retained directly within the cladding material. 14 
The total amount of fission product activity differed considerably in the two cases, one being over 18 of the total fission products contained in the original fuel and the other being about 0.158. Obviously such levels of fission product retention in the cladding would interfere with the measurement of fuel residues in the range of $0.1-18$ of the original fuel charge. The report contains no further information on which fission products were investigated, so it is not possible to assess completely the significance of this result.. Considering, for example, the reported ${ }^{106} \mathrm{Ru}$ levels from windscale which range from 0.09-0.88 of the level in the original fuel charge, it would seem that the two sets of measurements are not inconsistent.

These studies are also of interest to leached hull measurements because they include comparison of actinide and fission product levels predicted by the code ORIGEN with actual measurements. These studies show rather good agreement (108 or better) for the major plutonium isotopes, ${ }^{144} \mathrm{Ce}$ and ${ }^{137} \mathrm{Cs}$. They show very much poorer agreement for ${ }^{106} \mathrm{Ru}$, heavy actinides such as curium (the major neutron source in spent fuel), and shielded fission products such as ${ }^{134} \mathrm{Cs}$ and ${ }^{154} \mathrm{Eu}$. This should be considered when choosing a fission product hull residue indicator.

Though not used directly in any of the above discussions several other references are given here which provide useful background material for this subject. Additional information on the physical description of hulls resulting from the chop and leach process and the possible formation mechanisms for the fuel residue are found in Refs. 22-24. References 25-27 contain useful information and bibliographies on fission product migration in irradiated fuel.

In sumary several potential error sources have been discussed in this section. The results of tests at the windscale reprocessing plant would seem to prove the validity of using the ${ }^{144} \mathrm{Ce}-\mathrm{Pr}$ fission product as an indicator of the leached hull fuel residue. Measurements at Windscale and Oak Ridge National Laboratory seem to indicate high fission product retention in the fuel cladding for at least some fission products. Further work on fission product retention would be desirable to clarify this situation. Finally more experiments of the type, leach-measurement-releach, need to be performed to better verify the reliability of the fission product signatures.

H. User List

The following is a list of facilities who use or plan to use fission product gamma-ray signatures as an indicator of fuel holdup on leached hulls. 
This is only a list with very little detail presented to show the organizations making use of these signatures. For further detail refer to the individual user chapters at the end of the report and to the respective references. The BNFL reprocessing plant at Windscale, United Ringdom, has extensive experience with a NaI-based leached hull monitor. 1,8 It has been used for hulls from BWR, PWR, SCHW, GCHW, and AGR fuels with burnups of 2000-30000 MWD/MTU and cooling times of 1-3 yr. The fuel residue determination is based on the $2186-\mathrm{keV}$ Iine from ${ }^{144} \mathrm{Pr}$ and a determination of the $\mathrm{Pu} / \mathrm{U}$ ratio from the dissolver solution sample. The windscale plant is not presently reprocessing fuel.

Both the AT-I and HAO facilities at La Hague, France, have hull monitors which measure the $2186-\mathrm{keV}$ line of ${ }^{144} \mathrm{Ce}-\mathrm{Pr} .6$ The AT-1 facility is a small pilot operation to test reprocessing procedures for fast reactor fuel. It is used principally for treating fuel from the experimental reactors RAPSODIE and PHENIX, both of which use fuel with stainless steel cladding. The hull monitor at $A T-1$ uses a $15-\mathrm{cm}^{3} \mathrm{Ge}(\mathrm{Li})$ to measure the ratio of ${ }^{144} \mathrm{Pr}$ to ${ }^{60} \mathrm{Co}$ or ${ }^{54} \mathrm{Mn}$ before shearing and after dissolution. The HAO facility is a new LWR oxide fuel head end to the UP2 plant. It has been tested on both BWR and PWR fuel with zircaloy cladding and structural elements of Inconel and stainless steel. The hull monitor consists of 6 NaI detectors viewing different vertical positions in the dissolver basket. Each detector has an Am stabilization source and two single channel analyzers all interfaced to a computer. The system has been tested on BWR fuel with burnup 16000-20000 MWD/MTU and cooling time 1-2 yr and on PWR fuel with burnup 25000-28000 MWD/MTU and cooling time $3 \mathrm{yr}$.

The WAK plant in Karlsruhe, Germany, is another small pilot plant for LWR fuel reprocessing. While no hull monitor has ever been installed for routine measurement, a Ge(Li)-based hull monitor has been developed and tested at the nearby national research center KFK (Rernforschungzentrum Kar lsruhe). 28,29 The measurement is designed for the 47-cm-diameter, cement-filled drums which are to be the disposal container from WAK rather than directly on the dissolver basket. The hull residue determination is based on a measurement of the 2186keV gamma ray from ${ }^{144} \mathrm{Ce}-\mathrm{Pr}$. Various tests have been performed with this system including the measurement of actual hull burial drums brought over from WAR. A system is just now being installed at the WAK plant. 
The hull monitor at the Tokai reprocessing plant is a NaI-based system with a multichannel (and single channel) analyzer. ${ }^{3}$ It was originally designed to measure the $2186-\mathrm{keV}$ gamma ray from ${ }^{144} \mathrm{Ce}-\mathrm{Pr}$ but to date the reprocessed fuel has all been of such long cooling times that this activity was not measurable. Instead the ${ }^{106} \mathrm{Ru}-\mathrm{Rh}$ and ${ }^{137} \mathrm{Cs}$ activities were measured and converted to fuel residue data using fission product/fuel ratios generated by the ORIGEN code. Both BWR and PWR fuel hulls have been measured in the three initial campaigns. Fuel burnups have varied from 110-20000 MWD/MTU and cooling times from less than $2 \mathrm{yr}$ to nearly $8 \mathrm{yr}$.

The EUREX plant at Saluggia in the north of Italy is a multipurpose pilot facility for reprocessing MIR or LEU power reactor fuel. ${ }^{9}$ The hull monitor system here is NaI-based and is designed to measure the 2186-kev gamma ray from ${ }^{144} \mathrm{Ce}-\mathrm{Pr}$. The system was originally built for the General Electric Midwest Fuels Reprocessing Facility at Morris, Illinois, but was never tested since this plant never began hot operations. To date it has only been tested on a basket of cold hulls with a ${ }^{144} \mathrm{Ce}$ source at the Italian facility but should begin producing data as soon as the plant begins operation again. It has been shut down for modifications to handle power reactor fuel.

The AGNS (Allied-General Nuclear Services) fuel reprocessing plant in Barnwell, South Carolina, was constructed to be the first commercial-sized facility with an annual throughput of $1500 \mathrm{MTU}$. It has a leached hull monitor based on a $12.7-\mathrm{cm} \times 12.7-\mathrm{cm}$ NaI detector which was designed for the plant by the IRT corporation. 30,31 It is designed to measure the 2186-kev gamma ray from ${ }^{144} \mathrm{Ce}$ and uses a thick lead absorber as a selective filter and an electronic pulse pileup rejection system to enhance the $2186 \mathrm{keV}$ peak relative to any underlying background. It is the only installation which has a pileup rejection system. To date the system has been tested only with calibration sources to simulate the fission product and cladding activation product gamma rays in a actual leached hull basket. The future operation of the AGNS facility is at best uncertain, so it is not possible to speculate on when actual hull measurement experience might begin.

The above discussion shows the number of facilities attempting to use fission product gamma-ray signatures to measure the fuel residue on leached hulls. A more detailed description of each installation is given in the later user chapters. 
IV. MEASUREMENT OF SPONTANEOUS FISS ION NEUTRONS

\section{A. Introduction}

The preceding discussion has dealt mostly with the measurement of fission product gamma rays. However, as was indicated in Chapter II, the fuel residue on the leached hulls is also a copious source of neutrons largely from the spontaneous fission decay of ${ }^{242} \mathrm{Cm}$ and ${ }^{244} \mathrm{Cm}$. Table XXV summarizes information from the end of Chapter II on gamma-ray and neutron activity from a sample basket of leached hulls. The example was an initial fuel charge of $231 \mathrm{~kg}$ of uranium (zircaloy cladding) with a burnup of $33000 \mathrm{MWD} / \mathrm{MTU}$ and a fuel residue after leaching of 0.58 of the initial fuel charge. All but a few percent of the neutrons come from the isotopes ${ }^{242} \mathrm{Cm}\left(162.8\right.$ day) and ${ }^{244} \mathrm{Cm}$ (18.10 $\mathrm{yr}$ ). The most important source is ${ }^{244} \mathrm{~cm}$ which in this example accounts for 748 of the neutrons at $1 \mathrm{yr}$ and 968 at $4 \mathrm{yr}$.

There are several advantages to the neutron signature. The neutron signal comes entirely from the fuel residue so there is relatively little background with which to contend. As pointed out in chapter $I$ the neutron level from a basket of leached hulls is equivalent to the neutron signal from approximately $500 \mathrm{~g}$ of clean plutonium whereas the fission product gamma-ray level is equivalent to approximately $10^{7} \mathrm{~g}$ of clean plutonium. This means that the neutron measurement makes it more difficult to divert clean plutonium from the reprocessing facility using the high radiation levels of leached hulls to mask the clean plutonium. Probably the major advantage of the neutron signature is the very high penetrability of neutrons in dense, high-z materials. Table XXVI

TABIE XXV

CHARACTERISTICS OF LEACHED HULLS: EXAMPLE

\section{Characteristic}

Uranium

Plutonium

Total Activity

(Fission Product + Cladding)

Total gamma

Total neutron

Percentage from $(\alpha, n)$

Percentage from $\mathrm{Pu}$
$1 \mathrm{yr}$

$1.2 \mathrm{~kg}$

$10.5 \mathrm{~g}$

$7.19 \times 10^{3} \mathrm{Ci}$

$1.78 \times 1014 \mathrm{r} / \mathrm{s}$

$3.25 \times 10^{5} \mathrm{n} / \mathrm{s}$

2.98

0.98
$4 \mathrm{yr}$

$1.2 \mathrm{~kg}$

$10.5 \mathrm{~g}$
$2.48 \times 10^{3} \mathrm{Ci}$

$9.16 \times 1013 \mathrm{r} / \mathrm{s}$

$2.23 \times 10^{5} \mathrm{n} / \mathrm{s}$

1.78

1.28 
shows linear attenuation coefficients (or macroscopic interaction cross sections for neutrons) and mean free paths for gamma rays and neutrons of representative energy is lead and zircaloy. The neutron cross sections vary relatively little from the value listed down to quite low energies. Since no energy spectroscopy is done for neutron counting a simple scattering interaction does not preclude its eventual detection, whereas almost any interaction removes a gamma ray from the full-energy peak and therefore removes it from consideration. The neutron scattering results in a change in direction and a small change in energy (the maximum change in lead is only 28). The neutron is not lost, in fact, it undergoes many such collisions and may eventually emerge from the material to be detected. The table shows that on the average approximately 1000 scatterings occur before the neutron is absorbed in lead. These occur in random directions and result in a straight line travel of approximately $1.9 \mathrm{~m}$. This illustrates the great penetrability of neutrons and accounts for the desire to use them as an assay tool.

On the other hand there are several problems which complicate their use in this situation. Neutron detectors are also sensitive to gamma rays and the leached hulls represent a very intense gamma-ray source which must be shielded before the neutron signal is detectable. The calibration of the system probably represents the largest problem. The passive neutron signal, like the fission product gamma-ray signal, is indirect since it does not come from the uranium and plutonium of direct interest. Only at very low burnup and/or very long cooling time (many 10's of years) does the plutonium spontaneous fission

TABLE XXVI

ATTENUATION OF GAMMA RAYS AND NEUTRONS IN LEAD AND ZIRCALOY Mass Attenuation Coefficient or Macroscopic Cross section

Radiation/Absorber $\left(\mathrm{cm}^{-1}\right)$

Mean Free Path

$\gamma(2186 \mathrm{keV})$ in $\mathrm{pb}$

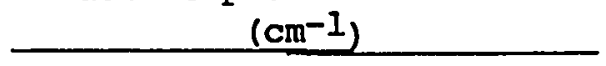

(cm)

$\begin{array}{lllr}\gamma(2186 \mathrm{keV}) & \text { in } \mathrm{Pb} & 0.50 & 2.0 \\ \mathrm{n}(\sim \mathrm{I} \mathrm{MeV}) & \text { in } \mathrm{Pb}: \text { scattering } & 0.16 & 6.1 \\ \mathrm{n}(\sim \mathrm{IMeV}) & \text { in } \mathrm{Pb}: \text { capture } & 0.00017 & 6000.0 \\ & & & \\ \gamma(2186 \mathrm{keV}) & \text { in } \mathrm{Zr}\left(\text { } 0.8 \mathrm{~g} / \mathrm{cm}^{3}\right) & 0.032 & 31.0 \\ \mathrm{n}(\sim \mathrm{MeV}) & \text { in } \mathrm{Zr}: \text { scattering } & 0.042 & 24.0 \\ \mathrm{n}(\mathrm{IMeV}) & \text { in } \mathrm{Zr}: \text { capture } & 0.000042 & 23600.0\end{array}$


signal begin to become important. Furthermore, the relation between ${ }^{244} \mathrm{Cm}$ (the major neutron source) and plutonium is difficult to calculate or measure. Finally neutrons are rapidly slowed and absorbed in water or other hydrogenous media and the hulls are likely to be wet. The water content will probably be low, but it will be variable and unknown and may perturb the interpretation of the neutron signal. These three problems will be discussed in the remainder of this chapter.

B. Detectors, ${ }^{3} \mathrm{He}$ or $\mathrm{BF}_{32}$, and Shielding Reguirements

It is probably most convenient to measure the hulls directly in the dissolver basket or in a transfer basket of dimensions as given in Table IrI (diameter $10-40 \mathrm{~cm}$, height $40-200 \mathrm{~cm}$ ). The basket would probably be counted directly in a well detector (i.e., a moderating annulus with $\mathrm{BF}_{3}$ or ${ }^{3} \mathrm{He}$ proportional counters), however, the neutron signal will probably be of sufficient intensity that a simple slab detector (moderating rectangular block with $\mathrm{BF}_{3}$ or ${ }^{3} \mathrm{He}$ tubes) or pair of slabs would provide adequate efficiency. The slab detector should certainly be adequate if only the total singles rate is to be measured rather than the coincidence rate. Considerable experience exists in building and operating such detectors albeit mostly for unirradiated fuel materials. Detectors have been fabricated with sample wells ranging from 2-cm diameter for plutonium fuel rods to $84-\mathrm{cm}$ diameter for 200-l waste drums. 32,33 A rather complete discussion of the design and operation of a typical well coincidence counter can be found in a recent report on a detector built for inspectors of the International Atomic Energy Agency. 34 Due to the gamma-ray shielding requirements the well diameter of the leached hull monitor will be quite large even for small basket sizes. These detectors can easily be designed with adequate efficiency. The large barrel counter described in Ref. 33 has a detection efficiency for single neutrons (fission spectrum) of approximately 148 or a coincidence efficiency of approximately 28.

In these detectors the ${ }^{3} \mathrm{He}$ or $\mathrm{BF}_{3}$ proportional counters capture neutrons thermalized in the surrounding moderator. They exhibit neutron die-away times ranging from $30 \mu \mathrm{s}$ in undermoderated systems to $100 \mathrm{\mu s}$ in heavily moderated annuli. This long die-away time complicates the coincidence detection of the multiple neutrons from spontaneous fission events in the sample. Many different circuits have been developed to analyze the correlated fission events 
in the presence of the large accidental coincidence background. These are explained in detail in the listed references. $35,36,37$ while the various circuits function differently, if used properly, each could yield a number proportional to the spontaneous fission rate in the counter well.

In deciding whether to use $\mathrm{BF}_{3}$ or ${ }^{3} \mathrm{He}$ proportional counters in the system the major consideration is to choose a tube that is adequately insensitive to gamma-ray pileup. Since the hull monitor is likely to require a large number of counter tubes, price may also influence the choice. The concern regarding gamma-ray pileup is that several gamna rays may interact simultaneously (i.e., within the resolving time of the system, several $\mu s$ ) and deposit sufficient energy to be interpreted as a neutron event. Careful selection of the gas proportional counters to be used in the hull detector can reduce this concern and simplify the gamma-ray shielding requirements.

Both types of proportional counters work by capturing a thermal neutron in a highly exothermic reaction. The charged particle reaction products share the reaction energy which they then lose by ionizing the fill gas of the proportional counter tube. The two reactions of importance are:

$$
\begin{array}{ll}
{ }^{3} \mathrm{He}(n, p){ }^{3} \mathrm{He}: & (765 \mathrm{keV}, 5327 \mathrm{~b}) \\
{ }^{10} 0_{\mathrm{B}(n, \alpha)}{ }^{7} \mathrm{Li}: & (2780 \mathrm{keV}, 3837 \mathrm{~b}) .
\end{array}
$$

In the first the proton and triton share $765 \mathrm{keV}$. The thermal capture on ${ }^{10} \mathrm{~B}$ usually goes through an excited state of ${ }^{7} \mathrm{Li}$ at $480 \mathrm{keV}$. This state decays by emitting a gamma ray which usually escapes from the tube volume without further interaction. Therefore, the energy deposited by the charged reaction products in the $\mathrm{BF}_{3}$ counter is usually $2300 \mathrm{keV}$. Both of these reactions have very high cross sections for thermal capture. The macroscopic cross section for ${ }^{3} \mathrm{He}(6 \mathrm{~atm})$ is $1.14 \mathrm{~cm}^{-1}$ and for $\mathrm{BF}_{3}(1.18 \mathrm{~atm})$ is $0.82 \mathrm{~cm}^{-1}$ which means that the typical counter tube is nearly opaque to thermal neutrons.

The probability of a gamma-ray interaction in the counter tube is low compared to the neutron interaction probability as shown in Table XXVII. The table shows that most of the gamma-ray interactions are with the tube wall and not the gas filling. The resulting scattered electron then loses some energy in crossing the gas filling creating a small pulse in the detector. While the gamma-ray interaction probabilities are much smaller than neutron interaction probabilities, there are many more gamma rays than neutrons coming from the 
leached hulls. The unattenuated ratio of gamma rays to neutrons is $5.5 \times 10^{8}$ in the example given here (Table XXV). Even after transversing $15 \mathrm{~cm}$ of lead the gamma rays exceed neutrons by $5 \times 10^{4}$.

All of the energy of the heavy neutron capture reaction products is usually deposited in the fill gas of the proportional counter resulting in a large electronic pulse. In the ${ }^{3}$ He counter a higher-z gas such as argon is often added to shorten the proton range and guarantee total energy deposition. On the other hand electrons from gamma-ray interactions with the tube wall typically have ranges very much longer than the tube dimensions. They escape from the tube but deposit some energy in the fill gas before leaving. The amount of energy deposited increases with the atomic number of the filling and of course the density and tube dimensions. The ideal tube would have high proton and heavy ion stopping power and very low or zero electron stopping power lobviously not an achievable situation). Table XXVIII shows capture reaction particle ranges, electron energy loss, and the thermal capture mean free path $(1 / \Sigma)$ in typical neutron detectors. The fifth column is approximately the detection efficiency for a thermal neutron which crosses the proportional counter. The average electron path length in a long tube $12.54-\mathrm{cm}$ diameter and $100-\mathrm{cm}$ length) is 7-8 cm. Therefore, the typical gamma-ray induced electron energy loss is 10-50 keV ( $7 \mathrm{dE} / \mathrm{dX}$ from Table XXVIII) and is very much less than the neutron induced pulse. However, there are so many gamma rays that it is possible for several to pile up and sum to pulses which are of comparable energy with the neutron event. While the energy deposited by the neutron capture in $\mathrm{BF}_{3}$ is three times that of ${ }^{3} \mathrm{He}$, it is important to consider the ratio of this to the gamma-ray induced electron energy deposition. The last column of Table XXVIII shows the ratio of neutron reaction energy deposition to the average gamma-ray reaction energy deposition. The higher this ratio is, the lower would be the expected sensitivity to gamma-ray pileup. From this table $\mathrm{BF}_{3}$ is clearly superior to ${ }^{3} \mathrm{He}+\mathrm{Ar}$, and it is comparable or slightly superior to the ${ }^{3}$ He alone.

Experimental tests of ${ }^{3} \mathrm{He}$ in high gamma-ray fields $(1-10 \mathrm{R} / \mathrm{h})$ also lead to the recommendation that the argon be removed from the gas filling. 38 A 3-58 $\mathrm{CO}_{2}$ filling is added instead of the argon. As seen from Table XXVIII, this improves the gamma-ray rejection, however, the proton range is now very long (of the same order as the tube diameter) so all of the neutron reaction energy is frequently not deposited in the tube and the full energy peak nearly 


\section{Interaction}

Thermal $n$ in ${ }^{3} \mathrm{He}$ (6 atm)

$\gamma(1250 \mathrm{keV})$ in ${ }^{3} \mathrm{He}$ ( $\left.6 \mathrm{~atm}\right)$

$\gamma(1250 \mathrm{keV})$ in Ar $(2 \mathrm{~atm})^{b}$

$\gamma(1250 \mathrm{keV})$ in tube wallc
Attenuation Coefficient $-\mu$, or Macroscopic Cross Section $-\Sigma$ $\left(\mathrm{cm}^{-1}\right)$

1.14

0.94

0.000061

0.00016

0.00019

0.00047

0.416 0.031

a. $x=2.54 \mathrm{~cm}$, typical tube diameter or $0.76 \mathrm{~mm}$, typical wall thickness. This number is approximately the interaction probability in the stated material.

b. Argon is often added to ${ }^{3}$ He detectors to shorten the proton range and increase the pulse risetime.

c. The tube wall is taken to be $0.76 \mathrm{~mm}$ of stainless steel.

\section{TABLE XXVIII}

CHARACTERISTICS OF TYPICAI THERMAL NEUTRON GAS PROPORTIONAL COUNTERS

\begin{tabular}{|c|c|c|c|c|c|}
\hline $\begin{array}{r}\text { Al } \\
\text { Prot } \\
\text { Detector } \\
\end{array}$ & $\begin{array}{l}\text { pha or } \\
\text { on Range } \\
\mathrm{cm} \text { ) }\end{array}$ & $\begin{array}{r}\mathrm{dE} / \mathrm{dx} \text { for } \\
500 \mathrm{keV} \text { Electron }{ }^{\mathrm{a}} \\
(\mathrm{keV} / \mathrm{cm}) \\
\end{array}$ & $\begin{array}{l}\text { Neutron Mean } \\
\text { Free Path }(1 / \Sigma) \\
(\mathrm{cm}) \\
\end{array}$ & $\left(1-e^{\left.-\sum x\right)^{b}}\right.$ & $\frac{E \text { neutron }}{\text { E electron }}$ \\
\hline $\begin{array}{l}{ }^{3} \mathrm{He}(6 \mathrm{~atm}) \\
\quad+\mathrm{Ar}(2 \mathrm{~atm})\end{array}$ & 0.64 & 7.36 & 0.88 & 0.94 & 15 \\
\hline $\begin{array}{l}3 \mathrm{He} \text { (4 atm) } \\
+ \text { Ar (2 atm) }\end{array}$ & 0.73 & 6.67 & 1.32 & 0.85 & 16 \\
\hline${ }^{3} \mathrm{He}(4 \mathrm{~atm})$ & 2.7 & 1.39 & 1.32 & 0.85 & 76 \\
\hline $\mathrm{BF}_{3}(0.66 \mathrm{~atm})$ & 0.41 & 3.64 & 2.17 & 0.69 & 92 \\
\hline $\mathrm{BF}_{3}(1.18 \mathrm{~atm})$ & 0.23 & 6.55 & 1.22 & 0.88 & 50 \\
\hline
\end{tabular}

a. $500 \mathrm{keV}$ is approximately the average Compton electron energy from the gamma-ray interaction with the tube wall.

b. $x=2.54 \mathrm{~cm}$. This is the approximate detection efficiency for a thermal neutron striking the counter tube.

c. Ratio of neutron energy deposition (765 keV for ${ }^{3} \mathrm{He}, 2300 \mathrm{keV}$ for $\mathrm{BF}_{3}$ ) to estimated average gamma-ray deposition ( $7 \mathrm{dE} / \mathrm{dx})$, see text. 
disappears from the pulse height distribution. Crane shows pulse height distributions for various tube fillings from a neutron source by itself and in the presence of a $1 \mathrm{R} / \mathrm{h}$ gamma-ray field. While ${ }^{3} \mathrm{He}+\mathrm{Ar}$ tube could function satisfactorily, the tube without argon does exhibit better gamma-ray pileup rejection. Crane feels that $I R / h$ is a good performance limit for the ${ }^{3}$ He tubes without argon and further feels that such tubes offer better gamma-ray rejection than $\mathrm{BF}_{3}$ counters. 39 The $1 \mathrm{R} / \mathrm{h}$ would seem to be a rather conservative limit, and operation in fields up to $10 \mathrm{R} / \mathrm{h}$ might still be reasonable. Furthermore, the considerations discussed above and illustrated in Table XXVIII would predict slightly better pileup rejection from a properly chosen $\mathrm{BF}_{3}$ tube. Such a tube would also exhibit a higher and better defined full energy neutron reaction peak because the alpha particle and ${ }^{7}$ Li ranges are much shorter than the proton range in pure ${ }^{3} \mathrm{He}$.

There is some concern over dissociation of the $\mathrm{BF}_{3}$ molecule in very high gamma-ray fields (>>10 R/h). Any significant quantity of free fluorine will prevent the counter from functioning until a resting period allows recombination to occur. A carbon coating is often added to $\mathrm{BF}_{3}$ proportional counters to sweep free fluorine from the counter gas and aid recombination thereby reducing the degradation that would otherwise result from the intense radiation. Researchers at Battelle's Pacific Northwest Laboratory have constructed a passive neutron leached hull monitor using $\mathrm{BF}_{3}(1.18 \mathrm{~atm})$ counters in a 33-cm-dicmeter well detector which will operate in a field of approximately $7 \mathrm{R} / \mathrm{h} .40$

The above discussion indicates that the gamma-ray field at the detectors must be limited to $1-10 \mathrm{R} / \mathrm{h}$. At $1 \mathrm{yr}$ the example basket of leached hulls emits $1.78 \times 10^{14} \mathrm{r} / \mathrm{s}$ which is equivalent to $4.81 \times 10^{3} \mathrm{Ci}$ with an average energy of approximately $1.25 \mathrm{MeV}$. If the tubes are on a 68-cm-diam circle (basket radius $11 \mathrm{~cm}$, clearance $5 \mathrm{~cm}$, shielding $15 \mathrm{~cm}$, moderator $2 \mathrm{~cm}$, detector radius $1 \mathrm{~cm}$ ), the dose rate at the tubes is approximately $2.9 \times 10^{4} \mathrm{R} / \mathrm{h}$. Therefore a shielding factor of approximately $10^{-4}$ is required to reduce the gamma-ray field to tolerable levels. The transmission of $10 \mathrm{~cm}$ of lead at $1250 \mathrm{keV}^{*}$ would be approximately $3.4 \times 10^{-3}$ (mass attenuation coefficient = $0.060 \mathrm{~cm}^{2} / \mathrm{g}$, buildup factor 3.02). 41 The transmission of $15.5 \mathrm{~cm}$ of lead

In a 22-cm-diam basket filled with zircaloy hulls ( $\left.\rho \sim 0.8 \mathrm{~g} / \mathrm{cm}^{3}\right)$ approximately 848 of the $60^{\circ} \mathrm{Co}$ gamma rays escape with no interaction. This implies that the hull energy spectrum is not changed significantly by scattering in the hulls. 
would be approximately $10^{-4}$ (buildup factor 3.74). Thus a shield of $15.5 \mathrm{~cm}$ lead should reduce the field at the tubes to approximately $2-3 \mathrm{R} / \mathrm{h}$ for this example.

One possible measurement scheme is to measure the neutron signal from the basket before and after leaching and assume the ratio is equal to the function of the original fuel charge left undissolved on the hulls. This is complicated by the much higher gamma-ray and neutron levels in the unleached fuel (see Chapter II). Table XXIX shows the approximate characteristics of the sample hull basket before leaching. The gamma-ray field is now equivalent to $1.4 \times 10^{5} \mathrm{Ci}$ with an average energy of approximately 700-800 keV. The unshielded field at the tubes would be $5.4 \times 10^{5} \mathrm{R} / \mathrm{h}$. This is larely a fission spectrum since the ${ }^{60}$ Co of the hulls no longer dominates. This spectrum extends to quite high energies. At $800 \mathrm{keV}$ the $15.5-\mathrm{cm}-$ thick lead shield has a transmission of approximately $1.5 \times 10^{-6}\left(\mu=0.97 \mathrm{~cm}^{-1}\right.$, buildup factor $\left.\sim 5\right)$ which should be sufficient to reduce the gamma-ray field to $1 \mathrm{R} / \mathrm{h}$. A more careful analysis of the entire spectrum of gamma rays may show that a thicker shield would be required.

This shield would be quite massive even for the rather small basket under consideration. A 15-cm-thick lead annulus with inside diameter 32 cm and height $100 \mathrm{~cm}$ would weigh approximately 10 metric tons. Past experiments with large neutron well counters show that large masses of high-z material in the well can lead to an additional background from cosmic ray induced neutron

TABLE XXIX

CHARACTERISTICS OF CHOPPED FUEL PIECES PRIOR TO LEACHING

\section{Characteristic}

Uranium

Plutonium

Total Activity (Fission Product + Cladding)

Total Gamma

Total Neutron

\section{1 year}

$231 \mathrm{~kg}$

$2110 \mathrm{~g}$

$5.36 \times 10^{5} \mathrm{Ci}$

$5.04 \times 10^{15} \mathrm{r} / \mathrm{s}$

$6.49 \times 10^{7} \mathrm{n} / \mathrm{s}$ 
spallation reactions. These events have very high neutron multiplicity and look like spontaneous fission decays unless some attempt is made to reject high multiplicity events. Experiments have shown that at an altitude of $2200 \mathrm{~m}$ $4.6 \mathrm{mT}$ of lead give approximately 4500 spontaneous fission-like multiple neutron events per second. 42 At sea level this is only 1300 events/s due to the reduced cosmic ray flux. If the counter is placed under $0.9 \mathrm{~m}$ of concrete ceiling, the rate is reduced further to approximately $65 / \mathrm{s} .^{43}$ This would be the normal situation inside the heavily shielded canyons of a spent fuel reprocessing plant. Thus the background count rate from this source is insignificant when compared to the $10^{5}$ spontaneous fissions per second expected from the basket of leached hulls. Further discussion of detector tube performance, shielding requirements, backgrounds, and moderator design can be found in Ref. 44.

\section{Typical Detector Parameters and Count Rates}

This section is largely a short summary of the preceding discussion in the form of a description of a typical well counter which could be used to measure a 22-cm-diam basket of leached hulls. The dimensions of the detector are as

\section{follows:}

well diameter:

well height:

diameter of tube circle:

lead shield thickness:

lead shield inside diameter:

lead shield height:

lead shield weight:

thickness of polyethylene moderator:
$32 \mathrm{~cm}$

$100 \mathrm{~cm}$

$68 \mathrm{~cm}$

$15 \mathrm{~cm}$

$32 \mathrm{~cm}$

$100 \mathrm{~cm}$

10 metric tons

$2 \mathrm{~cm}$.

The proportional counters have a diameter of $2.54 \mathrm{~cm}$ and a length of $100 \mathrm{~cm}$. They are either carbon-coated $\mathrm{BF}_{3}(0.66 \mathrm{~atm})$ or ${ }^{3} \mathrm{He}(4 \mathrm{~atm})$ with $58 \mathrm{CO}_{2}$ and no argon. The tubes are spaced $5 \mathrm{~cm}$ on centers which means 42 tubes are used around the 68-cm-diam circle. A $0.76-\pi m-t h i c k$ cadmium liner is placed on the inside of the 2-cm-thick polyethylene moderator. In this configuration the detector efficiency is approximately 148 and the neutron die-away time is 45 $\mu \mathrm{s.} 44$ If the moderator thickness is reduced to $1 \mathrm{~cm}$, these become 108 and $35 \mu \mathrm{s}$. 
Table XXX shows the neutron activity (total and spontaneous fission) from the example basket of hulls ( $33000 \mathrm{MWD} / \mathrm{MTU}, 0.58$ residue) and the estimated signals if the detector efficiency is 148 . The expected count rates after leaching are easily measurable with a shift-register coincidence circuit. These count rates would yield a statistical precision of approximately 0.38 in a 1000-s count.

However, the before leach count rates are too high to be measured with this counter. If all but one counter tube were turned off (Eff. $\sim 0.38$ ), the total and coincidence rates would be approximately $2 \times 10^{5} \mathrm{cps}$ and $2 \times 10^{2}$ cps respectively. This might just barely be measurable, but the response time of the single tube (several $\mu s$ ) is likely to prohibit counting so high a flux. Also, even if it were measurable, the signal-to-background ratio for the coincidence measurement is now very low due to the low efficiency (S/B proportional to efficiency). A possible alternative might be to measure a small sample of the unleached fuel pieces (perhaps 1-28 of the full basket). This would have reasonable count rates but would introduce the problem of obtaining a representarive sample since ideally fuel should be obtained from each part of the element. From a practical viewpoint it might be very difficult to obtain and measure such a sample.

TABLE XXX

NEUTRON ACTIVITY AND EXPECTED COUNT RATES: EXAMPLE

Cooling Time (years)

1

4
Neutron Activity

\begin{tabular}{cc}
\hline \multicolumn{2}{c}{ After Leach } \\
\hline $\begin{array}{c}\text { Total } \\
(\mathrm{n} / \mathrm{s})\end{array} \quad \begin{array}{c}\text { Spontaneous Fission } \\
(\mathrm{SF} / \mathrm{s})\end{array}$ \\
\hline
\end{tabular}

$3.25 \times 10^{5} \quad 1.09 \times 10^{5}$

$2.23 \times 10^{5} \quad 7.73 \times 10^{4}$

Total
$(\mathrm{n} / \mathrm{s})$

$6.49 \times 10^{7}$

$4.46 \times 10^{7}$
Before Leach

Spontaneous Fission (SF/s)

$2.18 \times 10^{7}$

$1.55 \times 10^{7}$

Expected Count Rate (Efficiency $=148$ )

\begin{tabular}{lccc}
$\begin{array}{c}\text { Total } \\
\text { (cps) }\end{array}$ & $\begin{array}{c}\text { Coincidence } \\
\text { (cps) }\end{array}$ & $\begin{array}{c}\text { Total } \\
\text { (cps) }\end{array}$ & $\begin{array}{c}\text { Coincidence } \\
\text { (cps) }\end{array}$ \\
\cline { 2 - 3 } & $2.1 \times 10^{3}$ & too high to count \\
$3.1 \times 10^{4}$ & $1.5 \times 103$ & too high to count
\end{tabular}




\section{A Simple Total Neutron Detector}

So far only the coincidence measurement of spontaneous fission neutrons has been considered. It may well be that a simple measurement of the total neutron rate will suffice for the leached hull measurement. If so this could greatly simplify the counter. The coincidence measurement is used when it is necessary to separate the spontaneous fission signal from a large background of $(\alpha, n)$ neutrons. In this case the signal is almost entirely spontaneous fission (see Table XXV) so there is very little $(\alpha, n)$ background. Furthermore the nature of the fuel does not change during the leaching process, so the specific neutron signal (neutrons per gram of fuel) would not be expected to change significantly. Thus the measurement would be as simple as counting the total neutron output from the hull basket before and after leaching. The ratio of after to before would be equal to the fraction of the initial fuel charge left undissolved.

The detector for this measurement could be very simple indeed since high efficiency is no longer required as it was for the coincidence measurement. Consider, for example, the so-called SNAP detector (shielded neutron assay probe). 45 This consists of two 2-cm-diam, 14-cm-long, 4-atm ${ }^{3}$ He counters in a 7.6-cm-diam, 23-cm-long polyethylene cylinder. This cylinder is wrapped in a thin cadmium sheet and placed in a small directional neutron shield. The whole detector wieghs only $9 \mathrm{~kg}$ and is portable. Its efficiency for counting fission neutrons at $50 \mathrm{~cm}$ is approximately $2.6 \times 10^{-4}$ (this doesn't strictly apply to the extended source presented by the hull basket, but a similar counter could be fabricated using 100-cm-long tubes). For this application the detector would, of course, need to be shielded from the basket by $15 \mathrm{~cm}$ of lead to reduce gama-ray pileup. At 1 yr cooling time the count rates expected from the basket considered here would be approximately $1.7 \times 10^{4}$ cps before leaching and $85 \mathrm{cps}$ after leaching. These should be workable count rates.

The detection efficiency of this simple detector varies with energy, and this makes it sensitive to matrix effects such as the reduced scattering in the leached hull basket. It is possible to design slab detectors, usually with considerably higher efficiency, which have a nearly constant detection efficiency for neutron energies from $25 \mathrm{keV}$ to $5 \mathrm{MeV} .{ }^{46}$

\section{E. Calibration}

The passive neutron signature is indirect like the fission product gammaray signatures discussed previously. The measured curium levels must be 
related either by measurement or computation to the fuel residual. Curium production is more complicated than the interesting fission products since it results from a long chain of neutron captures starting with ${ }^{238} \mathrm{U}$ and subsequent beta decays.

It may be possible to analyze the dissolver solution sample chemically or radiochemically for ${ }^{242} \mathrm{Cm}$ and ${ }^{244} \mathrm{Cm}$ as is done to interpret the ${ }^{144} \mathrm{Ce}$ gamma-ray signature. The actual amount of curium in the spent fuel is rather low, only $21 \mathrm{~g} / \mathrm{MTU}$ for the $33000 \mathrm{MWD} / \mathrm{MTU}$ example under consideration. This means that the curium concentration is rather low in the dissolver solution, approximately $3 \times 10^{-5} \mathrm{~g} / \mathrm{m}$.

A promising possibility would be to measure the neutron signal from a small sample of dissolver solution in a high efficiency neutron well counter. Assume that the dissolver solution from the sample basket $(231 \mathrm{~kg} U$ initial charge, 1 yr cooling time, $33000 \mathrm{MWD} / \mathrm{MTU}, 6.49 \times 10^{7} \mathrm{n} / \mathrm{s}$ ) is approximately 155 l. A $10 \mathrm{ml}$ sample would give off $4.2 \times 10^{3} \mathrm{n} / \mathrm{s}$ from $1.4 \times 10^{3} \mathrm{spon}-$ taneous fissions per second. Shielding requirements for the detector would be easily met. The gamma-ray output would be $3.3 \times 10^{11} \mathrm{r} / \mathrm{s}$ or $8.8 \mathrm{Ci}$ which would give a dose rate to the counter tubes of approximately $240 \mathrm{R} / \mathrm{h}$ if the tubes are on a 24-cm-diam circle (assume a 2-cm-diam sample in a 2.54-cm-diam well). A 6-cm-thick lead shield would provide a transmission of a little less than 18 (buildup factor $\sim 2.5$ ), so this would reduce the gamma field sufficiently. A detector can easily be designed with an efficiency of 20-308 for this size well. The expected count rates for the $10 \mathrm{ml}$ sample would be:

\begin{tabular}{|c|c|c|c|}
\hline Efficiency & Total (cps) & Coincidence (cps) & Precision in $1000 \mathrm{~s}$ \\
\hline 208 & 840 & 56 & $\sim 1.78$ \\
\hline 308 & 1260 & 126 & $\sim 18$ \\
\hline
\end{tabular}

which are adequate to measure the curium content. An activity one-tenth as high (as from lower burnup fuel) could easily be measured and, if just the total neutron rate is used, even lower levels could be seen. The subsequent chemical and/or mass spectrometric analysis of the solution sample would be used to establish the ratio of $\mathrm{Cm}$ (or just neutron activity) to uranium and plutonium for a particular batch of hulls.

As mentioned earlier it may be possible to measure the neutron activity from the chopped fuel element prior to dissolution. With a well counter the signal levels are probably too high to permit this measurement on the entire basket. A small subsample of the fuel pieces could be counted to establish 
the neutron/fuel ratio for each dissolver batch. It might be difficult logistically to perform this sampling. Probably the more practical and attractive approach is the simple total neutron count described in the previous section.

The final possibility is to calculate the $\mathrm{Cm} / \mathrm{Pu}$ ratio expected in the fuel using burnup codes. This is difficult and subject to large error due to the complicated process leading to curium production. The French have studied the sensitivity of the total neutron $(\mathrm{Cm})$ prediction to errors in the input data and find that the calculation is extremely sensitive. ${ }^{47}$ For example, they state that a 108 error in the assumed fuel burnup leads to a 508 error in the predicted total neutron output.

F. Water Content and Matrix Attenuation

As discussed at the beginning of the chapter absorption in heavy, high-z materials is basically of no consequence except in those materials with high fission cross sections. This is indeed the reason to try to measure neutrons. The only exception to this could come from water on the hulls which would be of variable and, in general, unknown level. It would seem that the hulls should just be wet so that the water content would be less than $0.1 \mathrm{~g} / \mathrm{cm}^{3}$ averaged over the volume of the basket. The macroscopic cross section for thermal capture in water is $0.022 \mathrm{~cm}^{-1}$ which corresponds to a mean free path of $45 \mathrm{~cm}$ (or $450 \mathrm{~cm}$ at $0.1 \mathrm{~g} / \mathrm{cm}^{3}$ ). In the wet hulls it does not seem that this should be a problem.

It is probably best to examine experience with existing neutron coincidence counters when measuring a variety of matrix materials and different densities of hydrogenous materials. One set of data involves the measurement of 200barrels of plutonium waste with a slab neutron detector counting total neutrons. 48 The material categories measured included wet combustibles (158 water, 808 cellulose), dry combustibles, raschig rings, ion-exchange resin, graphite, and washables (20\% polyethylene, $7 \%$ cellulose). These materials formed part of an extensive set of modular plutoniun waste standards. The relative standard deviation of the neutron response between drums of all categories was only 168. Another set of data involves the well-counter measurement of 4- $\ell$ cans containing a variety of typical scrap matrices. 49 Table XXXI shows the variation in total neutron and coincidence response with sample matrix. The last column includes a correction based on counting a small external ${ }^{252} \mathrm{Cf}$ spontaneous fission neutron source with and without the sample 
matrix present in the well. Both of these data sets would indicate that the expected variation due to matrix absorption and variable water content would be acceptably small.

TABLE XXXI

MATRIX EFFECTS ON NEUTRON MEASUREMENTS OF $4-\ell$ SCRAP CANS

Response (Normalized to Empty)

\section{Matrix}

Empty

Carbon pellets

Metal pieces

Concrete

$\mathrm{CH}_{2}\left(\rho^{\sim} 0.065 \mathrm{~g} / \mathrm{cm}^{3}\right)$

$\mathrm{CH}_{2}(\mathrm{\rho} \sim 0.12)$

$\mathrm{CH}_{2}(6 \sim 0.27)$

$\mathrm{H}_{2} \mathrm{O}$
Coincidence

Total

1

1.03

1.04

1.05

1.06

1.09

1.10

0.98
1

1.05

1.09

1.10

1.11

1.19

1.36

0.98

\section{Corrected Coincidence}

1

0.97

1.02

1.02

1.00

0.98

1.04

0.96 


\section{DELAYED FISSION NEUTRON ACTIVATION MEASUREMENTS}

\section{A. Introduction}

The third and final technique to be considered offers the only direct measurement of fissile content and doesn't rely on any assumed relationship of fissile content to fission products or other actinides. This fact is very important and represents the major attraction of the technique. Because it is a direct measurement, it is the most tamper-resistant of the proposed techniques.

Basically the measurement involves the irradiation of the leached hull basket with an intense neutron beam produced by either an accelerator or a radioactive neutron source. This induces fissions in the fissile nuclei which give rise to neutrons and gamma rays both prompt and delayed (from the decay of certain fission product precursors). These delayed neutrons ( 18 of total) can be counted after turning off the accelerator or moving the source or sample away. This technique in various forms has been well studied and used in many applications so no attempt is made here to discuss all the practical aspects of the measurement. Instead several examples are presented and discussed to demonstrate its feasibility for this measurement problem. It should also be noted that techniques using a low energy neutron irradiation and the simultaneous detection of prompt fission neutrons have also been considered. 42 The irradiation is done with a low energy source such as Sb-Be whose average energy is $\sim 24 \mathrm{keV}$. The prompt fission neutrons (average energy $\sim 2 \mathrm{MeV}$ ) are detected using ${ }^{4} \mathrm{He}$ (proton recoil) proportional counters biased above the energy of the irradiating source. This also seems to be a feasible approach, but it is not discussed here in detail.

These active techniques can directly measure total fissile content but by themselves can not measure individual isotopes. The fissile isotopes have different fission cross sections and delayed neutron yields as shown in Table $\operatorname{xXXII.}{ }^{50}$ It is possible to define a quantity called the effective ${ }^{235} \mathrm{U}$ mass based on the cross section and delayed neutron yield:

$$
{ }^{235} 5_{\text {eff }}={ }^{235} \mathrm{U}+0.5^{239} \mathrm{Pu}+1.7^{24 I_{\mathrm{Pu}}} \text { (thermal). }
$$

The delayed neutron response to a thermal irradiation is proportional to ${ }^{235} \mathrm{U}_{\text {eff }}$. This effective mass varies, of course, with the neutron energy because the fission cross sections change drastically (the neutron yields vary only little with irradiation energy). Thus delayed neutron activation analysis 


\section{FISSION CROSS SECTIONS AND DELAYED NEUTRON YIELDS}

\begin{tabular}{|c|c|c|c|c|}
\hline & Fission & tion & & \\
\hline & Thermal & $2 \mathrm{MeV}$ & Delayec & Neutron \\
\hline Isotope & (b) & (b) & & Thermal \\
\hline${ }^{235} \mathrm{U}$ & 577 & 1.2 & & 0.0061 \\
\hline${ }^{239} \mathrm{Pu}$ & 741 & 2.1 & & 0.0154 \\
\hline${ }^{24} I_{\mathrm{Pu}}$ & 1010 & 1.8 & & 0.0158 \\
\hline
\end{tabular}

can measure ${ }^{235} \mathrm{U}_{\text {eff }}$ but can not by itself provide information on ${ }^{235} \mathrm{U},{ }^{239} \mathrm{Pu}$, or ${ }^{241} \mathrm{Pu}$ independently. Still this is more direct information than comes from the other techniques.

Both the French and English have been operating accelerator-based systems to measure leached hulls from experimental fast reactor fuel. This fuel is of quite high fissile concentration. LWR fuel, on the other hand, has a much lower fissile content and much higher neutron and gamma-ray backgrounds. The large passive neutron signal discussed in detail in the previous chapter, of course, represents a background to this measurement which must be overridden by the activation signal. The next two sections will use data from these existing hull measurement systems to project the feasibility of LWR hull measurement. The final section will consider the use of radioactive source neutron interrogation systems to measure leached hulls. The main system to be considered is the so-called "shuffler" which involves a cyclic irradiation by a ${ }^{252} \mathrm{Cf}$ source which is moved near the sample for the irradiation then quickly transferred to a shield to count delayed neutrons.

\section{B. Accelerator-Based Systems}

The most directly related data on the use of accelerator systems for the delayed neutron assay of LWR leached hulls comes from an extensive study carried out approximately $10 \mathrm{yr}$ ago by Strain at the Oak Ridge National Laboratory. 51 These experiments involved a basket of simulated fuel hulls $20-\mathrm{cm}$ diam and $150-\mathrm{cm}$ long. This is almost identical to the example under 
consideration in this report. The measurement cavity was lined with 5-cm of lead. The detector had six 5-cm-diam $\mathrm{BF}_{3}$ tubes placed approximately $6 \mathrm{~cm}$ (on center) inside the polyethylene moderator. Its efficiency is estimated at approximately 5.5\%. The accelerator (a D-T generator) had a source strength of approximately $2 \times 10^{10} \mathrm{n} / \mathrm{s}$ and had $5 \mathrm{~cm}$ of polyethylene and $2 \mathrm{~cm}$ of iron in front of the tritium target to enhance the thermalization of the neutron flux in the cavity. A measurement cycle consisted of a 20-s irradiation, a 1-s delay, and a 30-s delayed neutron count. The basket is measured in a series of $20-\mathrm{cm}$ segments. The stated response was 9300 counts in $30 \mathrm{~s}$ per gram of ${ }^{235} \mathrm{U}$.

Now consider the response of the example basket that has been used throughout this report in the ORNL delayed neutron activation system. A summary of its characteristics (see Table XXV) at one year cooling time is as follows:

$\begin{array}{lll}\text { basket } & : & 22-\mathrm{cm} \text { diameter, } 140-\mathrm{cm} \text { height } \\ \text { uranium } & 1.2 \mathrm{~kg} \mathrm{U} \text { with } 10 \mathrm{~g}{ }^{235} \mathrm{U} \\ \text { plutonium } & 10.5 \mathrm{~g} \mathrm{Pu} \text { with } 6 \mathrm{~g}{ }^{239} \mathrm{Pu}, 1 \mathrm{~g}{ }^{241} \mathrm{Pu} \\ \text { neutron activity: } & 3.25 \times 10^{5} \mathrm{n} / \mathrm{s} \\ \text { gamma-ray activity: } & 1.78 \times 10^{14} \mathrm{r} / \mathrm{s} \\ \text { total activity : } & 7.2 \times 10^{3} \mathrm{Ci} .\end{array}$

As discussed in the previous chapter at least $15 \mathrm{~cm}$ of lead is required to adequately shield the counter tubes from the high gamma radiation. In the extensive discussion of detectors given in Ref. 51 strain notes that ${ }^{10}{ }_{B-}$ lined proportional counters may be the best detector tubes for irradiated fuel applications because they can operate successfully in much higher ganma-ray fields $\left(10^{3} \mathrm{R} / \mathrm{h}\right.$ and higher) than either $\mathrm{BF}_{3}$ or ${ }^{3} \mathrm{He}$ tubes.

since this is a thermal irradiation, the ${ }^{235} \mathrm{U}_{\text {eff }}$ is approximately $15 \mathrm{~g}$ in the entire basket. The response of $9300 / \mathrm{g}$ refers to the center of the basket. Averaged over the length of the basket the source response is approximately 0.32 of the response if it were concentrated at the center (see Fig. 11 of Ref. 51). Thus ${ }^{235_{\mathrm{U}}}$ eff is $5 \mathrm{~g}$ for any single irradiation of the example basket. For one measurement cycle $(51 \mathrm{~s})$ the predicted response for the example would be a delayed neutron signal of $4.7 \times 10^{4}$ counts on a passive background of $1.7 \times 10^{5}$ counts. It is necessary to first count the passive neutron signal which must then be subtracted from the active measurement. The precision of this single irradiation and 30-s count is then approximately 1.38. The precision expected from a basket of hulls containing only a 
0.058 residue would be 4.28 . Thus the system as operated is capable of acceptable performance on the hulls considered here. As will be discussed in detail In the next section this performance can be improved if necessary with a more intense neutron source, a more efficient detector, and the use of a rapid, cyclic irradiation regime.

The English have for many years operated a delayed neutron activation system to measure leached hulls at the small fast reactor fuel reprocessing facility at Dounreay in northern scotland. 8 This system measures a 10-cm-diam by 45- cm-high can containing normally $2 \mathrm{~kg}$ of stainless steel hulls from the Dounreay Fast Reactor (activity $\sim 10^{3} \mathrm{Ci}$ ). The detector contains 5 or $8 \mathrm{BF}_{3}$ counters and has an estimated efficiency of 38 . The maximum rated output of the 14-MeV neutron generator is $3 \times 10^{10} \mathrm{n} / \mathrm{s}$. Again $5 \mathrm{~cm}$ of paraffin are placed in front of the accelerator target to aid in thermalizing the irradiation flux in the cavity. The irradiation regime is a 120-s irradiation, a 5-s delay, and a 60-s delayed neutron count. The stated response is $3100 / 9{ }^{235} \mathrm{U}$ in $60 \mathrm{~s}$. This is almost identical to strain's reported response, if the lower detection efficiency and the $45 \%$ loss of neutrons during the 5-s delay are taken into account.

The response projected for the example $\left(5 \mathrm{~g}{ }^{235} \mathrm{U}_{\mathrm{eff}}\right.$, assuming same geometrical factor 0.32 ) in one measurement cycle (185 s total, 60-s count) would be $1.6 \times 10^{4}$ delayed neutron counts and a passive background of $2.9 \times 10^{5}$. This would imply a precision of approximately $3.9 \%$ for the 0.58 residue or 128 if the residue were only 0.058 . Again the measurement is feasible with the system as presently configured but considerable improvement would be possible using fast pulsing and eliminating the delay period.

The French active hull monitor at Cap de La Hague (AT-1) measures hulls from the RAPSODIE and PHENIX reactors in a 10-cm-diam by 95-cm-high basket. 6 The detector uses $4^{10} \mathrm{~B}$-lined proportional counters and has an estimated efficiency of 2.88. The accelerator output is approximately $1010 \mathrm{n} / \mathrm{s}$, and in this case there is no thermalizer directly in front of the target. Therefore, this system produces a harder irradiation with a larger direct component to the neutron flux in the cavity. The irradiation regime is a 180-s irradiation, a 2-s delay, and a 180-s delayed neutron count. The stated response is 50 counts per gram of fuel or about 70 counts per gram fissile. This is much lower than the previous two systems because of the harder irradiation. Typically the difference in response between a thermal and a fast irradiation is approximately 100. 
For this system the projected response from the example is a delayed neutron signal of $3.5 \times 10^{2}$ counts and a background of $5.2 \times 10^{5}(180-\mathrm{s}$ count). In this case the signal is to small to be seen above background using this measurement regime. Rapid pulsing plus a stronger neutron source are probably required to make this measurement feasible.

\section{Optimized Accelerator Systems}

The preceding discussion shows that the thermal irradiation systems could provide sufficient sensitivity as operated to measure the example basket of hulls. Nevertheless, several changes might be made to enhance their performance. First, consider the half-lives and abundances of delayed fission neutrons as they relate to an optimal irradiation regime. Table XXXIII shows half-lives and abundances of the normal six delayed neutron groups for thermal fission of ${ }^{235} \mathrm{U}$ and ${ }^{239} \mathrm{Pu}$. The corresponding values for fast fission do not differ significantly. The crude average given in the last columns is used later to study the effect of cycle time for a cyclic irradiation. The table shows that most delayed neutrons are emitted within the first several seconds of the irradiation. Therefore, long irradiations followed by long count periods lose most of the delayed neutrons produced and count too much background. Table XXXIV shows the function of delayed neutrons emitted by time $T$ after a fission (or equivalently the function of total delayed neutrons emitted after the irradiation is stopped which are emitted by time, T). This shows that by $10 \mathrm{~s}$ nearly three-quarters of the total delayed neutrons have already been emitted. Counting to $60 \mathrm{~s}$ only increases the delayed neutron signal 308 over the 10-s count, but it increases measured background six-fold. Obviously this is of great importance when measuring in high background conditions. It is possible to analyze the delayed neutron response as a function of the cycle parameters. The formula shown below gives the fraction of the total delayed neutrons emitted for a single group which are counted. 52

$$
\begin{aligned}
& F_{\lambda}=\varepsilon \frac{\left(1-e^{-\lambda t_{1}}\right)\left(1-e^{-\lambda t_{2}}\right) e^{-\lambda t_{3}}}{\lambda t_{1}\left(1-e^{-\lambda T}\right)} \\
& \text { where: } \varepsilon=\text { detector efficiency } \\
& \lambda=\mathrm{n} 2 / \mathrm{T}_{1 / 2} \\
& t_{1}=\text { irradiation time } \\
& t_{2}=\text { count time } \\
& t_{3}=\text { delay between irradiation and count } \\
& T=t_{1}+t_{2}+t_{3}=\text { total cycle time. }
\end{aligned}
$$


TABLE XXXIII

DELAYED NEUTRON HALF-IIVES AND RELATIVE ABUNDANCES

(Thermal Fission Ref. 50)

\begin{tabular}{|c|c|c|c|c|c|c|}
\hline \multirow[b]{2}{*}{ Group } & \multicolumn{2}{|c|}{${ }^{235} \mathrm{U}$} & \multicolumn{2}{|c|}{${ }^{239} \mathrm{Pu}$} & \multicolumn{2}{|c|}{ Average } \\
\hline & $T_{1 / 2}(s)$ & $\begin{array}{l}\text { Relative } \\
\text { Abundance }\end{array}$ & $\mathrm{T}_{1 / 2}{ }^{(\mathrm{s})}$ & $\begin{array}{l}\text { Relative } \\
\text { Abundance }\end{array}$ & $T_{1 / 2}(s)$ & $\begin{array}{l}\text { Relative } \\
\text { Abundance }\end{array}$ \\
\hline 1 & 55.7 & 0.033 & 54.3 & 0.035 & 55.0 & 0.03 \\
\hline 2 & 22.7 & 0.219 & 23.0 & 0.298 & 22.7 & 0.22 \\
\hline 3 & 6.22 & 0.196 & 5.60 & 0.211 & 6.0 & 0.20 \\
\hline 4 & 2.30 & 0.395 & 2.13 & 0.326 & 2.2 & 0.40 \\
\hline 5 & 0.61 & 0.115 & 0.618 & 0.086 & 0.6 & 0.11 \\
\hline 6 & 0.23 & 0.042 & 0.257 & 0.044 & 0.22 & 0.04 \\
\hline
\end{tabular}

TABLE XXXIV

FRACTION OF DELAYED NEUTRONS EMITTED TO TIME T

Time (s)

500

180

60

30

10

5

2

1

.5

.1

.01

.001
Fraction (8)

99.995

99.60

95.04

88.50

73.12

58.76

38.10

25.06

15.30

3.82

0.404

0.041 
The formula assumes that a saturated delayed neutron rate has been reached before counting begins. This means that the sample has been irradiated for approximately a minute so that the major delayed neutron groups have grown into equilibrium. The total fractional response is obtained by summing the above formula multiplied by the appropriate abundance over all six groups. The total number of delayed neutrons counted would be this sum multiplied by $\phi \Sigma \beta$ Vn $t_{1}$ where $\phi$ is the neutron flux $\left(\mathrm{cm}^{-2} \mathrm{~s}^{-1}\right), \Sigma$ is the macroscopic fission cross section $\left(\mathrm{cm}^{-1}\right), \beta$ is the delayed neutron yield per fission (Table XXXII), $V$ is the sample volume, and $n$ is the number of cycles (i.e., $\mathrm{nt}_{1}$ is total irradiation time). Table XXXV shows the value of the sum of $F_{\lambda} A_{\lambda}$ for a 508 duty cycle $\left(t_{1}=t_{2}\right)$ and no delay $\left(t_{3}=0\right)$. The half-lives and relative abundances $\left(A_{\lambda}\right)$ used are the average values from Table XxxIII. This shows that relatively large gains in response can be obtained simply by going to short cycle times. It also shows that most of this gain is obtained by using a count and irradiation time of 1-2 s. Pulsed accelerators have often been used successfully for the delayed neutron activation analysis of fissile material. Cycle times of $\mathrm{ms}$ or shorter have been used, although, as shown above, they are not necessary. It is also possible to achieve a cyclic irradiation by transferring a neutron source to and from the sample or vice versa. A general discussion of this technique is given by Binney and Scherpelz in Ref. 53.

TABLE XXXV

RELATIVE DELAYED NEUTRON RESPONSE VERSUS COUNT TIME (508 DUTY CYCLE)

\section{Count Time (s)}

180

60

30

10

5

2

1

0.1

0.01
$\underline{\Sigma_{F} A_{\lambda}(8)}$

6.78

15.31

21.79

34.16

41.04

46.35

48.45

49.98

50.00 $\frac{\text { Response }(t)}{\text { Response (180) }}$

1.0

2.26

3.22

5.04

6.06

6.84

7.15

7.38

7.38 
In addition to the enhancement from fast cycle times it is possible to improve the measurement precision in low signal/background situations by changing from a 508 duty cycle to one which has a longer irradiation period than count period (background counted a shorter time). Crane has studied this and states that for short cycle times and a very low signal-to-background ratio $(<1)$ a 75:25 cycle can improve the measurement precision as much as 258 with no additional expense in count time or source strength. 39

In addition to an optimized irradiation regime it is possible to improve sensitivity and measurement precision with increased source strength and detector efficiency. Some consideration must be given to the choice of counter tubes to be used in an active interrogation system. During the accelerator on-period the tubes receive a very high neutron dose which can degrade tube performance especially for $\mathrm{BF}_{3}$ counters. It may be necessary to gate off the counter high voltage and preamplifier during the irradiation. ${ }^{3} \mathrm{He}$ and

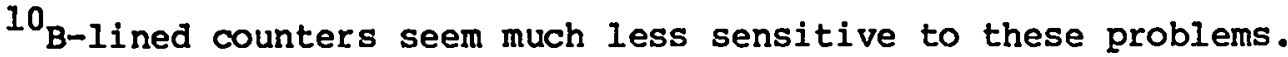

Now consider the improved performance possible with simple modifications to the three systems discussed in part $B$. If the irradiation regime of the ORNL system is changed to a fast pulsing one with $t_{1}=t_{2}=0.1 \mathrm{~s}$ and $t_{3}=0$, there is an improvement of more than a factor of 3 in delayed neutron signal for identical source strength and count time. Also the detector efficiency can be easily raised to 108 or even higher. With these modifications the same 51-s measurement time would yield a delayed neutron signal of $2.6 \times 10^{5}$ and a background of $3.1 \times 10^{6}$ for a measurement precision of 0.368 from a basket with 0.58 residue. If the residue were 0.058 the measurement precision would be 1.18. Of course, further improvement in delayed neutron signal would be possible with a more intense neutron generator.

The English system would show similar improvement except that its longer present count time would mean a larger enhancement factor (8) due to the use of an optimized count regime. The cycle enhancement factor for the French system would be approximately 12 which with a 108 efficient detector would give a delayed neutron signal of $1.5 \times 10^{4}$ (in a 6-min measurement period) and a background count of $1.9 \times 10^{6}$. This would imply a measurement precision of approximately 138 for the basket with 0.58 residue. This is just marginally adequate considering that smaller residues and lower burnup fuel should also be measurable. It seems here that an increase in source strength would be desired. The present source gives approximately $10^{10} \mathrm{n} / \mathrm{s}$, but 
accelerators are readily available with outputs of $10^{11} \mathrm{n} / \mathrm{s}$. This additional factor-of-ten improvement lowers the measurement precision to 1.38 and still offers the advantage of a harder irradiation.

In summary, the above discussion shows that existing systems prove the feasibility of measuring LWR leach hulls with the delayed neutron activation technique. It also shows the advantages of optimizing the irradiation and count times with a rapid cyclic regime. In general, this would seem to be a very attractive approach.

\section{Radioactive Source Systems}

It is also possible to use radioactive neutron sources to perform a delayed neutron activation analysis. Probably the most commonly used source is ${ }^{252} \mathrm{Cf}$ (spontaneous fission), but $S b-B e(\gamma, n)$ and $A m-L i(\alpha, n)$ can also be used. The source now can not be turned off as with an accelerator so the sample and source must be separated in order to count the delayed neutrons. Fither the sample or the source can be moved; both approaches have been used in existing measurement systems. Cycle times are more limited than with an accelerator because of the finite time required to transfer the sample or source. Obviously for this measurement problem it is far easier to move the source than the hulls. A system using the source-transfer approach (called the "Shuffler") has been extensively tested in a variety of applications over the last several years. 54 The parameters and response of the original (prototype) shuffler will be discussed in this section and used to study its applicability to the problem of measuring leached LWR fuel hulls. At the end measurements made with a larger prototype (up to 200- barrel samples) constructed to measure irradiated scrap samples will be discussed. While a routine application for irradiated materials has not yet been realized, this is envisioned in the near future.

The original shuffler has a sample well of 23-cm diameter surrounded by 25 3 He tubes in a polyethylene moderator. The detection efficiency is approximately 25\%. To measure the 22-cm-diam basket considered here a larger well is required to accommodate the $15-\mathrm{cm}$-thick lead shield. It would then be possible to scan the basket through the measurement cavity as is done with many of the present leached hull measurement systems. The irradiation is performed with a ${ }^{252} \mathrm{Cf}$ source on a long flexible cable moved by a stepping motor. The source is typically $0.5 \mathrm{mg}{ }^{252} \mathrm{Cf}$ which emits $10^{9} \mathrm{n} / \mathrm{s}$. Source transfer time is $0.45 \mathrm{~s}$ over a distance of $1.32 \mathrm{~m}$. The entire assay unit including extensive 
neutron and gamma-ray shielding is $2.4-\mathrm{m}$ long $\times 0.86-\mathrm{m}$ wide $\times 0.88-\mathrm{m}$ high. To irradiate the sample the source is transferred into one of two moderating assemblies near the detector cavity. The fast assembly consists of tungsten, beryllium, and nickel and is used to tailor the ${ }^{252} \mathrm{Cf}$ fission spectrum below the fission threshold of ${ }^{238} \mathrm{U}(1 \mathrm{MeV})$. This preserves the very high penetrability of a fast neutron irradiation. A lead and polyethylene moderator is used to provide a high sensitivity thermal irradiation. These moderators were carefully designed based on Monte Carlo neutronics calculations.

The observed response was $1500 \mathrm{cps} / \mathrm{g}{ }^{235} \mathrm{U}$ with the thermal irradiation and $13 \mathrm{cps} / \mathrm{g}^{235} \mathrm{U}$ with the fast irradiation. This was using a 508 duty cycle and is the actual count rate during the count period. For this system the optimum irradiation was given by equal count and irradiation times of approximately $5 \mathrm{~s}$. The projected thermal response from a basket containing $5 \mathrm{~g}$ ${ }^{235} \mathrm{U}_{\text {eff }}$ and a background of $10^{5} \mathrm{n} / \mathrm{s}$ in the sample cavity is $3.7 \times 10^{3}$ delayed neutrons per second of total measurement time and a background of $1.2 \times 10^{4} \mathrm{cps}$. This gives a measurement precision of 0.58 for $100 \mathrm{~s}$ and 0.148 for $1000 \mathrm{~s}$. It also predicts a precision of 1.48 for a 100-s measurement of a basket containing only $0.5 \mathrm{~g}{ }^{235} \mathrm{U}_{\mathrm{eff}}$. The fast irradiation yields a delayed neutron signal of only $30 \mathrm{cps}$ with the same background $\left(1.2 \times 10^{4} \mathrm{cps}\right)$. This predicts a measurement precision of 178 in $1000 \mathrm{~s}$ which is only marginally adequate. The system was tested with a 15.2-cm-diam (outside) $\times 2.5-\mathrm{cm}-d i a m$ (inside) lead shield for the measurement of small irradiated samples.

Generally the above figures show that the system should be capable of measuring LWR hulls at least with the thermal irradiation. Further tests were made using the source transfer and irradiation part of the original system (this was fabricated separately to facilitate use with other detector configurations) with a large, shielded detector designed to accept up to 200-l barrels of irradiated scrap $\left(10^{3} \mathrm{R} / \mathrm{h}\right)$. This unit had a $70 \mathrm{~m}$ diameter and a $15.2-\mathrm{cm}$-thick lead shield. The detection efficiency was 9.38. With a largely fast irradiation $\left(0.2 \mathrm{mg}{ }^{252} \mathrm{Cf}\right.$ ) the observed delayed neutron response was approximately $22 \mathrm{cps} /{ }^{235} \mathrm{U}$. This would imply a delayed neutron signal of $110 \mathrm{cps}$ and a background of $3 \times 10^{4} \mathrm{cps}$ from the example basket. This gives a precision of $7 \%$ for a measurement time of $1000 \mathrm{~s}$. This would be an acceptable performance. Reference 55 presents further discussion of different shuffler applications and the effect of moisture on its response. On the whole it seems this would be a promising alternative to the use of an accelerator. 78 
VI. ENGLISH HULL MEASUREMENT EXPERIENCE

\section{A. Introduction}

There are two leached hull monitoring systems presently in use in English fuel reprocessing facilities. The first is a NaI system measuring ${ }^{144} \mathrm{Ce}-\mathrm{Pr}$ at the Windscale fuel reprocessing plant of British Nuclear Fuels Limited. This is a large plant for reprocessing oxide fuel. The second is an active system using a D-T (14 MeV) neutron generator and measuring delayed neutrons from fission installed at the Dounreay Experimental Reactor Establishment. This is a small plant to handle fast reactor fuel from the Dounreay Fast Reactor and now from the Prototype Fast Reactor. What follows is essentially a summary of the major reports available on these two systems and includes a discussion of measurement system parameters, calibration procedure, and operating experience.

\section{B. Windscale Measurement System}

The windscale plant is an oxide fuel reprocessing facility with a capacity of $800 \mathrm{MTU} / \mathrm{yr}$. It was commissioned in July 1969 and operated until 1974 (it is due to reopen again). Many different kinds of fuel have been reprocessed including BWR, PWR, SGHW, GCHW, and AGR. Aspects of the hull monitoring system have been discussed in earlier chapters but will be summarized in toto here. The material presented is taken from Refs. 1, 8, and 14. Reference 1 in particular is a very detailed report and is probably the best and most complete document which has been written on the measurement of leached hulls using a fission product gamma-ray signature.

The gamna-ray system was chosen after an extensive theoretical and experimental study of the leached hull measurement problem. Active and passive neutron assay techniques were considered but rejected because of practical difficulties with a large diameter basket and calibration for many different types of fuel. The gamma-ray system was extensively studied during the design phase using calculational methods to investigate shielding, hull attenuation, gamma activity levels, and potential sources of error and performing experiments with a simulated hull basket filled with Raschig rings and small ${ }^{144} \mathrm{Ce}-\mathrm{Pr}$ sources. The design goal of the monitor was to measure 0.18 of the original fuel charge with a $50 \%$ accuracy.

The hull basket at windscale has a diameter of $38 \mathrm{~cm}$ and an average fill height of $150 \mathrm{~cm}$. On the average it contains $330 \mathrm{~kg}$ of fuel associated with approximately $100 \mathrm{~kg}$ of stainless steel or $140 \mathrm{~kg}$ of zircaloy-2. The activation product activity of a basket of hulls is about $10^{4} \mathrm{Ci}$. 
The monitor uses two $7.5-\mathrm{cm} \times 7.5-\mathrm{cm}$ NaI detectors located $255 \mathrm{~cm}$ from the basket center. The detectors are on opposite sides of the basket to reduce the response variability due to source position within the basket. It was not possible to rotate the hull basket. The hull basket is moved from the dissolver tank with a crane and lowered into a reentrant cylinder which contains the rinse bath and in which the hull measurement takes place (above the liquid level). This cylinder is in an annex to the dissolver cave behind 120-cm-thick concrete walls. One detector is located on the outside wall of the cell in a lead shield that can easily be moved aside to allow the use of a $\mathrm{Ge}(\mathrm{Li})$ detector for special measurements. The other is located at a position inside the opposite wall. It is on a track to provide accessibility from the outside.

The detector views the hull basket (through the reentrant cylinder) through a lead and concrete collimator which defines a $15-\mathrm{cm}$ segment of the basket. The collimator was chosen to help reduce the overall count rate and to limit the response variability in the axial direction. Lead and concrete shielding provide an attenuation of at least $10^{8}$ for $1-\mathrm{MeV}$ gamma rays from any point in the reentrant cylinder. For basket segments up to $20 \mathrm{~cm}$ above or below the collimated (viewed) region the minimum path lengths in the shielding are $30 \mathrm{~cm}$ of lead and $225 \mathrm{~cm}$ of concrete. The combination of the shielding and the large basket-to-detector distance reduce the radiation level at the detector to approximately $0.5 \mathrm{mR} / \mathrm{hr}$.

In addition to the large sample-detector separation and the collimation a selective filter ( $10 \mathrm{~cm}$ of lead minimum) is placed in each collimator. An additional $10 \mathrm{~cm}$ can be placed in the collimator and smaller filters of thickness $0.3,0.6,1.5$, and $4.0 \mathrm{~cm}$ can be placed in front of the detectors to control the count rate (maintained at approximately $10^{4} \mathrm{cps}$ ) for different burnup fuels.

Each detector has its own preamplifier and high voltage supply. The outputs are then summed to a common main amplifier. The amplifier pulse shape has been selected to minimize pulse pileup by adjusting the integrating and differentiating time constants. The shortest possible pulse which avoids serious degradation of resolution and long undershoots should be chosen to minimize pileup of low energy pulses into the $2186-\mathrm{keV}$ counting channel. Though not included, they would benefit from an electronic pileup rejection system. The amplifier output is fed to a single-channel-analyzer, timer, 
and scaler or to an MCA if more careful spectral analysis is desired. The routine signal window is $2.0-2.4 \mathrm{MeV}$ with small calculated corrections made for ${ }^{106} \mathrm{Ru}-\mathrm{Rh}$ and pulse pileup. All electronics are of the AERE-2000 series produced at Harwell. The hulls are first rinsed and then measured in 13 segments of $2 \mathrm{~min}$ each. The basket is raised $15 \mathrm{~cm}$ after each $2 \mathrm{~min}$ count.

\section{Windscale Calibration Procedure}

The uranium fuel residue is calculated from the measured sensitivity of the instrument to ${ }^{144} \mathrm{Pr}$ and the analysis of the dissolver solution for ${ }^{144} \mathrm{Pr} / \mathrm{U}$. The ${ }^{144} \mathrm{Pr}$ calibration was carried out before active material was introduced into the plant. A standard ${ }^{144} \mathrm{Ce}-\mathrm{Pr}$ source $(3.81 \pm 0.18 \mathrm{Ci})$ was placed at various positions inside a special calibration basket, 36-cm-diam $x$ 76-cm-high which fits inside the main dissolver basket. The dissolver basket is quite thick ( $1.9 \mathrm{~cm}$ steel) and contains a network of holes which made consistent measurements with the point test source difficult. Therefore the calibration was performed using the subsidiary basket only and correcting for the mean transmission of the dissolver basket.

The source was first measured with an empty basket. The measured count rate here includes the attenuation of $10 \mathrm{~cm}$ of fixed lead and the attenuation of the reentrant cylinder. The basket was then filled with clean hulls and remeasured giving a transmission from the center of the basket of 718 . This attenuation is assumed to be representative of all hulls and no further attenuation correction is applied.

They also measured the ratio of the count rate with the source at the periphery of the basket to that with the source at the center. This is called the "Range Factor". It has a value of 1.13 and is a measure of the magnitude of the error due to nonuniform distribution of the fuel residue.

A correction is made to the $2-2.4 \mathrm{MeV}$ window for gamma rays from ${ }^{106} \mathrm{Ru}-\mathrm{Rh}$. This was measured using calibration sources and has a value of approximately 88 for typical fuel where the ${ }^{106} \mathrm{Rh} /{ }^{144} \mathrm{Pr}$ activity ratio is about 0.5. This correction is assumed to be a constant for all hulls. The determination of ${ }^{144} \mathrm{Pr}$ in the dissolver solution is done in the analytical laboratory using a radiochemical separation and gamma spectroscopy. The uranium is measured with a ferrous reduction using phosphoric acid (the Davies-Gray technique). The typical range of values for fuel reprocessed here is $10^{10}-5 \times 10^{11} \mathrm{dpm}{ }^{144} \mathrm{Pr} / \mathrm{gU}$. The ratio is a function of fuel burnup and cooling time and they claim to find good agreement between measured values 
and those predicted by codes such as ORIGEN. They have also attempted to get a more immediate at-line measurement of this ratio counting a $5 \mathrm{ml}$ sample for ${ }^{144} \mathrm{Pr}$ and using a quick density/concentration relation for uranium. It might also be possible to count the $2186-\mathrm{keV}$ line with a germanium detector and use absorption edge densitometry or $x$-ray fluorescence for a quick uranium determi nation.

D. Windscale Operating Experience

The hull monitor was commissioned during the active commissioning of the plant in July 1969. The first tested fuel was from the windscale Advanced Gas Cooled Reactor with burnups varying from 2000-12000 MWD/MTU. The ${ }^{144} \mathrm{pr} / \mathrm{U}$ ratio for this fuel was $10^{10}-10^{11} \mathrm{dpm} / \mathrm{g}$. Most batches were double leached and the hull monitor was used to study leach efficiency. It was found that progressive leaches reduced the uranium to some "plateau level" below which further leaching is to no avail.

The system stability seemed acceptable. After testing it daily at the outset, it was found necessary only to check the energy calibration 2-3 times per week. When the plant starts up again, they plan to install an energy stabilization system using a small (5-mm-diam x 3-mm-thick) CsI(TI) in contact with a dispersed $10^{4} \mathrm{dpm}$ plutonium alpha particle source. This is incased in plexiglas and inserted between the NaI crystal and the photomultiplier tube. A neutral density filter is placed after the NaI crystal to reduce the effective light intensity from gamma-ray events. A 50 filter places the alpha stabilization peak at approximately $4 \mathrm{MeV}$ relative to the $2.18 \mathrm{MeV}$ gamma ray from ${ }^{144} \mathrm{pr}$.

The signal from $1 \mathrm{~kg}$ of fuel has a typical value of approximately $10^{4}$ cpm. The background count with no basket in the reentrant cylinder is about $200 \mathrm{cpm}$ or 5200 for the $26 \mathrm{~min}$ total scan. There is also a small but variable background level from the empty hull basket which is discussed but not given (numerically that is) in the report. This level is measured after the measured hulls are dumped from the basket and subtracted from the count obtained from the batch of hulls.

The precision from repeated counting of a basket of hulls is approximately $\pm 48(2 \sigma)$ with a $1 \mathrm{~kg}$ residue. The measurement reproducibility obtained by repeatedly dumping and reloading the same batch of hulls is $\pm 148(2 \sigma)$. This is in effect a measure of the error due to nonuniform distribution and actually combines a number of effects. They claim that the sensitivity of the monitor is approximately $200 \mathrm{~g}$ of uranium or about 0.078 of the original fuel charge. 82 
The instrument accuracy and potential sources of error are discussed in considerable detail. The uncertainty of the original ${ }^{144} \mathrm{pr}$ calibration source is $\pm 58(3 \sigma)$. The dissolver solution analysis is estimated to be accurate to $\pm 58(2 \sigma)$ for uranium and $\pm 108(2 \sigma)$ for ${ }^{144} \mathrm{Pr}$. This leads to a combined calibration error of approximately $128(2 \sigma)$. A series of possible error sources is discussed including axial rating variations in the fuel rod, gamma-ray self absorption in the fuel residue, and variations in the effective hull density. During the design phase these were studied statistically with a computer program and a simulated basket of hulls. This predicted an error of $\pm 138(3 \sigma)$ if the axial rating variation is 308 . It also said that the effect should average out over a campaign and many hull batches.

A study of fission product retention in the cladding and leach-measurereleach tests is discussed in detail earlier under signature reliability. The conclusion of these studies was that retention caused at most a positive bias of $100-200 \mathrm{~g}$ uranium $(<0.18$ of the original charge). The releach experiments showed that the overall accuracy for a single hull batch was better than 208 .

No retention of fission product solids could be detected in the dissolver basket. A laboratory test showed the effect of pileup from ${ }^{60} \mathrm{Co}$ in the 2.0-2.4 MeV count window was equivalent to about $270 \mathrm{~g}$ of uranium with a total count rate of $10^{4} \mathrm{cps}$. They claim measurements at the plant show this to be much less but the discussion is not completely convincing. The higher pileup level seems more realistic.

Over the $5 \mathrm{yr}$ of operation fuel has been processed from 9 different reactors including BWR, PWR, SGHW, GCHW, and AGR with specific powers and burnups varying from $10 \mathrm{MW} / \mathrm{MTU}$ and $2000 \mathrm{MWD} / \mathrm{MTU}$ to $30 \mathrm{MW} / \mathrm{MTU}$ and $35000 \mathrm{MWD} / \mathrm{MTU}$. Cooling times are 1-3 yr. The average fuel residue rejected with the hulls is approximately 0.58 of the original charge. This varies somewhat with reactor type.

Future developments planned for the leached hull monitor include changing the sample-to-detector distance to $410 \mathrm{~cm}$ for improved shielding and collimation and changing the detector height so that a maximum fill height of $240 \mathrm{~cm}$ (presently $180 \mathrm{~cm}$ ) can be scanned. A system for automatically inserting the standard sources will be added and the monitor data analysis will be automated using a computer and the on-line analysis of the ${ }^{144} \mathrm{Pr} / \mathrm{U}$ ratio. Finally the detectors will be energy stabilized as already discussed. 


\section{E. Dounreay Measurement System}

By comparison with the windscale plant the Dounreay reprocessing facility is very much smaller. It is designed to process highly enriched uranium fuel with an annual throughput of $0.5 \mathrm{MTO}$ for MTR fuel and $10 \mathrm{MTU}$ for FBR type fuel. Due to the vastly reduced scale it was thought possible to use an active hull measurement technique which directly measures the fuel residue. This technique is a $14-\mathrm{MeV}$ neutron irradiation followed by a measurement of delayed neutrons from fission. What follows is a sumary of Ref. 8 .

The leached hulls are measured in a can 10-cm-diam $\times 45-\mathrm{cm}-1$ ong. The typical can contains approximately $2 \mathrm{~kg}$ of stainless steel hulls having an activity of approximately $10^{3} \mathrm{Ci}$. The can of hulls is lowered into the irradiation chamber via a re-entrant tube in the cave roof. The irradiation chamber is a 63-cm-diam $\times$ 57-cm-high annulus of paraffin with a center hole of 23-cm-diam. The center hole is lined with $5 \mathrm{~cm}$ of lead to shield the fission product gamma rays from the hulls. This leaves a 13-cm-diam hole for the hull can. Eight neutron detectors are located in holes in the paraffin each lined with another $2.5 \mathrm{~cm}$ of lead to further reduce the gamma-ray level at the detectors. The detectors are 2.5-cm-diam $\times 31$-cm-active length $\mathrm{BF}_{3}$ tubes with a sensitivity of $12.5 \mathrm{cps} / \mathrm{n} / \mathrm{cm}^{2} / \mathrm{s}$ for thermal neutrons.

A recess is cut into the paraffin moderator to place the neutron target close to the hull can. The neutron source is a Philips PW5320 sealed tube generator with a maximum output of $3 \times 10^{10} 14-\mathrm{MeV} \mathrm{n} / \mathrm{s}$. A small $\mathrm{BF}_{3}$ tube is located in the moderator opposite the target to monitor the thermal flux during the irradiation. The fast neutron output has been measured with small copper foils measuring the 9.8 -min ${ }^{62} \mathrm{Cu}$ activity from ${ }^{63} \mathrm{Cu}(n, 2 n){ }^{62} \mathrm{Cu}$ which has

a 12-MeV threshold.

The measurement sequence is as follows:

1. A standard pin $\left(3 \mathrm{~g}^{235} \mathrm{U}\right)$ is lowered into chamber.

2. 2-min irradiation, 5-s delay, 1-min delayed neutron count.

3. Pin is removed and hull can brought in. The neutron background is measured.

4. 2-min irradiation, 5-s delay, 1-min delayed neutron count.

5. Can is lowered in $8-\mathrm{cm}$ steps and irradiation is repeated until maximum response is 10 ated.

6. Standard pin is lowered into chamber and can and pin are irradiated together. 
The effective response due to the standard pin in the last step is compared with that obtained in step 2 to check for gamma-ray pileup in the neutron counters. Backgrounds are subtracted and the count rates all normalized to the flux monitor count rate.

F. Dounreay Calibration and Operating Experience

The corrected delayed neutron count is converted to $g{ }^{235} \mathrm{U}$ using a calibration curve generated by measuring known weights of ${ }^{235} \mathrm{U}$ in sample cans of metal cuttings. The variation in response with position was studied with small ${ }^{235} \mathrm{U}$ sources measured in different positions. This showed that the response varied a factor of two over a distance of $10 \mathrm{~cm}$.

The sensitivity of the instrument is quoted as approximately $1 \mathrm{~g}$ of ${ }^{235} \mathrm{U}$ in $2 \mathrm{~kg}$ of leached hulls. The precision as determined by repeated measurements on the $3 \mathrm{~g}$ standard pin is $\pm 168(2 \sigma)$. They quote the overall instrument accuracy as $\pm 308(2 \sigma)$ in the range $10-100 \mathrm{~g}^{235} \mathrm{U}$ and $\pm 508(2 \sigma)$ in the $1-10 \mathrm{~g}$ range. The instrument has been in service for at least $5 \mathrm{yr}$ and is used to measure highly active solid residues in addition to leached hulls. The destructive analysis of a waste sample with $30 \mathrm{~g}$ of ${ }^{235} \mathrm{U}$ and a radiation level of $500 \mathrm{R}$ agreed with the active assay to better than 108 . 
VII. FRENCH HULC, MEASUREMENT EXPERIENCE

A. Introduction

There are three different leached hull measurement systems in use in the French center at La Hague. An active neutron and a passive gamma-ray system are in use at the AT-I facility and a different passive gama-ray system is in use at the HAO plant. The situation is somewhat analogous to the English one in that there is a large plant for oxide fuel using a gamma-ray monitor measuring the $2186-\mathrm{keV}$ line from ${ }^{144} \mathrm{Ce}-\mathrm{Pr}$ and a very small plant for fast reactor fuel using a delayed neutron activation technique with a 14-MeV neutron generator. What follows is essentially a sumary of Ref. 6 .

Initially a brief review is presented of the various possible hull measurement techniques. While the active neutron interrogation of the hulls has the advantage of being a direct measurement, it is limited by neutron absorption in hydrogen. The water content of hulls is unknown so they assume a complete water immersion. This limits the useful basket diameter to a maximum of 25-30 cm. This would be a serious constraint for a large plant. It is also a more complex measurement from the standpoint of equipment (particularly the neutron generator). Passive neutron counting is an indirect measurement because the major neutron contributors are the isotopes of curium. It would suffer similar limitations on basket diameter as per the active technique. An additional problem is that the $\mathrm{cm} / \mathrm{U}$ ratio is difficult to calculate accurately because it is very dependent on reactor history and cooling time.

In the final analysis they consider the passive measurement of the 2186-keV gamma ray from ${ }^{144} \mathrm{Ce}-\mathrm{Pr}$ the best signature overall. It permits basket diameters of 50-60 cm and is, therefore, more adapted to large plants. From a calculational standpoint the ${ }^{144} \mathrm{Pr} / \mathrm{U}$ ratio is much less dependent on reactor history. Two calibration methods are considered which they call pseudoabsolute and relative. In the former the ${ }^{144} \mathrm{Pr}$ is measured directly and the ${ }^{144} \mathrm{Pr} / \mathrm{U}$ ratio calculated with a reactor code. In the latter they count ${ }^{144} \mathrm{Pr}$ relative to a gamma ray in the cladding such as ${ }^{60} \mathrm{Co}$ or ${ }^{54} \mathrm{Mn}$. B. Gamma-Ray Hull Monitor at AT-I

AT-1 is a small prototype facility for reprocessing fast reactor fuel. Its annual capacity is $200 \mathrm{~kg} / \mathrm{yr}$ (Ref. 2 gave $400 \mathrm{~kg} / \mathrm{yr}$ ) which has principally been from the experimental reactor RAPSODIE and some from PHENIX. The dissolver basket contains only stainless steel hulls and no structural elements. 
Its diameter is $10 \mathrm{~cm}$ and maximum fill height $95 \mathrm{~cm}$. A typical fuel charge is not given but a rough estimate would be $20 \mathrm{~kg}$ of fuel and $4 \mathrm{~kg}$ of hulls. The basket is rotated and scanned in front of the detector collimator.

The detector is a $15 \mathrm{~cm}^{3} \mathrm{Ge}$ (Li) with a resolution of $2.4 \mathrm{keV}$ (FWHM) at $1332 \mathrm{kev}$. The detector has no selective filtering but uses source collimation to reduce the activity at the detector to a manageable level. As discussed in detail earlier the addition of at least 10-15 cm of lead would preferentially improve the system response to the ${ }^{144} \mathrm{Pr}$ gamma ray. A series of collimators is used: $88-\mathrm{cm}-1$ long $\times 4-\mathrm{cm}-\mathrm{diam}$, then $25-\mathrm{cm}-1$ long $\times 8-\mathrm{cm}-\mathrm{diam}$, and finally 15-cm-long $\times 1.6,3,4$, or 6-m-diam. The last collimator is chosen to maintain a reasonable count rate for fuel with varying burnup. The Ge(Li) spectrum is collected in a 4096-channel MCA and peak areas are evaluated by hand or by outputting the spectra to paper tape for treatment in a PDP-8. Count time varies from a few minutes to a few dozen minutes depending on cooling time. The analysis principle is to measure the ratio of ${ }^{144} \mathrm{Pr}(2186 \mathrm{keV})$ to ${ }^{60} \mathrm{Co}(1332 \mathrm{keV})$ or ${ }^{54} \mathrm{Mn}(835 \mathrm{keV})$ before and after dissolution and assume that the ratio of this ratio after to before is simply the percentage fuel residue remaining on the hulls with no other standard, calculation, or chemical analysis required. The ${ }^{60} \mathrm{Co}$ or ${ }^{54} \mathrm{Mn}$ come from the cladding and assumedly remain constant through the dissolution. The principal error sources are that the ${ }^{60} \mathrm{Co}$ is very weak in the spectrum taken before dissolution and ${ }^{54} \mathrm{Mn}$ is highly absorbed in the hull cladding. Also the ${ }^{144} \mathrm{Pr}$ is weak in the leached hull spectrum.

The detection level of the system is said to be approximately 0.28 of the initial fuel charge (perhaps $40 \mathrm{~g}$ ). This could be lowered with a more open collimator and selective lead or depleted uranium filter. The precision is estimated as approximately 208 for residues 0.58 of initial charge or above. The accuracy is stated by comparing with results from the active hull monitor (described at end of chapter) which is used to measure the same hull batches. Differences on individual batches can be quite large (factor of 2) but the averages over three campaigns which are presented below show rather good agreement. They conclude that the agreement between the direct neutron measurement and the indirect gamma-ray measurement is good evidence that the fuel residue rejected with the hulls has no significant fraction which is of different character from the rest of the fuel. 


\section{Campaign}

Rapsodie 74A

Rapsodie 78

Rapsodie 77A

\section{Batches}

8

7

11

Active Neutron Passive Gamma

1.14

1.07

1.03

1.26

0.47

\section{Gamma-Ray Hull Monitor at HAO}

The UP-2 complex is for reprocessing UNGG fuel and HAO is a head end added to it for the treatment of $400 \mathrm{MTU} / \mathrm{yr}$ of low enriched uranium oxide fuel (princlpally LWR). The ${ }^{144}$ Ce gamma-ray method was chosen because of the large volume of hulls to be measured since it permits the use of a large diameter basket. The chopped fuel pieces together with stainless steel and Inconel structural members go into a 40-cm-diam $\times 100-\mathrm{cm}-\mathrm{high}$ basket which holds approximately $280 \mathrm{kgU}$ and $80 \mathrm{~kg}$ of cladding and other metal (this implies a leached hull density of approximately $0.64 \mathrm{~g} / \mathrm{cm}^{3}$ ). The basket remains stationary throughout a measurement.

The leached hulls are viewed by 6 NaI detectors placed in two levels of three each. In each level the detectors are $90^{\circ}$ apart with the two levels separated by $70 \mathrm{~cm}$ and placed symmetrically about the basket center. The distance between the detectors and the basket center appears to be about 100 $\mathrm{cm}$. The detectors are uncollimated and use only attenuation to reduce the count rate to acceptable levels. This situation is, as discussed earlier, optimum for the measurement of the $2186-\mathrm{keV}$ gamma ray. Each detector has a ${ }^{241}$ Am stabilization source, amplifier, and two single channel analyzers. The timer and 12 scalers are interfaced to a computer. The two SCA's are centered on the $2186-\mathrm{keV}$ peak but have different window widths, one just including the peak and the other including also the background continuum on either side. Assuming a straight line background under the peak, a direct measured correction is made for the pileup background under the full energy peak.

The calibration is based on 0.58 of a PWR assembly (irradiated but not reprocessed) with well known history and ${ }^{144} \mathrm{Pr}$ activity. This gives the 144

Pr calibration and is assumed to take care of all efficiency and attenuation effects. For the actual leached hull measurements the ${ }^{144} \operatorname{Pr} / \mathrm{U}$ ratio is calculated using codes called APOLLO and EVOGENE. ${ }^{47}$ Reference 4 ? contains a typical graph of ${ }^{144} \mathrm{Ce}-\mathrm{Pr}$ gamma-ray activity as a function of 88 
burnup and cooling time which was prepared for the hull measurements at La Hague. It also describes a study of the sensitivity of the computation to various errors in the input data. Beginning with a reference PWR element ( $17 \times 17$ rods, Zircaloy clad, 3.28 initial enrichment, $24000 \mathrm{MWD} / \mathrm{MTU}$ burnup, and 1 yr cooling time) they report the following sensitivities:

Error in Input Data

108 in Burnup

108 in Cooling Time

108 in Irradiation Time and Specific Power

108 in Initial Enrichment
Error in Predicted ${ }^{144} \mathrm{Ce}$ Errors in Total Neutrons 508

78 38

78 18

18

This shows the origin of their concern regarding the passive neutron signature and preference for the ${ }^{144} \mathrm{Ce}-\mathrm{Pr}$ gamma-ray signature.

The estimated level of detectability is 0.18 of the initial fuel charge or about $300 \mathrm{~g}$. They give this also as the uncertainty of the measurement. Results are presented in the form of three spectra. They claim that the efficiency of the dissolution and rinse is so high that very small quantities of fuel are rejected with the hulls. A spectrum from the MUHLEBERG (BWR) reactor with $20000 \mathrm{MWD} / \mathrm{MTU}$ burnup and 300 day cooling shows a fuel residue of $0.5 \mathrm{~kg}$ or approximately $0.18 \%$ of the initial charge. Another spectrum from the same reactor shows an identical residue for an element with $16000 \mathrm{MWD} / \mathrm{MTU}$ burnup and 600 day cooling. A spectrum from the STADE (PWR) reactor with 25000 MWD/MTU burnup and 900 day cooling shows no measureable fuel residue. They claim that their experience proves that what they called the "berlingot" effect (where a hull piece is pinched shut on both ends allowing poor acid contact) is negligible. They had speculated that this was a major holdup mechanism in the leached hulls.

D. Active Measurement System at AT-1

The active measurement of hulls from AT-1 is performed on the same basket as described in part $B$ for the passive monitor. These two systems have been used together to provide a comparison and investigate some of the assumptions necessary to use the direct fission product gamma-ray signature. The basket is lowered into an irradiation assembly which is a moderating annulus of 80-cm-diam lined with approximately $10 \mathrm{~cm}$ of lead for gamma-ray shielding. 
Four boron coated proportional counters are inserted in the half of the annuIus opposite the neutron source. The neutron generator has a output of $10^{10}$ $14-\mathrm{MeV} \mathrm{n} / \mathrm{s}$ and is located in a recess in the moderator annulus approximately $22 \mathrm{~cm}$ from the basket center. Data collection is with a simple timer and scaler chain. The basket is measured in five increments stepping it $20 \mathrm{~cm}$ after each measurement. Each of the five measurements includes a 180-s-irradiation, 2-s-delay, 180-s-delayed neutron count, and 180-s-background count. The calibration is generated by putting known masses of fuel of the same type as under treatment in the basket. The measured delayed neutron response is approximately 50 counts per gram of fuel. The stated level of detectability is 0.058 of the initial fuel charges (perhaps $10 \mathrm{~g}$ ). If the fuel residue is above $0.5 \%$ of the initial charge the precision is estimated to be $20 \%$. The comparison with the $2186-\mathrm{keV}$ gamma-ray measurement has been discussed earlier in section $B$. 
VIII. JAPANESE HULL MEASUREMENT EXPERIENCE

\section{A. Introduction}

The Tokal Fuel Reprocessing Plant is a new pilot LWR plant with an annual capacity of approximately $250 \mathrm{MTU}$. It has been in operation since september 1977 and has carried out three reprocessing campaigns on fuel from the Japan Power Demonstration Reactor (PWR), FUKUSHIMA-1 (BWR), and MIHAMA-2 (PWR). This fuel had burnups of $110-30000 \mathrm{MWD} / \mathrm{MTU}$, initial enrichments of $2-38{ }^{235} \mathrm{U}$, and cooling times of 1.4-8 yr. This chapter is essentially a summary of Refs. 3 and 17 with most of the material taken from the latter. This newly released report contains a detailed description of monitor design, response calculations, and operational experience.

An active leached hull assay system was considered briefly for rokai, in fact, the hull measurement cave was designed large enough to handle a neutron generator and irradiation cavity. It was decided that a passive gamma-ray system would function equally well and was much simpler. The system was designed with a single NaI detector to measure the $2186-\mathrm{keV}$ gamma ray from ${ }^{144} \mathrm{Ce}-\mathrm{Pr}$. Fuel in the initial reprocessing campaigns had such long cooling times that the $2186-\mathrm{keV}$ line was not visible and the present analysis was based on the gamma rays from ${ }^{137} \mathrm{Cs}$ and ${ }^{106} \mathrm{Ru}-\mathrm{Rh}$.

\section{B. Hull Monitor Design}

The Tokai dissolver basket is 22-cm-diam $\times 180-\mathrm{cm}-1$ ong and the typical fill height appears to be approximately $150 \mathrm{~cm}$. Hull pieces are 3-5 cm long. The NaI detector is $4.5-\mathrm{cm}-\mathrm{diam} \times 5.1 \mathrm{~cm}$ thick mounted on the outside of the 62-cm-thick cell wall approximately $115 \mathrm{~cm}$ from the center of the basket.

A two part collimator is used. The first being $20-\mathrm{cm}-1$ ong with a 1-mm $\times$ 25-mm slit and the second being 30-cm-long with a 3-mm $\times$ 25-mm slit. The second can be rotated by hand from outside the cell making the angle between the two slits continuously variable so as to vary the collimator efficiency as required by fuel burnup and cooling time. At maximum efficiency when the two slits are lined up, the half opening angle in the horizontal plane is approximately $2.6^{\circ}$ which subtends a radius of $4 \mathrm{~cm}$ at the basket. The effective vertical height visible at the center of the basket is just over $3.5 \mathrm{~mm}$. This means a very small volume of the basket is visible at any one time ( 0.0338 ). Reference 17 contains a detailed description of the collimator calculations. The collimator also has the effect of suppressing the response from the periphery of the basket relative to the response from the center. 
This procedure, called "Rotation-Collimation" is sometimes used to achieve a "flat" gamma-ray response across the radius of a cylindrical sample, the required degree of collimation being determined by the average attenuation coefficient of the matrix. ${ }^{56}$ In this case the attenuation is really rather minimal and the degree of collimation too severe to achieve the flat response.

No selective filtering is included with the detector-collimator system which means the design was not optimized for the $2186-\mathrm{keV}$ radiation. A.factor of 20-30 enhancement of the $2186-\mathrm{keV}$ peak with respect to the lower energy radiation is possible with the addition of the proper filter. The 2186-kev assay would benefit greatly from the addition of a germanium detector (which is planned) and about $15 \mathrm{~cm}$ of lead or $10 \mathrm{~cm}$ of depleted uranium (or more) with a correspondingly opened collimator.

The basket is rotated and scanned in front of the collimator at $5 \mathrm{rpm}$ and $10 \mathrm{~mm} / \mathrm{min}$. This means the time for one $140-\mathrm{cm}$ scan is of the order of 140 min. The electronics include either an SCA and a time-scaler or a multichannel analyzer. The original idea was to use an SCA on the 2186-keV peak, however, this peak was not visible and a multichannel analyzer is absolutely necessary to attempt a measurement of the lower energy lines. Reference 17 contains the best, most complete spectra published of BWR and PWR leached hulls, albeit NaI spectra.

\section{Operating Experience}

Preliminary experiments were conducted with a ${ }^{60}$ Co point source and a clean basket of hulls. They measured the visual field of the collimator to check the computations and found very good agreement. The hull transmission at $1332 \mathrm{keV}$ as measured from the center of the basket is $70 \%$.

The first actual use of the hull monitor was on BWR fuel hulls from 24 assemblies with burnups 7000-10000 MWD/MTU. The elements were sheared into 4.4-cm-long pieces, one element per basket. In the resulting spectra they found no measureable ${ }^{144} \mathrm{Pr}$ but identified ${ }^{137} \mathrm{Cs},{ }^{106} \mathrm{Ru}-\mathrm{Rh},{ }^{125} \mathrm{Sb}$, and ${ }^{60} \mathrm{Co}$. The ${ }^{125} \mathrm{Sb}$ comes mostly from the activation of the $\mathrm{zircaloy}$ cladding as explained in chapter II though a small contribution comes as a fission product in the fuel. The ${ }^{60} \mathrm{Co}$, of course, comes from the structural elements of the assembly. The actual lines used for the ${ }^{106} \mathrm{Ru}-\mathrm{Rh}$ analysis are not reported. There is a feature in the published spectrum around $511 \mathrm{keV}$ which could be the $511.9-\mathrm{keV}(20.68)$ line from ${ }^{106} \mathrm{Ru}-\mathrm{Rh}$ but which could also be 
positron annihilation radiation (e.g., from ${ }^{58} \mathrm{Co}$ in the stainless steel hardware). This would seem a dangerous line to use for hull assay because of this correspondence. The ${ }^{137} \mathrm{Cs}$ activity at $661.6 \mathrm{keV}$ is not clean but forms a multiplet with radiation from ${ }^{125} \mathrm{Sb}$ or ${ }^{106} \mathrm{Ru}-\mathrm{Rh}$. This is a difficult spectrum from which to extract peak areas (except for ${ }^{60} \mathrm{Co}$ and ${ }^{125} \mathrm{Sb}$ the activation products).

An interesting series of graphs is presented which show the comparison of the measured activities for all four isotopes to the assumed burnup. In general these graphs show a great deal of scatter (probably due to difficulty in determining peak areas) and are difficult to interpret. The magnitude of the fuel residue is estimated by computing the expected ${ }^{137} \mathrm{Cs}$ and ${ }^{106} \mathrm{Ru}-\mathrm{Rh}$ content in the irradiated fuel with the code ORIGEN. The ratio of the measured activity to that predicted in the total element by the code is taken to be the percentage of the fuel charge remaining on the hulls. The calibration for contained curies of ${ }^{137} \mathrm{Cs}$ and ${ }^{106} \mathrm{Ru}-\mathrm{Rh}$ was apparently done with the ${ }^{60} \mathrm{Co}$ point source and computations. The ${ }^{137} \mathrm{Cs}$ results are reasonably consistent ranging from $0.1-0.58$ with an average residue for the compaign of approximately 0.278 . The ${ }^{106} \mathrm{Ru}-\mathrm{Rh}$ are much more scattered ranging from 0.2-28 of the original fuel charge. There appears to be no good correlation between results from the two indicators.

The vertical distribution of each of the four isotopes in one batch of hulls is also shown. ${ }^{137} \mathrm{Cs}$ and ${ }^{125} \mathrm{Sb}$ look roughly like the neutron flux profile in the reactor which is expected since the pieces fall into the basket approximately as they were in the whole element. The ${ }^{106} \mathrm{Ru}-\mathrm{Rh}$ profile is very strange with all of the measured activity at the bottom of the basket. It is known that ${ }^{106} \mathrm{Ru}$ is found in metallic ingots which are extremely hard to dissolve. Such ingots might be expected to collect at the bottom of the dissolver basket. The ${ }^{60}$ co profile shows 7 sharp peaks which correspond to the approximate location of the Inconel grids which form part of the assembly hardware. This illustrates an interesting thing, namely, that collimation may be designed to reduce the ${ }^{60}$ Co interference with other gamma rays because the source of ${ }^{60} \mathrm{Co}$ is not uniformly distributed in the hull basket.

Sixteen PWR assemblies with burnups 11000-19000 MWD/MTU were processed and the resulting hulls measured in the monitor. These assemblies are sheared into $4 \mathrm{~cm}$ lengths, half an assembly per basket. Unfortunately the rotator had stopped working for this campaign, so results can't be quantitatively analyzed. 
Without rotation less than 408 of the hulls are effectively seen by the detector. In the resulting spectra the same four isotopes were identified and similar graphs were prepared of measured activity compared with burnup. Again ${ }^{60} \mathrm{Co}$ and ${ }^{125} \mathrm{Sb}$ show the dependence most clearly. One spectrum is presented of a bit of pure fuel material in which the $2186-\mathrm{keV}$ gamma ray is clearly visible.

In conclusion this hull monitor would benefit considerably from the planned use of a germanium detector, a selective filter, and a more open collimator. The ${ }^{137} \mathrm{Cs}$ is probably a useful hull residue indicator but the ${ }^{106} \mathrm{Ru}-\mathrm{Rh}$ is much more subject to doubt. 
IX. U.S., GERMAN, AND ITALIAN HULL MEASUREMENT EXPERIENCE

\section{A. Introduction}

Very little actual hull measurement has been done in these countries so this chapter presents a brief summary of the research which has been conducted and reported. In the U.S. three efforts are summarized. The AGNS reprocessing plant is a large $1500 \mathrm{MTU} / \mathrm{yr}$ facility but its operational future is, at best, in doubt. A NaI based ${ }^{144} \mathrm{Pr}$ hull monitor has been installed and undergone a limited amount of testing. A passive neutron hull monitor is being tested at Battelle's Pacific Northwest Laboratories for use in the Commercial Nuclear Waste Vitrification Program. About 10 years ago an extensive study was conducted at Oak Ridge National Laboratory of the delayed neutron activiation analysis of leached hulls.

At the WAR reprocessing plant in Karlsruhe, Germany a hull monitor has never been installed for routine use (one is being installed at present). However, a $\mathrm{Ge}(\mathrm{Li})$ based ${ }^{144} \mathrm{Pr}$ has undergone extensive testing and has measured drums of cement encased hulls brought over to KFK for testing.

At the Italian facility EUREX in Saluggia, a NaI-based ${ }^{144} \mathrm{Ce}-\mathrm{Pr}$ system has been installed and should shortly undergo hot testing. They are also working on the feasibility of a simple weighing procedure to determine the fuel residue. At the ITREC facility in Rotondella (a small Th-U test facility) a NaI system is being tested for hull measurements based on the 2615-keV gamma ray from ${ }^{208} \mathrm{Tl}$ in the thorium decay chain.

\section{B. Hull Measurement System at AGNS}

The Allied-General Nuclear Fuel Services Reprocessing Plant at Barnwell, South Carolina was built to be the first large U.S. commercial reprocessing facility. Its design throughput is a maximum of $6 \mathrm{MTU} /$ day or $1500 \mathrm{MTU} / \mathrm{yr}$ (i.e., sufficient to handle the fuel from thirty 1000 MWe nuclear plants). The head-end shear cuts BWR and PWR fuel elements into pjeces 5-12 cm in length. The dissolver basket is $76-\mathrm{cm}-\mathrm{diam} \times 210-\mathrm{cm}-\mathrm{h}$ igh and will contain 290-390 kg of hulls from 1 MTU. The hulls from I MTU occupy a fill height of approximately $90 \mathrm{~cm}$ implying a mean density of $0.70-0.94 \mathrm{~g} / \mathrm{cm}^{3}$. The level of induced radioactivity on the hulls is approximately $2.5 \times 10^{4} \mathrm{Ci} / \mathrm{MTU}$. The time necessary to fill one basket is approximately $3.5 \mathrm{hr}$; there are three separate dissolver tanks. The hulls are dumped if less than 0.18 of the original fuel remains and releached if more than 18 is found (in between it is a management decision to dump or releach). 57 
The monitor detector is a $12.7-\mathrm{cm} \times 12.7-\mathrm{cm}$ NaI with a resolution of 48 (FWHM) at $2186 \mathrm{keV}$. This is mounted on a cart with a small ${ }^{144} \mathrm{Ce}-\mathrm{Pr}$ source to check gain stability. The collimator is 91-cm-long with a 7.6-cm-diam collimating hole lined with a 4.6-mm-thick copper sleeve to stop lead x-rays which might strike the detector. The collimator is mounted on a separate cart and separated from the hull basket by a 4l-cm-thick wall of high density concrete. The wall has a 61-cm-wide $x$ 15-cm-high window lined with lead bricks to leave a $10-\mathrm{cm} \times 15-\mathrm{cm}$ hole through which the basket can be seen.

A third cart contains an adjustable thickness selective filter with thicknesses 2.5, 5, ana $10 \mathrm{~cm}$ of $\mathrm{Pb}$. All three carts can be moved to find the optimum counting geometry. The electronics (and total system) was designed by the IRT corporation. ${ }^{30}$ The principal variation over other ${ }^{144} \mathrm{Ce}-\mathrm{Pr}$ systems is the inclusion of an electronic pileup rejection system. The actual procedure used is not explained in detail but any of the pileup rejection systems on the market would greatly aid the situation. IRT studied the pileup suppression with calibration source combinations $\left({ }^{144} \mathrm{Ce}+{ }^{60} \mathrm{Co}\right.$ and ${ }^{106} \mathrm{Ru}-$ ${ }^{106} \mathrm{Rh}+{ }^{95} \mathrm{zr}-{ }^{95} \mathrm{Nb}$ ) which showed considerable background suppression around the fission product peak of interest.

A calibration basket is available with clean hulls and ${ }^{144} \mathrm{Ce},{ }^{60} \mathrm{Co}$, and other calibration sources. Basically the unit is built and has been undergoing preliminary tests. Problems such as cladding retention of fission products are discussed but these are handled adequately in earlier chapters. ${ }^{31}$ C. Passive Neutron Hull Monitor at Battelle - PNWL

The hull monitor was designed to measure wastes of fuel sent to PNWL to be used in the high level waste vitrification program. At the time of Ref. 40 the instrument had been studied, designed, and partially built. It is finished at present and test results from actual hull samples of fuel at $20000 \mathrm{MWD} / \mathrm{MTU}$ and $28000 \mathrm{MWD} / \mathrm{MTU}$ should be available shortly.

The instrument is basically a well-shielded neutron well counter with sample cavity designed to accept a 20-liter can of leached hulls. The cavity has $33-\mathrm{cm}$ diam and is $47-\mathrm{cm}$ high. The cavity is followed by a 10-cm-thick lead shield $(800 \mathrm{~kg})$ to reduce the radiation dose at the neutron detector tubes from $10^{4}$ to approximately $7 \mathrm{R} / \mathrm{hr}$. This is followed by $2.5 \mathrm{~cm}$ of polyethylene, two rings containing 100 5-cm-diam x 65-cm-Iong carbon coated $\mathrm{BF}_{3}$ tubes, and then another $2.5 \mathrm{~cm}$ of polyethylene moderator. The carbon coating in the $\mathrm{BF}_{3}$ tubes serves to reduce the normal degradation caused by 
such a high gamma-ray flux. The tubes are $90-\mathrm{cm}-\mathrm{Hg}$ of $\mathrm{BF}_{3}$ enriched to 968 ${ }^{10}{ }_{B}$. The detector assembly is surrounded by a modular tank 15-30 cm thick filled with a saturated aqueous solution of boric acid. This provides gamnaray and neutron shielding from outside sources. The major background is expected to be neutrons produced by cosmic ray induced spallation events in the massive lead shield. The design goal of this detector seems to be to measure dense transuranic wastes at the $10 \mathrm{nCi} / \mathrm{g}$ level which is the U.S. criterion for retrievable waste storage.

The electronics is designed to keep track of neutron multiplicity (i.e., it counts separately single neutrons, double coincidences, triple coincidences, quadruple coincidences, and higher order events). Neutrons from the leached hull fuel residue are largely single or double coincidence events whereas cosmic ray induced neutrons will usually have a higher multiplicity. This is expected to provide a means of distinguishing between the two sources. Tests made with plutonium sources $(200 \mathrm{n} / \mathrm{g} / \mathrm{s})$ show a total efficiency for single neutrons of approximately 78 and a sensitivity of $2 \mathrm{mg}$ of plutonium in a $10^{4}$-s count. Unfortunately from this it is difficult to estimate the hull sensitivity because the major neutron emitters in the fuel residue are the curium isotopes, ${ }^{242} \mathrm{~cm}$ and ${ }^{244} \mathrm{Cm}$, which produce $10-100$ times or more as many neutrons as plutonium. The hull measurement will be a curium measurement so if the $\mathrm{Cm} / \mathrm{Pu}$ ratio can be determined fuel sensitivities $1 / 10$ to $1 / 100$ of the stated $2 \mathrm{mg}$ Pu level may be achievable (ignoring the effect of the large gamna-ray flux on the counter operation). Results on actual hull samples may be available shortly.

D. Delayed Neutron Activation Analysis of Leached Hulls at ORNL

Approximately $10 \mathrm{yr}$ ago an extensive study was made of the active neutron measurement of leached hulls at Oak Ridge National Laboratory. 51 They first studied other passive techniques using two fuel pins containing $0.85 \mathrm{~g}$ of $\mathrm{No}_{2}$ (2.5-cm-long $\times 6$-mm-diam stainless steel clad) with burnup $480 \mathrm{MWD} / \mathrm{MTU}$ and cooling time $2 \mathrm{yr}$ (this very low burnup and long cooling time make many of the fission product gamma-ray signatures of doubtful use). All fuel material was removed from the cladding with a nitric acid leach and then added in measured quantities to study the instrumental response to varying fuel residue levels. The only fission product gamma ray visible in the hulls with a NaI detector was from ${ }^{137} \mathrm{Cs}$ (the $2186-\mathrm{keV}$ line from ${ }^{144} \mathrm{Ce}-\mathrm{Pr}$ was not measurable). 
Neutrons can be produced by the $B e(\gamma, n)$ reaction with the high energy (2186 keV) gamma rays from ${ }^{144} \mathrm{Pr}$ (the photoneutron threshold is $1630 \mathrm{keV}$ ). These samples did not have sufficient levels of ${ }^{144} \mathrm{Ce}-\mathrm{Pr}$ for these tests to give positive results. They also tried a differential absorption measurement using $59.5-\mathrm{keV}$ and $661.6-\mathrm{keV}$ gamma-ray transmission sources. Their ultimate conclusion was that the delayed neutron activation analysis is much simpler and more sensitive.

The neutron source was a Cockcroft-Walton generator operating at $150 \mathrm{kV}$ and using the D-T reaction to produce $14.7-\mathrm{MeV}$ neutrons. Reference 51 gives an extensive discussion of sources, moderator design, detectors, flux monitors, sensitivities, and economics. Two monitor prototypes were constructed and tested, a double chamber and a single chamber design.

The double chamber system has a 6-cm-diam $\times 40-\mathrm{cm}-\mathrm{high}$ irradiation chamber in front of the Cockcroft-Walton generator and a 6-cm-diam $x$ 30-cm-high detection chamber containing $620-\mathrm{cm}-1$ ong $\times 2.5-\mathrm{cm}$-diam ${ }^{10}{ }_{\mathrm{BF}_{3}}$ tubes in an appropriate moderator. The two chambers are located one above the other and connected by a $60-\mathrm{cm}$ drop tube. In principle the irradiation chamber would be fed by a cup conveyor from the dissolver cell; in their tests it was loaded by hand. The small quantity of hulls in the irradiation chamber is irradiated for $20 \mathrm{~s}$ with the moderated neutron field and then allowed to fall into the counting chamber where after a 2-s wait the delayed neutrons from the induced fission products are counted for $30 \mathrm{~s}$. In tests conducted with clean hulls and unirradiated fuel samples a sensitivity of approximately $1 \mathrm{mg}{ }^{235} \mathrm{O}$ was obser ved.

The single chamber prototype was designed to measure a basket of leached hulls with $20-\mathrm{cm}$ diameter and $150-\mathrm{cm}$ length containing approximately $50 \mathrm{~kg}$ of hulls. The central part is a 64-cm-diam $\times 61-\mathrm{cm}-\mathrm{high}$ cylindrical neutron moderator with a 30-cm-diam central hole lined with $5 \mathrm{~cm}$ of lead. The moderator contains 6 -cm-diam ${ }^{10} \mathrm{BF}_{3}$ detectors to count delayed neutrons. A measurement consists of a 20-s irradiation, a 1-s delay, and a 30-s delayed neutron count. The basket is measured in 20-cm segments. Tests on this configuration show a sensitivity of approximately $10-\mathrm{mg}{ }^{235} \mathrm{U}$.

E. Fission Product Gamma-Ray Hull Monitor at WAR

The WAK-l reprocessing plant in Rarlsruhe, Federal Republic of Germany is $r$ un by the Gesellschaft zur Wiederaufarbeitung von Rernbrennstoffen m.b.H. and has an annual capacity of $50 \mathrm{mT}$ of LWR or HWR fuel. It has recently completed 
the installation and calibration of a leached hull measurement system based on the $2186-\mathrm{keV}$ gamma ray from ${ }^{144} \mathrm{Ce}-\mathrm{Pr}$. The fission product gamma-ray activity is measured with a Ge(Li) detector and a multichannel pulse height analyzer. The activity ratios $\mathrm{Pu} / \mathrm{J}$ and $\mathrm{Pu} / \mathrm{Ce}$ are determined by laboratory analysis of a small sample of the dissolver solution.

The hulls are measured in the 150- $l$ drum which is used for waste disposal. The hulls are imbedded in a matrix of cement to retard migration of the radioactive contents after disposal. The choice to measure these drums rather than the dissolver basket was partially dictated by the ease of handling. This, of course, rules out the releaching of the hulls should a large residue be found by the monitor. The measurement system was originally developed and tested by Baumung at the $\mathrm{KfK}$ research center. 28,29 The final study and calibration has been carried out by plant personnel. 58 Reference 58 contains a very thorough and detailed study of the hull measurement problem and the calibration of this instrument. The calibration was carried out using dummy standard drums spiked with well analyzed dissolver solution and a variety of point sources to provide calibration curves for cemented and uncemented hulls for the entire energy range $500-2500 \mathrm{keV}$.

The ${ }^{144} \mathrm{Ce}-\mathrm{Pr}$ signature was chosen, first of all, because of the high energy gamma ray, the high fission yield, and the reasonably long half-life. A further reason given was that ${ }^{144}$ Ce behaves much like plutonium as regards position in irradiated fuel. 59 The following assumptions are made to interpret the measurement:

1. Hulls from at least one entire fuel element are contained in each drum.

2. There is no significant cerium migration. Experimental evidence from English and Swedish studies is cited in support of this assumption.

3. The fuel-to-cerium ratio determined from the dissolver solution is the same as that in the hulls.

4. There is no selective dissolution of zones with high or low cerium content. Experience to date supports this.

5. No large self-attenuating fuel kernels remain on the hulls. Visual inspection has shown this to be the case.

6. The attenuation of different hull drums can be treated as being a constant. This is guaranteed by carefully controlling the composition of the contained cement. 
The gamma-ray signal is measured with a Ge(Li) detector having an efficiency of approximately 6.28 and a resolution of $2.3 \mathrm{keV}$ at $1332 \mathrm{keV}$. Data are collected in 256-channel spectra which seems unusually small. The cerium content of the dissolver solution sample is determined to better than 108 with a gamma-ray spectroscopy measurement of the $133-\mathrm{keV}$ gamma ray of ${ }^{144} \mathrm{Ce}$. Isotope dilution mass spectrometry is used to determine the fuel content of the dissolver sample. The barrel of hulls is rotated inside a cell and viewed through a hole in the 104-cm-thick shield wall. The sample-to-detector distance is $3 \mathrm{~m}$. The collimator was designed to take advantage of "RotationCollimation" technique described in section B of chapter VIII. The collimator restricts the detector to viewing only approximately half of the barrel diameter. This reduces the response variation due to nonuniform source distributions to approximately 208. The optimal lead filter thickness is extensively studied and discussed. The expected performance was studied using fission product activity levels predicted by the ORIGEN code for hulls with a 0.58 residue of PWR fuel with $34000 \mathrm{MWD} / \mathrm{MTU}$ burnup. Their studies project that for cooling times longer than approximately 3 yr the 2186-kev gamma ray becomes unusable if the ${ }^{60}$ co-active steel structural components (e.g., element end pieces) remain with the hulls. On the other hand if the structural pieces are separated from the hulls, the ${ }^{144} \mathrm{Ce}$ signature should be useful with cooling times up to $8 \mathrm{yr}$.

The detector efficiency at $3 \mathrm{~m}$ was first measured with a variety of point sources. A small ${ }^{152} \mathrm{Eu}$ source provided various lines between $122-1408 \mathrm{kev}$. A diluted dissolver solution sample (19 $600 \mathrm{MWD} / \mathrm{MTU}, 5.8 \mathrm{yr}$ cooling) provided the following gamma rays: ${ }^{144} \mathrm{Ce}-133 \mathrm{keV},{ }^{106} \mathrm{Ru}-511 \mathrm{keV},{ }^{134} \mathrm{Cs}-609,795$ $\mathrm{kev},{ }^{137} \mathrm{Cs}-662 \mathrm{keV},{ }^{154} \mathrm{Eu}-1256 \mathrm{keV}$, and ${ }^{144} \mathrm{Pr}-2186 \mathrm{keV}$. A set of standard spectroscopy calibration sources was also measured. All measured points were fit to a single power-law function. Next several dummy drums were fabricated each with five 4.8-cm-diam pipes placed at various positions to allow the placement of small vials of undiluted dissolver solution. The activity of these vials had been carefully calibrated against laboratory gamma-ray standards. First a drum was filled with 5-cm-long zircaloy BWR hulls $(1.5-\mathrm{cm}$ diam). Vials were placed in various positions and a volume average response was used to determine the actual calibration point. Again these points were fit to a power law function giving a calibration from 500-2500 keV. The drum was then filled with a mixture of BWR and PWR ( $1-\mathrm{cm}$ 
diameter) hulls and the measurements repeated. No significant difference was observed between the response of the two types of hulls. At $2186 \mathrm{keV}$ the gamma-ray leakage from the fuel hulls alone was 0.37 relative to the point source determination. Next the mixture of PWR and BWR hulls was filled with concrete and the calibration measurements repeated. The leakage at $2186 \mathrm{keV}$ from the cemented hull drum was 0.11 relative to the point source calibration. Finally a drum was filled with a mixture of lead and sand to simulate the attenuation of a drum of cemented hulls. The response for this drum was only measured at $2186 \mathrm{keV}$ and it fell on the line determined with the cemented hull drum. The measured efficiency for cemented hulls at $2186 \mathrm{keV}$ is $4 \times 10^{-8}$. This involved calibration procedure was carried out in order that the system might be used for measurements other than the 2186-kev determination. This way other fission product gamma rays could be measured and the system could be used to measure single hulls, sludge, shear dust, filter material, and other wastes.

The estimated accuracy of the $2186-\mathrm{keV}$ hull measurement is 108 if the hulls are not fixed in cement and 208 if they are fixed in cement. The cement lowers the sensitivity of the system by approximately a factor of three. The counting statistical precision is for most cases in the range 1-58. Uncertainties increase if lower energy gamma rays are measured. The estimated accuracy for measurements based on gamma rays of approximately $600-\mathrm{keV}$ energy is of the order of 508. Finally this report emphasizes strongly that separating the ${ }^{60}$ Co-active structural pieces from the hulls aramatically improves the measurement sensitivity and accuracy. 


\section{REFERENCES}

1. G. H. Fox and B. J. McDonald, "A Leached Hull Monitor for Use in the Reprocessing of Oxide Fuels," British Nuclear Fuels Limited report $213(\mathrm{~W})$, windscale, England (1975).

2. H. J. Arenz and E. Van der Stijl, "Euratom Experience of Verification Methods in Reprocessing Facilities," in Safeguarding Nuclear Materials, Proc. Symp., Vienna, October 20-24, 1975 (International Atomic Energy AGency, Vienna, 1976, STI/Pub/408), Vol. II, Paper IAEA-AM-201/70, pp. $361-376$.

3. K. Nakajima, T. Koizumi, T. Yamanouchi, S. Watanabe, and N. Suyama, "Development and Demonstration of Safeguards Techniques in the Tokai Fuel Reprocessing Plant," Intern. Symp. on Nuclear Material Safeguards (Proceedings to be published), Vienna, October 2-6, 1978, Paper IAEA-SM-231/34.

4. "The Safety of Nuclear Power Reactors (Light Water-Coled) and Related Facilities," U.S. Atomic Energy Commission report WASH-1250 (July 1973), pp. 1-20.

5. "Nuclear Fuel Recovery and Recycling Center -- Preliminatry Safety Analysis Report," Docket 50-564, Exxon Nuclear Company, Inc., September 1977, Appendix 4A, pp. 1-17.

6. J. Constant, D. Hebert, J. P. Macarez, G. Malet, and J. Regnier, "Experience Acquise a La Haque sur Le Controle des Coques," Intern. Symp. on Nuclear Material Safeguards (Proceddings to be published), Vienna, October 2-6, 1978, Paper IAEA-SM-231/46.

7. H. H. Van TuYl, W. K. Winegardner, R. R. Hilliard, and C. R. Cooley, "A Survey of Alpha Waste Generation and Disposal as Solids in the U.S. Nuclear Fuel Industry " Battelle-Pacific Northwest Laboratories report BNWL-B-34 (December 1970).

8. B. J. McDonald, G. H. Fox, and W. B. Bremner, "Nondestructive Measurements of Plutonium and Uranium in Process Wastes and Residues," in Safeguarding Nuclear Materials, Proc. Symp., Vienna, October 20-24, 1975 (International Atomic Energy Agency, Vienna, 1976, STI/Pub/408), Vol. II, Paper IAEA-SM-201/61, pp. 589-597.

9. F. Dozzi, G. Ossola, and G. Bardone, "Testing and Demonstration of Autamation of the Nuclear Material Accountability Control at Irradiated Fuel Reprocessing Facility," Intern. Symp. on Nuclear Material Safeguards (Proceedings to be published), Vienna, October 2-6, 1978, Paper IAEA-SM-231/1.

10. Department of Energy Working Task Group, "Barnwell Nuclear Fuels Plant Applicability Study, Vol. III, Appendices," Department of Energy report DOE/ET-0040/3 (March 1978) pp. B:I-2l. 
11. S. T. Hsue, T. W. Crane, W. I. Talbert, Jr., and John C. Lee, "Nondestructive Assay Methods for Irradiated Nuclear Fuels," Los Alamos Scientific Laboratory report LA-6923 (Janaury 1978).

12. C. M. Lederer, J. M. Hollander, and I. Per lman, Table of Isotopes, Sixth Edition (John Wiley and Sons, Inc., New York, 1967).

13. E. H. Ottewitte, "Evaluation of analytical Capabilities for Accurate Prediction of Isotopic Correlation Ratios," in Analytical Methods in Safeguards and Accountability Measurements of Special Nuclear Material, (NBS Special Publication 528, Nat. Bur. Std., 1978) H. T. Yolken and J. E. Bullard, Eds., Proc. ANS Topical meeting, Williamsburg, VA, May 15-17, 1978, pp. 170-200.

14. B. J. McDonald, British Nuclear Fuels Limited, Windscale Works, personal. communication, December 1978.

15. C. M. Lederer and U. S. Shirley, Table of Isotopes, 7th Edition (John Wiley and Sons, Inc., New York, 1978).

16. J. H. Hubbell, "Photon Cross Sections, Attenuation Coefficients, and Energy Absorption Coefficients from $10 \mathrm{keV}$ to $100 \mathrm{GeV}$," National Bureau of Standards publication NSRDB-NBS 29 (August 1969).

17. T. Koizumi, K. Takeda, K. Yokoyama, and N. Iwata, "A Demonstration of Hull-Monitoring System," Power Reactor and Nuclear Fuel Development Corporation Report TAXTEX Task-C (January 1979).

18. E. Storm and H. I. Israel, "Photon Cross Sections from 0.001 to $100 \mathrm{MeV}$ for Elements 1 through 100," Los Alamos Scientific Laboratory report LA-3753 (June 1967).

19. J. I. Parker and T. D. Reilly, "Transmission Measurement Correction for Self-Attenuation in Gamma-Ray Assays of Special Nuclear Materials," Nucl. Mater. Manage. $V$, No. 2, 28-62 (1976).

20. E. van der Stijl, Directorate of Euratom Safeguards, Luxembourg, personal communication, January 1979.

21. D. O. Campbell and S. R. Buxton, "Hot Cell studies of Light Water Reactor Fuel Reprocessing," American Nuclear Society Meeting, Washington, D.C., November 15-19, 1976, CONF-761103-13.

22. B. C. Finney, B. A. Hannaford, G. A. West, and C. D. Watson, "Shear-Leach Process: Semicontinuous and Batch Leaching of Sheared, Unirradiated Stainless-Steel-Clad and $\mathrm{zircaloy}-2-\mathrm{Clad} \mathrm{NO}_{2}$ and $\mathrm{NO}_{2}-\mathrm{ThO}_{2}$," Oak Ridge National Laboratory report ORNL-3984 (July 1969).

23. R. L. Dillon, "Cladding Hulls," Battelle-Pacific Nor thwest Laboratories report BNWL-SA-5833 (1976). 
24. R. L. Dillon, B. Griggs, R. S. Kemper, and R. G. Nelson, "Chemical Decontamination and Melt Densification," in Management of Radioactive Wastes from the Nuclear Fuel Cycle, Proc. Symp. Vienna, (March 22-26, 1976, STI/PUB/433), Vol. I, paper IAEA-SM-207/69.

25. C. E. Johnson and C. E. Crouthamel, "Cladding Interactions in Mixed Oxide Irradiated Fuels," J. Nucl. Mater. 34, 101-104 (1970).

26. B. M. Jeffery, "Microanalysis of Inclusions in Irradiated $\mathrm{NO}_{2}, " \mathrm{~J}$. Nucl. Mater. 22, 33-40 (1967).

27. J. R. BahI and M. D. Freshley, "Plutonium and Fission Product Redistribution in Mixed-Oxide Fuels During Irradiation," Nucl. Tech. 15, 114-124 (August 1972).

28. K. Baumung, "Huelsenmonitor," in Kernforschungszentrum report KFK-1618 Jahresbericht 1971 fuer Projekt Spaltstoffflusskontrolle, pp. 68-71 (September 1972).

29. K. Baumung, "Huelsenmonitor," in Kernforschungszentrum report RFK-1852 Jahresbericht 1972 fuer Projekt Spalstoffflusskontrolle, pp. 81-85 (Oktober 1973).

30. T. Gozani, "Leached Hull Monitor for Detection of Undissolved Irradiated Nuclear Fuel," Nucl. Mater. Manage. III, No. 3, 203-216 (Fall 1974).

31. K. J. Hofstetter, B. C. Henderson, J. H. Gray, and G. A. Huff, "Nondestructive Assay of Leached Hulls in a Nuclear Fuel Reprocessing Plant," in Analytical Methods in Safeguards and Accountability Measurements of Special Nuclear Material, (NBS Special Publication 528, Nat. Bur. Std., 1978) H. T. Yolken and J. E. Bullard, Eds., Proc. ANS Topical meeting, Williamsburg, VA, May 15-17, 1978, pp. 71-77.

32. R. A. Forster and H. O. Menlove, "Neutron Coincidence Detector for FBR Fuel Pins: Description and Operating Procedures Manual," Los Alamos Scientific Laboratory report LA-5156-M (February 1973).

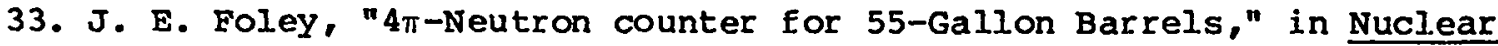
Safeguards Research and Development Program Status Report, SeptemberDecember 1970, Ios Alamos Scientific Laboratory report LA-4605-MS (January 1971) pp. 24-28. This information can also be found in J. L. Parker, T. D. Reilly, J. E. Foley, R. B. Walton, and L. V. East, "Passive AssayInnovations and Applications," Proc. 12th Annual Meeting of the Institute of Nuclear Materials Management, West Palm Beach, Florida, June 29-July I, 1971, Vol. II, pp. 514-547.

34. M. S. Krick and H. O. Menlove, "The High-Level Neutron Coincidence Counter (HINCC): User's Manual," Los Alamos Scientific Laboratory report LA-7779-M (1979).

35. N. Ensslin, M. L. Evans, H. O. Menlove, and J. E. Swanson, "Neutron Coincidence Counters for Plutonium Measurements," Nucl. Mater. Manage. VII, No. 2, 43-65 (Surmer 1978). 
36. K. P. Lambert and J. W. Leake, "A Comparison of the V.D.C. and Shift Register Neutron Coincidence Systems for 240 Pu Assay, "Nucl. Mater. Manage. VII, No. 4, 87-108 (Winter 1978-1979).

37. E. W. Lees and B. W. Hooton, "Variable Deadtime Counters: 1. Theoretical Responses and the Effects of Neutron Multiplication," United Ringdom Atomic Energy Authority (Harwell) report AERE-R9168 (October 1978).

38. T. W. Crane, "Gas Mixture Evaluation for ${ }^{3}$ He Neutron Detectors," in Nuclear Sageguards Research and Development Program Status Report, MayAugust 1977, Los Alamos Scientific Laboratory report LA-7030-PR (March 1978) pp. 39-40.

39. T. W. Crane, Los Alamos Scientific Laboratory, private communication, May 1979.

40. N. A. Wogman, R. L. Brodzinski, and D. P. Brown, "An Instrument for Monitoring the Transuranic Content of Chopped Leached Hulls from Spent Nuclear Fuel Elements," in Analytical Methods in Safeguards and Accountability Measurements of Special Nuclear Material, (NBS Special Publication 528, Nat. Bur. Std., 1978) H. T. Yolken and J. E. Bullard, Eds., Proc. ANS Topical Meeting, Williamsburg, VA, May 15-17, 1978, pp. 284-288.

41. "Reactor Physics Constants," Argonne National Laboratory report ANL-5800, Second Edition (United States Atomic Energy Commission Division of Technical Information, July 1963) pp. 651-657.

42. T. W. Crane, D. A. Close, M. S. Rrick, and H. O. Menlove, "Neutron Methods for Assay of Fissionable Material in the Presence of Fission Products," in Analytical Chemistry in Nuclear Fuel Reprocessing, (Science Press, Princeton, 1978) W. S. Lyon, Ed., Proc. 21st Conf. on Analytical Chemistry in Energy Technology, Gatlinburg, TN, October 4-6, 1977, pp. 285-291.

43. T. W. Crane and H. O. Menlove, "Application of the Shuffler system with Shielding for Small Hot Samples," in Nuclear Safeguards Research Program Status Report September-December 1976, Los Alamos Scientific Laboratory report LA-6788-PR (June 1977) pp. 1-2.

44. T. W. Crane and D. A. Close, "Assay of Reprocessing Waste: Prototype for 55-gal Barrel Assay; Shielding for 3 He Detectors; and Neutron Transport Calculations," in Nuclear Safeguards Research Program Status Report MayAugust 1976, Los alamos Scientific Laboratory report LA-6675-PR (January 1977) pp. 2-6.

45. R. H. Augustson and T. D. Reilly, "Fundamentals of Passive Nondestructive Assay of Fissionable Material," Los Alamos Scientific Laboratory report LA-5651-M (September 1974), pp. 63-68.

46. L. V. East and R. B. Walton, "Polyethylene Moderated ${ }^{3}$ He Neutron Detectors," Nucl. Instrum. Methods 72,161 (1969). 
47. J. Bouchard, G. Dean, P. Patigny, and M. Robin, "Possibilites Offertes Pau La Prise en Compte De L'Histoire du Combustible Dans le Controle a L'Entree des Usines de Retraitement," Intern. Symp. on Nuclear Material Safeguards (Proceedings to be published), Vienna, October 2-6, 1978, Paper IAEA-SM-23I/45.

48. T. D. Reilly and M. M. Thorpe, "Neutron Assay of 55-gal Barrels," in Nuclear Safeguards Research and Development Program status Report May-August 1970, Los Alamos Scientific Laboratory report LA-4523-MS (1970), pp. 26-29.

49. H. O. Menlove and R. B. Walton, "4 4 Coincidence Unit for One-Gallon Cans and Smaller Samples," in Nuclear Safeguards Research and Development program Status Report January-April 1970, Los alamos Scientific Laboratory report LA-4457-MS (1970), pp. 27-31.

50. G. R. Keepin, Physics of Nuclear Rinetics (Addison-Wesley Publishing Company, Inc., Reading, MA, 1965), pp. 85-99.

51. J. E. Strain, W. J. Ross, G. A. West, and J. W. Landry, "The Design and Evaluation of a Delayed-Neutron Leached-Hull Monitor," Oak Ridge National Laboratory report ORNL-4135 (February 1968).

52. T. W. Crane, "Prototype for Neutron Interrogation of 55-gal Barrels," in Nuclear Safeguards Research Program status Report, September-December 1976, Los Alamos Scientific Laboratory report LA-6788-PR (June 1977), pp. 12-15.

53. S. E. Binney and R. I. Scherpelz, "A Review of the Delayed Fission Neutron Technique," Nucl Instrum. Methods 154, 413-431 (1978).

54. H. O. Menlove and T. W. Crane, "A 252 Cf Based Nondestructive Assay System for Fissile Material," Nucl. Instrum. Methods 152, 549-557 (1978).

55. T. W. Crane, G. W. Eccleston, and L. G. Speir, "Design of the ${ }^{252} \mathrm{Cf}$ Shuffler for SRP;" G. W. Eccleston and H. O. Menlove, "Preliminary Design of a ${ }^{252} \mathrm{Cf}$ Shuffler for the Idaho Chemical Reprocessing Plant;" D. A. Close, H. O. Menlove, and G. W. Eccleston, "Moisture Effects on the Assay of Waste Canisters for ICPP," in Nuclear Safeguards Research And Development Program Status Report September-December 1977, Los Alamos Scientific Laboratory report LA-7211-PR (July 1978), pp. 29-34.

56. J. L. Parker, R. B. Walton, and T. D. Reilly, "Gamma-Ray Scanning System for Assay of Fifty-Five Gallon Drums;" T. D. Reilly, "Gama-Ray Scan Computations;" L. V. East and J. L. Parker, "Gamma-Scan of Medium Density ${ }^{239} \mathrm{Pu}$ Scrap Can;" in Nuclear Safeguards Research and Development Program Status Report, January-April 1970, Los Alamos Scientific Laboratory report IA-4457-MS (1970) pp. 19-26.

57. "Barnwell Nuclear Fuels Plant Separations Facility -- Final Safety Analysis Report," Docket 50-332, Allied-General Nuclear Services, October 10, 1973, Section 4-Process Systems, 4.1-4.32. 
58. E. Schultes, "Ralibrierung des GfK-Ruelsenmonitors," Gesellschaft zur wi ederaufarbeitung von Kernbrennstoffen m.b.H. report TB-227 (September 1977).

59. W. E. Roake, "Irradiation Alternation of $\mathrm{NO}_{2}$, " Hanford Engineering report HW-73072 (1962). 